\title{
Becoming the Camera: Body worn video and shifting expectations of police work
}

by

Jessica Chapman

A thesis submitted to the Faculty of Graduate and Postdoctoral Affairs in partial fulfillment of the requirements for the degree of

Master of Arts

in

Communication

Carleton University

Ottawa, Ontario

(C) 2016, Jessica Chapman 


\section{$\underline{\text { Abstract }}$}

Traditionally positioned at the top of the hierarchy of visibility, police are being incorporated into the surveillant assemblage as a result of the proliferation of citizen cameras and viral footage of misconduct. As they struggle with their new visibility, many departments have turned to body worn video (BWV) as a solution. These devices record from a first-person perspective, giving police the opportunity to present their point-of-view.

By discrediting external footage and positioning their own as 'official' police are able to manage their visibility strategically, establishing a privileged position within the assemblage. The creation of technologically extended officers with superior claims to truth gives police the opportunity to shape narratives.

A consequence of these embodied devices is that officers are turned into collectors of visual evidence, tasked with ensuring the camera is interpreting the situation appropriately in the moment. This new responsibility forces officers to adopt the logic of their cameras. 


\section{Acknowledgements}

I would first like to thank Sheryl Hamilton for being the best supervisor I could have asked for. Without your guidance and feedback this project would not have been nearly as successful. You kept me on track, forced me to push the boundaries of my thinking, and challenged me to look beyond the dominant discourse and approach BWV from a unique angle. I thoroughly enjoyed working with you and am forever grateful for the time and effort you put into helping me produce the best thesis I possibly could.

I would also like to thank Josh Greenberg for not only agreeing to be my second committee member but for giving me indispensable feedback throughout the writing process. By offering a fresh set of eyes and a new perspective you helped to ensure my thesis was well grounded and insightful. Thank you to Dale Spencer for really challenging me during my defence, you were a fantastic external and pushed me to think about my work in new ways. Finally, thank you to Chris Russill for chairing my defence, your calm demeanour cut my anxiety by a solid 10 percent.

Thank you to my partner, Nic, for putting up with my never-ending chatter about body cams and for providing unwavering support and an endless supply of motivational pep talks. Most of the time your confidence in me far exceeded my own and I cannot thank you enough for that. I would also like to thank you for your insight; debating the various aspects of this project with you helped to develop my arguments and added to the overall strength of my thesis.

I would also like to thank my family. Specifically, I would like to thank my parents for supporting me in all my endeavours and for instilling in me a strong work ethic and an insatiable curiosity.

Finally, I would like to thank my MA colleagues for providing much needed social interaction even if it was in the office while we were working. I would specifically like to thank Jess Wind for offering moral support even when I turned into 'a little ball of panic'. Always remember: we are strong, confident women and we do not need to smoke. 
Table of Contents

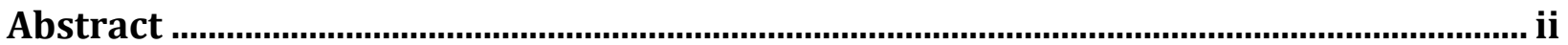

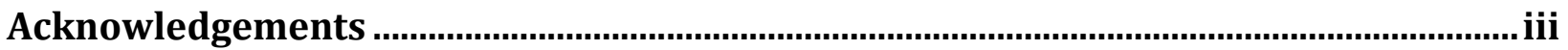

Table of Contents.................................................................................................................. iv

1. Looking at BWV from a New Perspective: Introduction .......................................... 1

1.1 Situating the Use of BWV in the Policing Context: Literature review...................................... 4

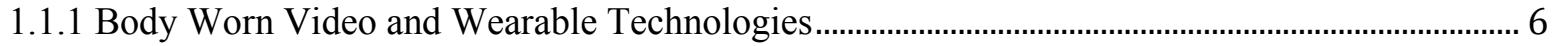

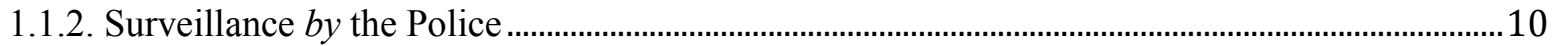

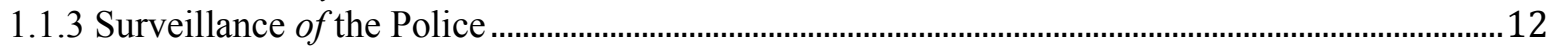

1.1.4 Police Culture and Professional Organization ...............................................................................

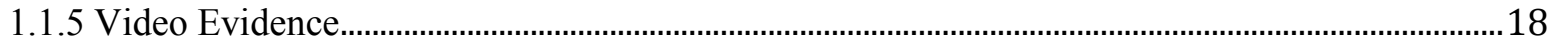

1.2 Conceptualizing Cops as Cameras: Theoretical framework ....................................................... 25

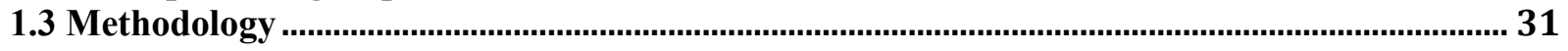

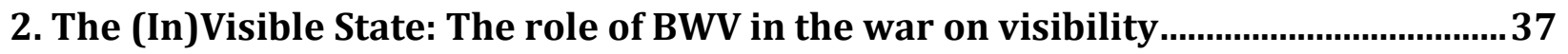

2.1 BWV as a "Natural Progression" in Surveillance and the Future of Policing ......................... 40

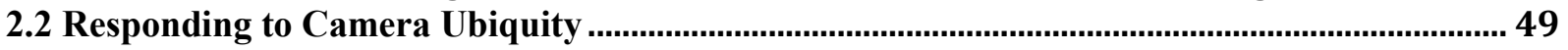

2.3 Pressure to Adopt BWV as a Mechanism of Accountability ................................................. 55

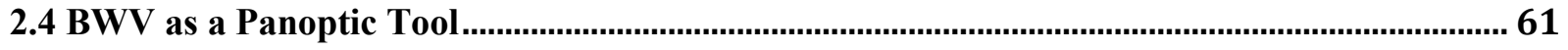

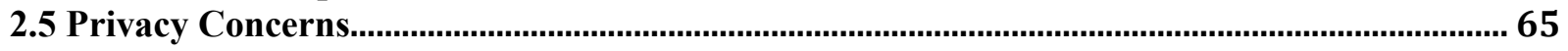

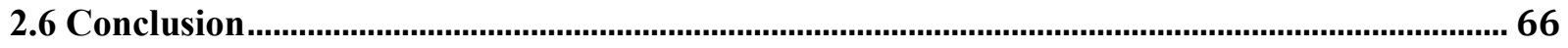

3. Building the RoboCop: The extension and protection of officers ................................69

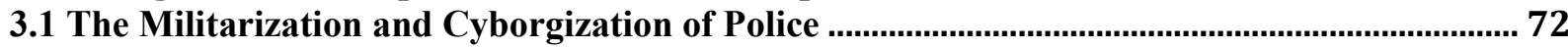

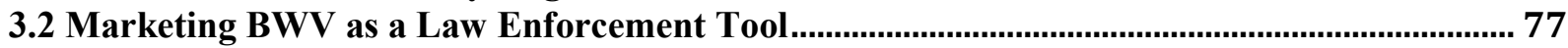

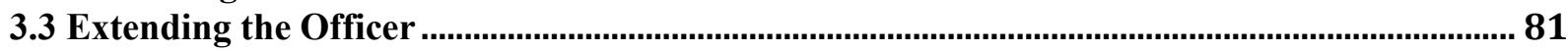

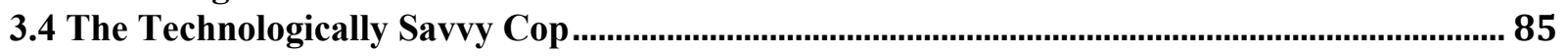

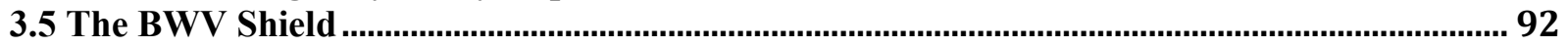

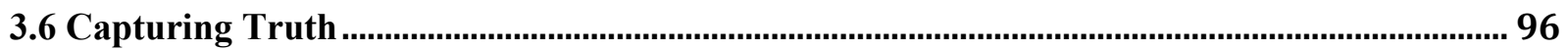

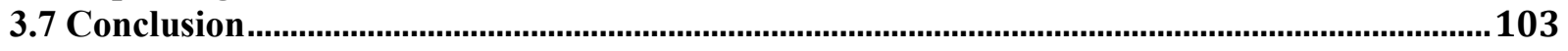

4. A Different Kind of Shot: Redefining how police look ................................................ 106

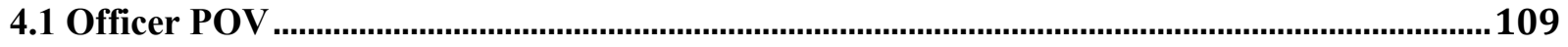

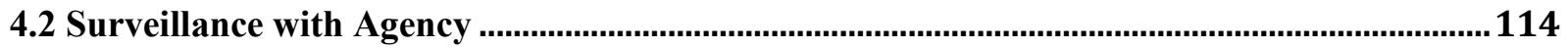

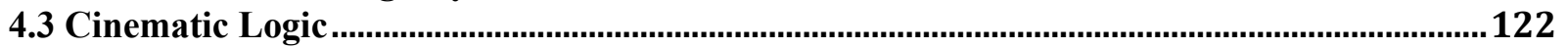

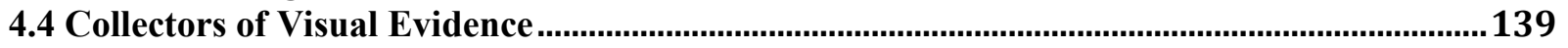

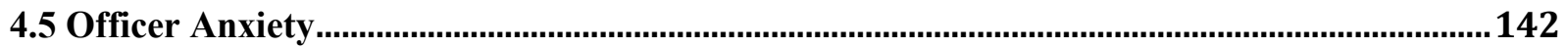

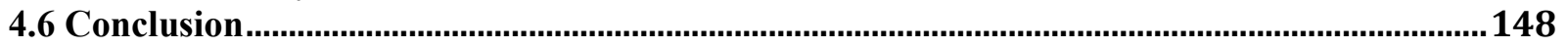

5. A Future with BWV: Conclusion ........................................................................... 150

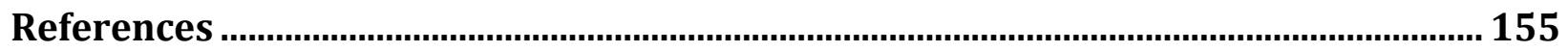




\section{Looking at BWV from a New Perspective: Introduction}

'I'm standing with him, still trying to calm him down, but I'm aware of Reade standing a few feet away and turning in a slow circle, taking a sweep shot like we've been trained to do" (Lichfield, 2015, p. 1). Taken from a piece of speculative fiction written by Gideon Lichfield, the statement describes a police officer's attempt to get a full shot of his surroundings on his body cam, ensuring that his device picks up contextual footage of the event. Although the narrative is fictional, it depicts the cinematic logic that officers must adopt, as the production of video surveillance becomes the officer's responsibility. What the Lichfield piece offers is a glimpse of the practical changes to policing that result from mounting surveillance technology directly onto the body. Reade's preoccupation with ensuring that his body cam picks up all of the necessary footage is reflective of his knowledge that his footage will become official evidence. Reade is no longer just wearing the camera; he has become the camera.

Following several very public instances of police misconduct in the United States, body worn video (BWV) technologies have become a popular 'solution' to public cries for additional oversight and accountability in policing. ${ }^{1}$ Having historically enjoyed a position outside of the scope of the surveillant gaze, police are now being incorporated into the surveillant assemblage as a result of the visibility that results from camera ubiquity and the viral sharing facilitated by digital platforms. Therefore, although BWV

\footnotetext{
1 Instances of police misconduct and excessive use of force include, but are not limited to, the cases of: Freddie Gray (April 12, 2015, see http://www.nytimes.com/interactive/2015/04/30/us/what-happenedfreddie-gray-arrested-by-baltimore-police-department-map-timeline.html?_r=0), Walter Scott (April 4, 2015, see http:/www.nytimes.com/2015/04/08/us/south-carolina-officer-is-charged-with-murder-in-blackmans-death.html), Michael Brown (August 4, 2014, see http://www.bbc.com/news/world-us-canada28841715), Eric Garner (July 17, 2014, see http://www.nytimes.com/2015/06/14/nyregion/eric-garnerpolice-chokehold-staten-island.html), Sammy Yatim (July 27, 2013, see http:/www.theglobeandmail.com/news/toronto/ontario-police-watchdog-lays-second-degree-murdercharge-in-sammy-yatim-shooting/article13837354/).
} 
might be part of a solution to misconduct, the adoption of these devices can also be considered a strategic move by police organizations to regain a level of control over their own visibility as camera wielding citizens continue to turn the surveillant gaze toward them. As a result of their positioning on the body and the subsequent first person perspective, these devices allow police to document their experience during an encounter.

However, the bodies in question are police bodies, they represent the state; they are the official authority and the video traces of their surveillance may become the official account. BWV offers police organizations the opportunity to manage their visibility strategically by laying a foundation on which to position their BWV footage as having a superior claim to truth and justice. The coupling of these technological extensions with ongoing police militarization represents a shift toward a cyborg officer whose body and capabilities are enhanced. Additionally, as these cyborg officers are being constructed as a defensive strategy against a public that is perceived as malicious, they are politically motivated making the transition past cyborg into RoboCop. By discrediting external footage and presenting their own as unbiased, these RoboCops and the footage they produce are poised to control narratives in the event that misconduct occurs.

In order to maintain the monopoly on truth necessary to achieve strategic visibility within the assemblage, officers must produce quality footage - something fictional officer Reade is obviously aware of. The result is that officers must have a deep understanding of the affordances and limitations of their devices and they must be cognisant enough of their surroundings to ensure that any necessary details are documented. Goold's (2003) work found that officers who understand the limitations of 
recording technology often modify their behaviour in order to ensure that CCTV cameras get the 'right shot'; becoming increasingly concerned about the way that their actions will look and take the appropriate steps to ensure that the angles, lighting, framing, etc. are favourable. It can be suggested that having the camera mounted on their bodies will exacerbate officers' awareness of the gaze and any anxiety that comes with it.

As officers consciously modify their looking and recording behaviours in a manner that will produce more flattering video footage, they adopt the perspective of the camera. They become the directors of their own films, adopting what I describe in this study as a "cinematic logic" that requires an understanding of the technology and consciously moving in a manner that leverages its affordances in an effort to both record the desired footage and ensure that it clearly reflects what the officer wants it to. In many ways, the adoption of this logic can be considered both an example of officers being taken over by the surveillant assemblage and their opportunity create resistance within it. On one hand, the police are more visible than ever before as increasing camera ubiquity forces them into the assemblage. On the other hand, their adoption of cameras they control represents an attempt to maximize control within the assemblage.

By taking on the corporealized responsibility of recording video footage that will likely serve as evidence, the practical job of policing changes significantly. Previously responsible for interpreting situations after the fact in their notes, police must now ensure that the camera is interpreting the situation appropriately in the moment ${ }^{2}$. Policing no longer relies on the officer's interpretation - full of experience, but limited by her or his subjectivity - but on the 'truth' captured by the camera and the data that comes with it.

\footnotetext{
2 It is important to consider that traditionally an officer's notes are not entered as evidence; rather officers refer to their notes when preparing for oral testimony. This is shifting with the use of BWV, as the visual 'notes' recorded by the camera are being treated as actual evidence.
} 
Shifting the focus of policing in this way raises significant questions about the role that police play in society and how that is changed as they are forced to become videographers tasked with making sure the video tells the right story. This transition fundamentally changes what police $d o$ and reshapes how we understand what police do and what they are. It is not my intention to make a normative judgement about BWV, instead I seek to attend to the tensions emerging as a result of these devices and the practical changes to policing that they demand.

\subsection{Situating the Use of BWV in the Policing Context: Literature review}

On August 9, 2014, Ferguson police officer Darren Wilson shot and killed unarmed black teenager, Michael Brown. Brown's death sparked widespread protest calling for a solution to the excessive use of force by police that many communities throughout the United States were routinely experiencing. The Michael Brown case was the first in a string of excessive force cases that became very public. What contributed to the incredible visibility of these situations was the widespread circulation of video footage of the events, in many cases originating from citizens using their smartphones to record actions that they perceived as misconduct.

In response to public outcry for additional police oversight - and perhaps also to ensure the existence of their own video footage - police departments across the United States have turned to BWV as a solution. BWV can be defined as,

mobile audio and video capture devices that allow officers to record what they see and hear. Devices can be attached to various body areas, including the head ... or to the body by pocket ... [and] they have the capability to record officer interactions that previously could only be captured by in-car or interrogation room camera systems (Mateescu, Roseblat, \& Boyd, 2015, p. 5). 
In the case of police adoption of BWV, the technology allows officers to record their interactions with the public, a double-edged sword that can either vindicate or condemn them.

To date, critical research regarding the use of BWV by police has been limited to questions of implementation, effectiveness, or privacy and the pragmatic policy solutions that will resolve these kinds of concerns (Ariel, Farrar \& Sutherland 2015; Drover \& Ariel 2015; Jennings, Fridell \& Lynch 2014; Mateescu et al., 2015; White 2014). Although the kinds of questions being asked by other researchers are valuable, considering the implications from a policy perspective is reactive and forces us to approach the topic from a perspective of having already accepted the legitimacy of the technology. I argue that the adoption of these devices should not easily be accepted, as they have widespread implications that go far beyond what can be regulated by the creation of sound policy. These devices have intimate and important implications for how police are located in the surveillant apparatus, a consideration that provokes much deeper questions regarding the validity and desirability of BWV in the policing context.

In order to address the adoption of BWV from a perspective that exceeds evaluating its 'effectiveness' at its stated goals, I will map the scholarly fields of body worn video and wearable technologies, police surveillance, police culture and professional organization, and video evidence. It is at the intersection of these fields that we can ask what it means to transform a police officer's body into a technology of surveillance - a camera - and what ramifications this might have for the officers themselves and their role in society. In addition, the map created by these fields provides the opportunity to question our assumptions about the reliability of video footage, our 
tendency to privilege the visual as truth telling, and the broader notion of risk management that is contributing to the uncritical popularity of BWV. Incorporating police into the physical surveillance infrastructure in this way provokes substantial change in the role that police play, making it imperative to ask questions about the implications of their adoption before moving on to questions of policy and implementation.

\subsubsection{Body Worn Video and Wearable Technologies}

Recently, BWV devices have enjoyed a surge in popularity as people become increasingly interested in documenting their lives. However, as BWV gains momentum, its potential for state surveillance and police oversight are also being explored. It is important to note that these technologies have emerged out of a long history of wearable technology design; therefore, much of the pertinent research does not deal specifically with BWV, but rather with wearable technologies in general.

Historically, much of the research concerning wearable technologies has focused on their use as helpful extensions of the body and the mind (Dvorak 2008; Mann 2001; Pentland 2000). This utilitarian perspective has highlighted the necessity of design, specifically size, comfort, and ease of use (Dvorak, 2008, p.82). These discussions draw on the figure of the cyborg human with augmented capabilities, which may explain the continued optimism toward wearables as extensions of the body (Dvorak 2008; Mann 2001). In a related vein, the potential for wearables to empower users has been the focus of those who see BWV as a means for individuals to gain an increased level of control over their surroundings (Mann 2001; Schaefer \& Steinmetz 2014). 
Dvorak (2008) presents an extensive history of wearable technologies from early dreams of futuristic cyborgs to the necessary characteristics that make modern wearables successful including size and technical simplicity. Like many researchers, Dvorak emphasizes the potential for wearable technologies to become meaningful extensions of our minds and bodies. Similarly, Steve Mann (2001), one of the earliest proponents of wearable technologies, has continuously emphasized their potential for user empowerment (Mann, Nolan \& Wellman 2003). Although the utilitarian potentials that wearables offer have been a common theme among those researching these technologies, Mann specifically underscores the use of BWV for purposes of sousveillance and/or subverting authoritative surveillance systems. For Mann, BWV technologies offer an opportunity for ordinary citizens to take back a level of control over the systems that watch and sort them.

In contrast, those specifically discussing the use of BWV by police forces have offered extensive criticism regarding the implementation and regulation of wearables (Jennings et al. 2014; Mateescu et al. 2015; Pentland 2000; White 2014). BWV has become an increasingly popular tool for police departments - particularly, as noted above, those that have been on the receiving end of public criticism concerning inappropriate use of force and/or search and seizure. As BWV is predominantly being adopted by police departments with the intention of monitoring interactions between police and the public, a research emphasis on the potential for these technologies to modify behaviour is not a surprise (Ariel et al. 2015; Mann et al. 2003; Mateescu et al. 2015; Nasiopoulos, Risko, Foulsham and Kingstone 2015; White 2014). In addition to the panoptic potential of BWV technologies, those discussing their use in policing 
contexts have also raised questions regarding the prevailing impression that video footage is superior to other forms of documentation (Mateescu et al., 2015).

Much of the research in this field has added to the conversation regarding the legal and ethical implications of wearable technologies - particularly those with recording capacity as they present significant challenges to traditional conceptions of privacy (Intille 1999; Jennings et al. 2014; Mann 2001; Mann et al. 2003; Nasiopoulos et al. 2015; Mateescu et al. 2015; Pentland 2000; White 2014). Although video surveillance technologies have become a ubiquitous part of our everyday experience, there is something that sets BWV technologies apart from other video surveillance. Those discussing the legal and ethical implications of BWV have made it clear that the fact that these technologies follow the wearer makes them much more invasive than cameras that are limited to public areas, such as CCTV (Mateescu et al., 2015). As BWV accompanies the wearer and records their interactions, these technologies can enter homes or record seemingly private conversations. As a result, many researchers have questioned the potential ethical dilemmas posed by BWV, particularly the impact that these technologies could have on individual privacy.

Intille (1999) attempts to make sense of the need for privacy protection by offering a detailed account of the interconnected histories of privacy and technology. By creating a timeline of court rulings in favour of privacy over surveillance, Intille gives a detailed account of how privacy has historically been conceptualized and addressed. While valuable, the focus on an individualistic understanding of privacy has drastically limited the conversation about BWV by narrowing the discussion to a set of predictable policy oriented questions. The scope of this conversation needs to be widened and its 
point of departure should precede questions of privacy, as the current discussion fails to confront whether or not these technologies should even be embraced in the first place.

Among wearables researchers, there has tended to be a strong emphasis on the positive potentials of these technologies. Aside from questions concerning potential implications for privacy, very little work has critically questioned the adoption of BWV and other wearable devices. I suggest that we need to refocus our analytic gaze on issues of embodiment, as the consequences of forcing officers to embody their surveillance technology shifts expectations of police work in ways that cannot necessarily be avoided or resolved. Therefore, it is necessary to question whether or not these shifts in policing are desirable before moving on to questions of appropriate implementation and policy.

As Pentland (2000) so aptly described, "when we build the computers, cameras, microphones, and other sensors into a person's clothes, the computer's view moves from a passive third person to an active first person vantage point. Such devices can be more intimately and actively involved in the user's activities" (pg. 116). BWV changes the vantage point of surveillance by giving it a more active, intimate position from which to record. This important difference has been largely neglected by those investigating the use of BWV by police, leaving a rather large gap in the research. These technologies are being adopted across Western nations at a dizzying pace (Jennings et al. 2014; Mateescu et al. 2015), making it essential that we stop considering BWV as just another surveillance technology and begin to discuss the characteristics that set these particular devices apart from more traditional surveillance. 


\subsubsection{Surveillance by the Police}

As risk management continues to be a main societal priority, policing has shifted to take on a more proactive approach focused on deterrence. As we continue to make decisions based on the mitigation of risk, extensive surveillance becomes imperative to policing strategies. The result is a form of policing that must heighten its ability to monitor, sort, categorize, and predict people (Finn, 2009). We have watched the expansion of police surveillance powers to include dash cams, complex databases, CCTV and, most recently, BWV devices that document the officers' encounters on an intimate level. With the adoption of every new surveillance tool, police work changes and their role is redefined.

In their work Policing the Risk Society (1997) Ericson and Haggerty discuss how surveillance has become a main policing strategy aimed at reducing risk and maintaining security. As a result, an entire spectrum of surveillance practices ranging from strategically built environments to sporting BWV have been integrated into our everyday environments (p.133-134). The rise of surveillance as a means of proactively mitigating risk is a familiar theme among surveillance theorists; however, what the emerging risk management approach means for policing is of particular interest considering the role that police play in maintaining public safety and social order (Ericson \& Haggerty, 1997).

Stemming from research in the area of police culture, a significant portion of the literature concerning the use of surveillance by police has concentrated on how officers adapt to new technologies. Given the unique, and often defensive, nature of police organizations many attempts at oversight have been seen as intrusive and their implementation has been met with resistance (Chan 1997; Drover \& Ariel; 2015; Loftus 2009). Initial resistance generally comes from supervisors and middle management who 
see being forced to implement BWV as a threat to their professional autonomy (Drover \& Ariel 2015; Skogan, 2008). However, resistance trickles down to "frontliners" who often perceive the addition of these technologies as a threat to their discretion (Drover \& Ariel, 2015). This resistance poses questions for how successful the use of BWV will be if officers resist and undermine its implementation and use. Additionally, this raises questions regarding how BWV can actually facilitate this kind of resistance.

Influenced by questions of panopticism, some researchers have investigated how extensive surveillance influences the way that police officers approach their work and the ways that they interact with the public (Drover \& Ariel 2015; Goold 2008). These avenues of investigation are particularly pertinent. The assumption is that the implementation of BWV will force both police and the public to act in a more cooperative manner, as both parties will be influenced by the knowledge that they are being watched. Goold (2008) argues that after interviewing police about the use of CCTV footage to resolve complaints of police misconduct there is evidence that officers are modifying their behaviour because they have internalized the gaze of the camera. It is the knowledge that they are being watched coupled with the understanding that video footage could be used against them that have influenced the way that officers approach their work (Goold, 2008). However, the changes to behaviour are not necessarily cooperative, but largely involve second guessing their actions and focusing on getting the 'right' video footage (Goold, 2008). Although Goold's findings are based on a short-term study, officers were repeatedly reminded about how CCTV footage has haunted their colleagues, likely renewing their concerns as long as the footage continues to be used as evidence. As the footage recorded by BWV will also serve as evidence, the fact that it 
offers a more intimate point-of-view than CCTV surveillance it is likely to amplify these anxieties. In addition, the officers are aware that BWV is being implemented, in many cases, specifically to monitor their interactions, upping the ante for officers who are cognisant that these technologies necessarily only record one specific vantage point in the shared experience of the filmed encounter.

Although useful, research in this area has been too focused on questions concerning what increased police surveillance will mean for police, the public, and society as a whole. What has been neglected is what such extensions $d o$ to social realities. It is as though extensive police surveillance has become so commonplace that its existence is no longer being questioned. As the trend toward ever more police surveillance continues, we must question what the ramifications are, recognizing that at some point the mitigation of risk will not be worth the trade offs required to achieve it. Further, the adoption of these technologies should be provoking questions how policing will change as officers' bodies become part of the surveillance infrastructure. Goold's (2008) observations regarding officer anxieties and behaviour modification to ensure 'the right shot' should be considered in tandem with questions regarding mechanical objectivity and the privileging of 'official' footage.

\subsubsection{Surveillance of the Police}

In response to the ways in which police surveil the public, some research has taken up the tactics citizens can use to push back and turn the gaze toward the police. Cop-watching and counter-surveillance have become a popular response among those who feel that police power has become too extensive (Monahan, 2006). Cop-watching refers to the process where citizens capture police activities ranging from the mundane (i.e., traffic stops) to the visceral (i.e., beating of handcuffed suspects), is a form of 
counter-surveillance viewed as democratic action capable of raising awareness and empowering individuals to combat police deviance and governance (Schaefer \& Steinmetz, 2014, p. 502).

In an effort to turn the tables and shed light on police misconduct, many citizens have used video technology to record the police - something that has become increasingly common due to the prevalence of smartphones with excellent video capacity (Schaefer \& Steinmetz, 2014; Wall \& Linneman 2014).

Schaefer and Steinmetz (2014) consider cop-watching, "a form of video-activism where citizens attempt to expose deviant police behaviour, monitor routine interactions between citizens and the police, and to challenge the largely unidirectional gaze of surveillance" (p. 503). Literature on cop-watching is naïve in many ways, as it often overstates the potential for producing meaningful change in policing by failing to consider factors like the lack of centralized organization among cop-watchers and the unequal distribution of power between those watching and the system they are attempting to expose. However, it is worth noting there are examples of viral citizen-made recordings that have succeeded in provoking substantial criticism of police misconduct and have highlighted the need for additional oversight. One of the most compelling examples is the footage filmed by a bystander as an NYPD officer put Eric Garner in a chokehold, ignoring Garner as he repeatedly gasped the words "I can't breathe" (The Guardian, December 4, 2014). Garner died as a result of the illegal chokehold and the footage went viral online, sparking widespread criticism of the NYPD. We cannot forget that police are grappling with the abundance of eyes that are now watching and recording them, in many cases hoping to document any potential misconduct. It is important that we consider BWV in the context of an organization that is trying desperately to manage 
narratives in a time where its control is being eroded, in large part, by smartphones and online platforms that allow viral sharing.

\subsubsection{Police Culture and Professional Organization}

Like most occupations, police officers navigate a professional culture specific to their work; however, due to the nature of that work, the professional culture occupied by police exhibits a very specific set of characteristics. Police culture refers to the, "values, norms, perspectives and craft rules which inform police conduct" (Chan, 1996, p. 110). It is important to consider that various police cultures exist within the police hierarchy, as officers of different rank will demonstrate different characteristics and perceptions of their work. However, police culture generally involves a core set of characteristics that are exhibited at all ranks of the hierarchy and are perpetuated as new officers are informally trained to adopt this shared culture.

The core characteristics demonstrated by police officers were first described by Reiner (1985) in his seminal work, The Politics of the Police. Reiner argues that the core characteristics of police culture generally stem from the masculine ethos and conservatism that form the foundation of this particular occupational culture. This hypermacho mentality is coupled with an exaggerated sense of mission and an emphasis

on exciting, and often violent or dangerous, work (McConville \& Shepherd 1992; Reiner 1978, 2000; Skolnick 1966). Tending to go out of their way to avoid less exciting police work such as responding to domestic disputes, officers gravitate toward what they consider to be 'real' police work. 'Real' police work is that which is more exciting and dangerous, often requiring the use of force (Loftus, 2009, p. ix). 
As a result of the work they do, police often become suspicious and subsequently socially isolated (Reiner 2000; Skolnick 1966; Westley 1970). Feelings of suspicion and isolation tend to breed cynicism; further isolating the officers from those outside of the force (Loftus 2009; Manning 1977). In addition, officers often feel isolated from the rest of society because those who have not shared their experiences do not properly understand what it means to be a police officer (Loftus, 2009, p. 6). These core characteristics, particularly those that breed isolation, cause officers to turn inward toward their comrades, creating a defensive solidarity among police (Brown 1981; Manning 1977; Reiner 2000; Skolnick 1966; Westley 1970). It is often argued that the isolation and defensive solidarity of officers contributes to the failure of so many attempts to reform policing.

Skolnick (1966) highlights the prevalence of racism among officers, arguing that the tendency toward racism results in over-policing of certain groups. One of Skolnick's greatest contributions is his discussion of the symbolic assailant. Skolnick observes that, "the policeman ... develops a perceptual shorthand to identify certain kinds of people as symbolic assailants, that is, as persons who use gesture, language, and attire that the policeman has come to recognize as a prelude to violence" $(1966$, p. 45). The construction of the symbolic assailant is similar to the notion of 'thin slicing' discussed by Malcolm Gladwell (2005), which refers to, "the ability of our unconscious to find patterns in situations and behaviour based on very narrow slices of experience" (p. 23). Thin slicing allows us to cut through an abundance of information and draw conclusions very quickly, the symbolic assailant is an example of thin slicing that allows officers to make quick judgements about what constitutes a troublemaker or criminal based on their 
own narrow slices of experience. Although this might seem reminiscent of the criminal profiling practices that are often used in policing, the symbolic assailant is created by the subjective experiences of the officer and has no official basis in any reputable research.

Although the core characteristics of policing have been observed consistently since the 1960 's, contemporary studies have attempted to highlight the nuances that exist in this occupational culture. The homogenous makeup of many police forces that has played a large role in shaping police culture has begun to shift as more diversity is sought during the recruitment process (Loftus, 2009). However, as the dominant white, heterosexual, male culture becomes challenged those officers that embody it have been known to dig in and compensate by becoming resentful and hostile toward those who challenge the traditional culture (Loftus, 2009). In addition, some researchers have argued that police culture differs depending on the various unique social, political, economic, and cultural contexts in which it exists (Chan 1997; Holdaway 1996; McConville, Sander \& Leng, 1991). Although context plays a role in the specific culture of each police force, the core characteristics continue to be relevant and exist to one degree or another regardless of broader context.

Chan $(1996,1997)$ assumes the task of trying to address the question of why it has proven so incredibly difficult to change police culture. For Chan (1996) the solution rests in acknowledging that there are multiple cultures within policing and that each needs to be uniquely addressed when it comes to reform. Although there may be common characteristics that exist among all ranks within policing, there are also meaningful differences. Understanding these differences is key to provoking real change in policing. 
Much of modern police organization can be attributed to its professional culture, attempts to gain recognition as a profession, and the development of police unions. These developments have not only allowed police culture to emerge and thrive, they have also shielded policing from reform and external or civilian oversight. As suggested by Feuille and Juris (1976), occupations seek to become recognized and accepted as professions because of the benefits that accompany such recognition: increased prestige, income, and power (p. 90-91). Further, Feuille and Juris (1976) argue that, "from the group's point of view, such collective autonomy is desirable for having it means that the group is able to exercise considerable control over the professional-client relationship, rather than having outsiders exercise such control” (p. 91). The quest for power and autonomy through professionalization has been a main consideration for police (Brown 1981; Feuille \& Juris 1976; Green \& Gates 2014; Manning 1977; Potts 1982; Price 1977).

Unions have actively pushed for this autonomy and discretion, and have systematically shot down attempts at external oversight (Feuille \& Juris, 1976). Although it can be argued that police unions have traditionally acted inconsistently with the process of professionalization they have been clearly in line with the process when it comes to autonomy and control (Feuille \& Juris 1976). Police unions have launched public relations campaigns in order to counteract negative publicity, which we continue to see today in the rhetoric surrounding the most public cases of police misconduct and brutality. This attempt to manage the narrative is directly in line with the way that professions deal with criticism (Feuill \& Juris, 1976, p. 104). Feuille and Juris (1976) point out that, ... union behavior over the corruption issue seems to follow closely the bahavior of the traditional professional association: they are highly unlikely to be the first 
to call public attention to the problem, they are careful to insist that those who are charged are not representative of the class, and they are insistent upon due process for the accused (p. 105).

In addition, unions have fought off public oversight and made attempts to influence law enforcement policy (Feuille \& Juris, 1976). Essentially, police unions have established the autonomy and control that comes with professionalization without having to adopt the accountability, cohesion or education necessary to classify as a true profession. As Green and Gates (2014) highlight,

somewhat confusingly, or perhaps very intentionally, police flirt with the idea of professionalization but switch between making a positive stance in the direction of policing as a profession, while quickly flipping back to references to the 'professional' behaviour of police (p. 82).

The result is that police, in large part thanks to their unions, have positioned themselves to have their cake and eat it too.

I found the literature in both the area police culture and professionalization particularly productive with few significant gaps. Perhaps the complete nature of these areas is due to the resiliency of the culture, as Loftus (2009) found, change since the 1960's has been incremental at best. While police culture plays a large role in shaping the context in which BWV is emerging, perhaps most noteworthy is the demonstrated motivation among police organizations to achieve autonomy. Considering these motivations, the adoption of BWV as a response to criticism can be considered an attempt to maintain control over their visibility in the face of significant public scrutiny.

\subsubsection{Video Evidence}

As the adoption of BWV by police forces has been touted as a solution to a lack of police oversight, it can be assumed that the resulting footage will be used as evidence that either vindicates or incriminates officers and citizens alike. However, as video surveillance 
continues to become the solution of choice for the management of risk in various contexts, it is worth considering their technical limitations as highlighted by researchers. We often fall prey to the assumption of mechanical objectivity by accepting that video footage is a direct, objective reflection of reality. However, filmmakers have long acknowledged, video footage only reflects one plausible interpretation of reality (Carrabine 2012; Feigenson forthcoming; Kahan, Hoffman \& Braman 2009; Mnookin 2014; Silbey 2008; Silbey 2010; Young 2014). As Silbey (2010) states, “films - all films - tell $a$ story but certainly not the only story that could be told about particular issue" (p. 1258). In other words, video footage cannot be considered an unbiased reflection of reality, but rather must be acknowledge as the partial truth that it is (Carrabine, 2012; Mnookin, 2014; Silbey, 2010). Our tendency to privilege the visual and assume the objectivity of video footage is particularly significant when we consider the volume of video surveillance footage that is now being used in legal proceedings.

The shortcomings of video technologies as evidential truth-claims have been taken up primarily by visual criminologists, many of whom have focused on the impact of the social and discursive construction of images on legal decision makers' perception and interpretation of them. For scholars who take this approach, what makes video footage so susceptible to competing interpretations is the socially constructed narrative in which it exists. Highlighting the storytelling capacity of video acknowledges that it is presented in a particular context which is not unbiased, but socially constructed (Carrabine, 2012; Mnookin, 2014; Silbey, 2010; Young, 2014).

In Just Images: Aesthetics, Ethics and Visual Criminology, Carrabine (2012) focuses on the ways that images construct, rather than record, reality using documentary 
photography to demonstrate the subjectivity of the image. Pointing out that those who take the image often impose their own aesthetic understanding of the world on it, Carrabine (2012) argues that images are often both constructed and understood based on our pre-existing understanding of a given thing, an understanding that might vary from person to person. Furthering the examination of the role that storytelling and narrative play in the subjectivity of image, Silbey (2010) discusses the storytelling and iconization of images and films used in legal proceedings. As Silbey argues,

... when a photograph is asserted as evidence, the nature of the story being told is changed. This is because, often times, a photograph becomes iconic in a court of law. The photograph becomes more than mere evidence of some fact. It serves as symbol around which a central, potentially even dominant, message revolves.

This happens in the same way a photograph becomes iconic in culture: through its various documentary, rhetorical, and appropriative uses (p. 1261).

Essentially, like images that circulate outside of the legal realm, those that serve as evidence often become symbols that embody the dominant narrative through which they were presented (Mnookin 2014; Silbey, 2010; Young, 2014). Again, this challenges the perceived objectivity of images by pointing out that they exist as part of a narrative, constructed using particular rhetoric that cannot stand for the whole truth.

Despite naïve claims to the contrary, video does not speak for itself; it is open to multiple interpretations. Mnookin (2014) argues that the majority of video and photographic evidence is semi-legible, which, "usefully focuses our attention on the ways that much visual evidence neither speaks for itself nor permits unbounded interpretations, but rather, has a range of plausible - and potentially inconsistent - readings" (p. 48). Our interpretation is both highly dependent on the questions being asked, and in some cases, the level of expertise or background of those watching it (Carrabine 2012; Goodwin1994; Mnookin 2014; Silbey 2010; Young 2014). The fact is it matters who is viewing the 
footage, as multiple people are likely to come to multiple conclusions based on the same video clip (Feigenson forthcoming; Kahan et al. 2009; Mnookin 2014).

It is also important to highlight the potential impact of expert testimony and construction of narratives that require an expert to lead lay-people through a complicated explanation (Goodwin 1994; Mnookin 2014). Goodwin (1994) uses the example of the video footage of LAPD officers brutally beating Rodney King in 1991 to illustrate that expert construction of seemingly straight forward video footage can be incredibly important for visual truth-claims. The footage of King's beating was used by both sides in the initial trial; however, the defence created reasonable doubt by calling on Sergeant Charles Dukes, an expert on the use of force by police, to lead the jury through the footage using a particular coding system that allowed him to explain the situation in terms of how the police involved would have perceived it (Goodwin, 1994, p. 618-619). The implication is that lay-people do not have the expertise needed to properly understand police work. In King's case, both sides used the exact same video footage to spin competing narratives demonstrating that even footage that seems clear-cut can be interpreted in multiple ways.

In addition to the contextual factors that influence the biases of video footage, there are many technical factors at play. Some of these factors, such as lighting, quality, and point-of-view are the result of placement. Others, including technical limitations, production, and editing can be attributed to the technology itself and those handling it. All of these technical factors play a part in how the audience perceives the recorded event. In many ways, the mechanical recording of an event can be considered a practice of exclusion. Video is a snapshot of reality from one point-of-view, some factors are 
included, some are excluded, others are emphasized, and some are lost. As Silbey (2008) asserts we must, “consider the film's frame: what is visible in the film, what is not, due to its beginning, ending, and spatial attributes - its borders, its point-of-view and its mechanical capacity" (p. 122). We must also remain conscious that visual clarity might be a trap as many of the gaps between reality and the video we see are not obvious.

As described by Mnookin (2014), “A shaky, blurry surveillance image captured in low light may make the scene depicted feel scarier and less secure than the same image taken in conditions generating a more legible image" (p. 64). As video is a construction of the real, it is depicted, "in artificial light and color" which undoubtedly blurs the distinction between reality and the visual recording of that reality (Silbey, 2008, p. 102). The interpretation of video footage can also be impacted by camera angles and field-ofview as these factors often privilege certain objects over others (Silbey, 2008, p. 113). Further, and perhaps most importantly when considering BWV, all video footage has a point-of-view as a result of where the camera is placed (Mnookin 2014; Silbey 2008). In the case of policing, the BWV technology is placed directly on the officer's body, facing away from her or him. There is something incredibly symbolic about the fact that these cameras are meant to serve as a mechanism of police oversight and yet their gaze faces away from the officer. The result is that the officer's point-of-view is automatically privileged.

In addition to visual distortions, factors such as production, editing, and technical limitations also manipulate both the image and, in many cases, the sound gathered by recording technologies (Mnookin 2014; Silbey 2008). The processes of production and editing that may have gone into the final footage will likely be unknown to those 
reviewing it, making it difficult for audience members to question the authenticity of what they are seeing. For example, blurry images are often enhanced by experts to attempt additional clarity; however, this is a physical manipulation of the image(s) and one has to question how much discretion is afforded to the expert doing the editing (Mnookin, 2014, p. 58). The cutting and splicing of video footage that is often done during the editing process removes certain portions of the video making it incomplete (Silbey, 2008, p. 105). These practices raise questions about the motivation behind what is removed and what is left. Further, additions are sometimes made to enhance the story being told in video evidence. As Feigenson (forthcoming) argues, visual and audio simulations are often added to clarify subjective evidence. The circumstances surrounding the construction of video evidence can be incredibly problematic if they are not disclosed to those tasked with determining the truth-claims of a particular video.

One of the most influential concepts proposed in this field is that of evidence verité - films made by the state for the purpose of improving law enforcement and the legal process (Silbey, 2010, p. 1259). As Silbey (2010) describes,

... surveillance or "real time" film images that purport to capture an event from the past about which there is a dispute. Increasingly, this kind of "evidence verite" - film footage of arrests, criminal confessions, and crime scenes - is routinely admitted in U.S. courts of law as the best evidence of what happened (p. 1257).

Silbey (2010) argues that these types of evidence verité often overwhelm any additional evidence as a result of their perceived truth-value (p. 1257). In addition, "these evidence verité ... go largely untested for bias, incompleteness, or ambiguity" (Silbey, 2010, p. 1259). As the scholarship in this area has argued, this perception of video as truth is flawed and problematic. It is essential to consider the possible limitations of recording technologies in order to ensure that their claim to the truth is not over-estimated. The 
evidence documented by police BWV devices is state evidence and will therefore fall under the category of evidence verité. This reality makes challenges to the assumption of evidence verité paramount to any discussion regarding the future of $\mathrm{BWV}$, particularly given that BWV footage will be taken from the point-of-view of the officer, privileging the officer's perception of reality.

Although the literature concerning the validity of video as truth takes up some very important questions, what is almost entirely left out is any recognition of the fact that in many cases video footage is accompanied by audio capacity as well. This gap in the research is particularly pertinent given that BWV technologies often include both audio and video recordings of police interactions. A significant element of the technology being used (and its limitations) has not been considered. As the visual criminologists discussed above have clearly demonstrated, recording technologies have their limitations when it comes to telling the truth. It is certainly worthwhile to question constraints of technology that records audio, as these too have a significant impact on our perception of a recording. Consideration should be given to the ways in which what we hear shapes what we see, and vice versa.

In addition, it is often assumed in the literature that raw surveillance footage is unedited, unself-conscious and free of narration making it less biased (Silbey, 2008). However, if officers are consciously taking steps to ensure that the footage reflects their experience of a given situation and in some cases even narrating, we can hardly argue that BWV footage in unedited. Perhaps there is no post-production manipulation being done but the officers are engaging in soft editing and manipulating the text as they simultaneously view, frame, and experience it. 
At the intersection of the fields above is a conversation about what the adoption of BWV devices means for policing in contemporary society. Although research has mapped the potential policy implications, particularly where they pertain to individual privacy, the research has failed to question how these technologies are changing the role of the police in society, the practical act of policing, or the potential implications of turning police into cameras. I aim to offer an alternate look at the use of BWV in policing by raising questions that precede policy considerations. By looking at how these technologies and their position on the body change the way that officers approach their jobs, an entirely new set of questions arise. What anxieties accompany the officer's knowledge that she or he is now responsible for getting the necessary shots to ensure that justice is served? How does the knowledge that these technologies are meant to watch the police change officers' interactions with and use of the technology? How will police ensure that their experience, training, and gut feelings are captured by the cams? These technologies are not simple and certainly have their limitations. As a result, in what ways can we see police adopting a cinematic logic in order to ensure that their body cams record the 'right' footage? How are we, as a society, making sense of these shifts?

\subsection{Conceptualizing Cops as Cameras: Theoretical framework}

The ubiquity of surveillance that surrounds us today is exceptional, but it is not accidental. The continued addition of more surveillance results from very specific decisions that stem from our growing obsession with eliminating risk. We believe that if we can just see more, catalogue more, and predict more, we can eliminate unknown variables and mitigate risk. This approach has been adopted by countless institutions ranging from those concerned with national security to those that provide health care. For 
this reason, much of the recent scholarship in the area of surveillance has focused on risk management as the motivation for expanding surveillance powers, with many arguing that we have transitioned to a risk society where the management of uncertainty is at the core of our social fabric. As the desire to eliminate risk continues to dominate the social psyche, surveillance becomes the technique of choice to accomplish the task. This approach calls for the proactive identification of potential unknown or undesirable factors in order to take the steps necessary to avoid danger or discomfort. Ericson and Haggerty's Policing the Risk Society (1997) describes rationalities of risk as being, designed to reduce uncertainty to the point where the actor feels confident in taking action. Grounded in probabilistic thinking and predictions, they allow deselection of specific factors and thereby point to preferable courses of action. They are hyperrational and deeply pragmatic, always scanning for technical solutions to problems that incapacitate action (p. 87).

As this line of hyperrational thinking becomes our default setting surveillance becomes the logical solution to problems of risk, as these surveillance systems simplify the processes of monitoring, sorting, categorizing and predicting on a massive scale.

Foucault's panopticon ${ }^{3}$ continues to dominate discussions of surveillance and serve as a model to explain modern surveillance. Although the advanced and interconnected surveillance systems with which we interact today have long surpassed the level of Foucault's panopticon, the spirit of panopticism remains. Many of today's surveillance systems have no distinct centre or periphery like the panopticon did, but the self-censorship that comes from knowing that one could be watched at any given time

\footnotetext{
3 Panopticism, as described by Foucault in Discipline and Punish, is inspired by the prison design created by Jeremy Bentham. The defining features of the prison's architecture are a circular periphery of cells with a guard tower in the center. In this model prisoners are highly visible but the gaze cannot be reciprocated, nor can it be confirmed. The result is a sense of permanent visibility that inspires prisoners to self-police, as if they are being watched at all times. Foucault argues that panopticism can be observed in many other institutions including hospitals, workshops, and schools. Foucault's panopticon marks a shift from the attempt to control bodies to the desire to control the mind and spirit.
} 
remains a relevant concern, particularly as surveillance becomes increasingly pervasive. I would argue that control over the mind and the creation of docile bodies were the most important aspects of Foucault's panopticon and despite our current surveillance systems having surpassed anything he could have imagined, the essence of his work remains relevant. In fact, the extraction of panopticism from the panopticon itself can be seen in the work of scholars including David Lyon and Mark Poster, both of whom consider control over the mind/soul to be the defining aspect of Foucault's work. Therefore, future references to panopticism will not consider the panopticon itself, but rather a pervasive gaze used to prompt self-censorship.

Gandy's panoptic sort (1993) works to apply this panopticism to the growing number of databases that now track, sort, and categorize us. The panoptic sort refers to what Gandy considers a form of cybernetic triage, "through which individuals and groups of people are being sorted according to their presumed economic or political value" (p. 12). In other words, subjects are being sorted according to their level of risk, as determined by systems built specifically to sort the desirable from the undesirable. These seemingly mundane systems can be considered a nod to the risk society, as they sort individuals in a probabilistic manner that aims to minimize risk. By extension, the shift toward a society preoccupied with risk mitigation has changed the objective of policing from reactive to proactive. Policing has become less about justice and is increasingly dependent on monitoring, sorting, and evaluating risks associated with criminality in an effort to stop crime before it happens.

As the panopticon is no longer adequate to describe the extensive surveillance infrastructure that exists today, a more appropriate description of the current state of 
surveillance emerges from Deleuze and Guattari's (1987) discussion of the assemblage. Haggerty and Ericson extend Deleuze's assemblage in their work The Surveillant Assemblage (2000), arguing that the surveillant assemblage results from the conglomeration of a number of previously independent surveillance systems that begin working together to various extents. According to Haggerty and Ericson, the surveillant assemblage is a mechanism of disembodiment that separates physical bodies from the data that they generate and reassembles that information as virtual 'data doubles' ( $\mathrm{p}$. 605). It should be noted that in policing contexts these data doubles are often used to criminalize individuals and to predict and intervene in future behaviour (Wilkinson \& Lippert 2012; Finn 2009).

This conglomeration of surveillance systems results in an intertwined and interconnected assemblage tasked with constantly sharing and sorting information. The assemblage can be described as rhizomatic both because of its rapid expansion and because it is said to level the hierarchy of surveillance - subjecting everyone to the gaze. However, one of the most important parts of the rhizomatic nature of the surveillant assemblage is that, "a rhizome may be broken, shattered at a given spot, but it will start up again on one of its old lines, or on new lines" (Haggerty and Ericson, 2000, p. 614). Essentially, the system will compensate for any resistance by reorganizing itself in a manner that finds a way around resistance, much in the same way that rhizomes will grow around any obstacles in their path. It would seem that resistance is futile but in reality, things are much messier in the assemblage. I would argue that it is certainly possible to resist within the assemblage; however, effective resistance requires that we play by the rules of the system. In other words, by leveraging the tools of the assemblage 
it is possible to cause resistance inside the system, something that is largely facilitated by the lack of centralized power. I argue that this is what we are witnessing as police organizations adopt their own cameras in an attempt to maintain control over their visibility as they become incorporated into the assemblage.

Haggerty has also proposed that modern surveillance leads to a hierarchy of visibility that focuses the gaze on certain individuals while sparing others. Haggerty (2006) argues that, "the types of surveillance accentuated in the panoptic model typically involve the monitoring of people who reside at a lower point in the social hierarchy" (p. 29). However, Haggerty also considers the possibility that hierarchies of visibility are being recalibrated as the surveillant gaze becomes increasingly omnipresent and indiscriminant (p. 29). Although hierarchies are leveling as police are removed from the top and subjected to the gaze, their attempts to control their visibility is resulting in newly formed nodes of power within the assemblage. Consequently, hierarchies may be leveled, but some groups are able to maintain a privileged position.

These technologies are not only positioned on the body, they also serve as an extension of human capacities - extending the officer's audio and visual capacities and supplementing the subjective human memory with a mechanical one. If we consider BWV in this way, as an extension of the human body, discussions of the cyborg are essential.

Although the term cyborg often inspires thoughts of fictional dystopias and RoboCops (Tomas, 1995), the cyborg is, "a cybernetic organism, a hybrid of machine and organism, a creature of social reality as well as a creature of fiction" (Haraway, 2000, p. 50). In other words, a fusion of the mechanical with the biological in one being. 
Echoing this duality, Balsamo (1996) argues that the cyborg can longer be considered wholly fictitious; the cyborg figure is now both fictitious and real. We frequently create cyborgs without giving it a second thought. Perhaps the most obvious example being the use of devices such as pacemakers and prosthetics as replacements for body parts that are failing or absent (Wilson 1995; Balsamo 1996). The argument has even been made that with the level of technology we use on a daily basis to facilitate banal activities, we have all become cyborgs to a certain degree (Dvorak 2008; Balsamo 1996; Jordan 1999).

As it becomes commonplace to integrate technologies with the body in an effort to prolong life and facilitate mobility, it is not surprising that devices that can enhance the body are becoming increasingly popular (Shilling, 2005). BWV devices do not replace deficient body parts, they extend capable ones. The officer is capable of seeing, hearing, and remembering, BWV just helps them do it better. This attempt to perfect is articulated by Belsamo (1995), "techno-bodies are healthy, enhanced and fully functional - more real than real" (p. 216). The replacement of the officer's human capacities with mechanical ones reflects assumptions of mechanical superiority and objectivity; however, it also reflects posthuman ideas about pushing the boundaries of bodily limitations.

Discussions of the cyborg provide an avenue through which to push boundaries, both bodily and otherwise. The cyborg body provides a means for reimagining the body when traditional conceptions are challenged (Haraway 2000; González 2000). Relatedly, Balsamo (1996) suggests that cyborgs allow us to confront notions of identity and "the other" because, “... they are not like us and yet are just like us" (p. 32). Essentially, the cyborg provides a figure through which to challenge power structures, enabling us to both envision a different reality and critique our current one (Haraway, 2000). As officers are 
increasingly militarized and technologically extended our perceptions of police bodies, identities, and authority are challenged; the cyborg provides us with a way to make sense of these authoritative bodies that are no longer entirely human and whose power is being amplified by their adoption of technological enhancements. In fact, the tradition of cyborg imagery in relation to themes of militarization, industrialization, and corporatization (Tomas 1995; Haraway 1991) fits well into the context in which our militarized officers are adopting BWV.

Much of the research in this area has been taken up by feminist scholars who probe the significance of technology and the female body, creating a fantastic feminist foundation but leaving gaps in the research by neglecting to consider the implications for male bodies. As the majority of police officers continue to be male, it is important to note this gap in the research, as it is particularly significant in the case of BWV in the policing context.

\subsection{Methodology}

My research aims to answer questions regarding whether the adoption of BWV by police organizations can be considered an attempt to regain control and management over their visibility, what steps are involved in this process, and what the repercussions are. Specifically, I investigated how the use BWV technologies changes the way that police approach their work and whether we can see a cinematic logic emerging among officers who use the devices. In order to attend to these questions, I sought to establish the social and political context in which these devices are emerging, answering the question: why now? I explore these questions through a qualitative analysis, specifically a textual analysis of relevant Canadian media coverage, the websites and training manuals for 
BWV products, and the report produced by the Edmonton Police Service in 2015 following the completion of its BWV pilot program. These three sites represent the three dimensions of the problem that I have investigated: the context in which BWV are emerging, the technology itself, and how police officers experience these technologies.

I began by looking at Canadian press coverage of BWV in policing contexts. A framing analysis of news coverage at the local, provincial, and national levels allowed me to establish the context in which these technologies are emerging. This analysis addresses questions such as: Into what social, historical, and political context are these technologies being located? How is their adoption being discussed in the media? What is being emphasized? And by which actors? What are the justifications for adoption? How does the media characterize officers and citizens respectively? What lines of critical discourse are available?

The study identified patterns in framing and rhetoric surrounding the emergence of BWV. In an effort to pinpoint these patterns I looked at coverage starting in 2010, as this is the year that the first BWV pilot program began in Canada (Victoria, BC). The research sample included all Canadian TV, print, and online news coverage, which I examined to determine whether there are patterns between and across platforms. I included content from both tabloid and more reputable news outlets and filtered out any coverage that was either irrelevant or not helpful to my research. Content was eliminated if it was identical to coverage already included or if it offered no critical or analytical discussion of the adoption of BWV. After narrowing down the scope of my corpus, I reread it and coded it based on themes including "discusses officers as videographers", "discusses change in police work", "discusses officer as collector of visual evidence", 
"discusses officer anxiety about BWV", "adoption was tied to major event of misconduct", "discredits external video footage", "characterizes police BWV footage as the 'official' account", "frames BWV as a neutral/unbiased technology", and so on. As a framing analysis, the study identifies recurring frames used by the media when discussing the adoption of BWV by police organizations both in Canada and elsewhere.

My second site of investigation included the websites and training manuals for several BWV products. These resources provided necessary insight into how these products are being marketed as well as the technical and pedagogical components of their operation. An analysis of how these products are being marketed to both police and the public by the companies that produce them has allowed me to pinpoint some of the discourse surrounding their emergence. By looking at what technological capacities and limitations are being highlighted in these websites and manuals, this research pieces together the problem-solving discourse surrounding the use of BWV for policing. Specifically, it addresses the questions including: What policing problems do marketers argue can be solved with BWV? What technical functions are being highlighted? Understanding how the affordances and limitations of BWV are being communicated to both police and the public is essential to understanding which functions make them a particularly attractive tool for police work. The study includes both a textual and visual analysis, as the visual components of these resources, particularly the websites, are very telling.

The websites investigated included TASER, Digital Ally, Safety Vision, and Reveal Media. I chose these particular websites because these companies produce some of the most technically superior BWV, a claim that is validated by the U.S. Department 
of Homeland Security and the various police departments that have purchased them. In addition, they all share key attributes relevant to my study. The websites are clearly professional and reflect a significant level of marketing and sales strategy. With regard to the marketing of the products I coded based on categories like "marketed directly to law enforcement", "highlights specific technical functions for policing", "claims to provide policing solutions", "suggests BWV can capture the truth", "references police culture", etc. In addition, I examined the aesthetic components of the websites including how prominent law enforcement imagery is and what specific kinds of images are used.

To complement my investigation of the websites outlined above, I also analyzed the user manuals for the TASER AXON, the Safety Vision Prima Facie, and the Reveal Media RS3 SX. These products were chosen based on their popularity and the availability of their manuals. The Edmonton Police Service considered both TASER and Reveal Media's products for its pilot program (with the Reveal Media RS3 SX winning out), making them particularly valuable in conjunction with Edmonton's report. Prima Facie is a product offered by Safety Vision and is one of the top BWV products according to a comparison conducted by Homeland Security. These products reflect some of the best on the market, a status that is rooted in their technical performance, ease of use, physical attributes, and so on.

These particular products also come with detailed user manuals, making them the ideal choices for an analysis of the technical and pedagogical aspects of BWV. The technical aspect of these manuals provide an idea of their level of technical complexity and the training needed to use them effectively on the job. However, the manuals also provide glimpses into the pedagogical aspect and how officers are being taught to 
leverage the capacities of these technologies and compensate for their shortcomings. I coded these materials based on tags like "technical complexity", "tells user how to get the shot they want", "offers a function that allows user to review footage", "instructs user about positioning", "characterizes BWV as an extension of the body", and so on. Essentially, I looked at how these resources address police; are they addressing them as police or as videographers?

Finally, I analyzed the themes, language, and frames in the report released by the Edmonton Police Service following the completion of their BWV pilot program in 2015. Titled Body Worn Video: Considering the Evidence, the report gives a detailed account of Edmonton's experience with these devices and includes both expert analysis and firsthand accounts from officers who participated in the program. This report is indispensable because it provides a window into how these devices are actually interacting with the existing police culture in one Canadian jurisdiction. News coverage, websites, and manuals offer much to the analysis, but they operate from outside police culture. My analysis would be incomplete without an inside perspective of how officers are experiencing and interacting with these devices. ${ }^{4}$ I examined the report by looking for patterns in how the officers are characterized, how the technology itself is characterized (both by researchers and the officers that participated in the pilot), how problems in policing are framed, and which functions are attractive to police (officers and organizations) and which aspects of BWV are undesirable.

\footnotetext{
${ }^{4}$ Of course the report released by the Edmonton Police Service is not a complete inside perspective, as it was completed by researchers, not the officers themselves. However, the report includes firsthand testimony from officers who have used the devices in the field regarding their experience with BWV.
} 
The following chapters chronicle the shift toward officers as cameras and reframe the discussion of BWV as an attempt to regain over institutional visibility. First, the adoption of BWV is situated in the context of the risk society and an ongoing war on visibility. As police struggle to control their visibility BWV becomes an attractive solution, as these devices give police organizations the opportunity to manage narratives by establishing a monopoly on truth. Second, BWV is established as part of an ongoing militarization and cyborgization of police; however, the political nature of the truthclaims attached to these devices moves past images of the cyborg and establishes officers as truth capturing RoboCops with superior claims to justice. Third, the practical consequences for policing are investigated, as BWV forces officers to adopt new skills, new ways of looking, and a cinematic logic in order to properly leverage their devices. This shift from seeing to looking is the result of the officer's new role as collector of visual evidence and is essential to the maintenance of their monopoly on truth. Finally, conclusions will be outlined and avenues for future investigation will be suggested. 


\section{The (In)Visible State: The role of BWV in the war on visibility}

Seconds after BART police officer Johannes Mehserle shot and killed Oscar Grant, police immediately began confiscating cell phones containing videos that have yet to see the light of day (Miller, 2009).

As police grapple with the increasing number of mechanical eyes watching them, attempting to control their gaze, they are waging an important war on visibility, more specifically a war on state visibility. Miller's statement demonstrates the panicked response that many police officers have exhibited in the face of becoming subjects of the surveillant assemblage themselves, a position that until recently they had mostly avoided. The ubiquity of citizens with cameras has drastically changed the reality of policing by turning the gaze back at officers. As the proliferation of smartphones has meant that citizens are able to hold officers publically accountable by sharing footage of police misconduct and brutality, police organizations have responded by adopting their own official - cameras to regain control over their own visibility. The adoption of BWV presents police organizations with an opportunity to take back a level of authority over their visibility while simultaneous recapturing their hold over narratives about police misconduct. In large part, owning the footage means owning the story, making BWV a very attractive solution to calls for additional police accountability and oversight. At its foundation, the adoption of BWV can be considered a methodical attempt to regain authority over a situation and a narrative that has slipped away from police organizations. The result is that the status quo is more or less re-established with a state gaze that is evermore present and invasive. 
There are important theoretical implications to consider with regard to how the adoption of BWV by police organizations serves their war on visibility. As Haggerty and Ericson (2000) suggest, surveillance of the powerful,

... is often a mile wide but only an inch deep. The depth or intensity, of the surveillance directed at the powerful generally exists as a potentiality of connections of different technologies and institutions. It is activitated, or intensified, when there is some perceived ex post facto or prospective need to profile their movements, consumption patters ... (p.618).

The adoption of BWV is an attempt to control the gaze of the surveillant assemblage and return status quo to the hierarchy of visibility so that officers can reclaim their invisibility; the result is a tension between the assemblage and an institution that wants to remain exempt from its gaze. As discussed above, the surveillant assemblage can be resisted from within due to the messiness that results from its lack of centralized power. By adopting BWV, police organizations are resisting the assemblage from within cameras may have pulled them into the assemblage, but the adoption of their own cameras may get them out. Further, police organizations are using an existing and familiar mentality of risk management to establish public acceptance of BWV.

As I will argue below, the dominant discourse surrounding BWV not only provides glimpses of the conflict between the assemblage and police, it also lays the groundwork for public acceptance of the devices. Despite rhetoric that suggests BWV will be the solution to problems in policing, these devices can also be understood as a tool for shielding police from external visibility. Haggerty (2006) suggested the need to tear down the walls of the panopticon; what we are witnessing as police organizations adopt BWV in an effort to maintain control is an institution building up walls within the surveillant assemblage. 
Weaving together the historical, political, and cultural contexts in which BWV is emerging, actors including the Canadian news media, police, and BWV manufacturers have framed the issue in very particular ways. After conducting a framing analysis of news articles from English speaking Canada, a textual analysis of the Edmonton Police Service report titled Body Worn Video: Considering the Evidence, and an analysis of the websites and manuals of several BWV manufacturers, it is clear that the dominant discourse is overwhelmingly positive and paints BWV as the solution to issues of police misconduct.

Actors involved in shaping BWV discourse have consistently adhered to a few key ways of framing the use of BWV as a policing tool. First, BWV is being framed as a natural next step in the evolution of state surveillance, situating it as a logical progression from CCTV and dashcams. Relatedly, BWV is positioned as the inevitable future of policing. Second, BWV has also been routinely categorized as a response to the ubiquity of cameras being wielded by the public; implying that if everyone else is filming the encounter, the officer should be too. BWV is a means for police organizations to take back control from a perpetually video-ready public. Actors have taken to framing the adoption of BWV in a third way that categorizes the implementation of these devices as a response to pressure coming from politicians and the public following highly publicized instances of excessive, and sometimes fatal, force. This way of framing BWV positions the devices as a mechanism of accountability should misconduct occur. Fourth, BWV has been framed in terms of panopticism - a tool that will inspire police and citizens alike to behave themselves as a result of knowing they are on camera; deterring misconduct before it happens. Finally, a fifth frame that has become popular in the discussion of 
BWV is providing the only consistent critical discussion of the devices. Critics have positioned BWV as a threat to traditional conceptions of privacy. By limiting criticism of BWV to notions of privacy, actors are able to provide policy solutions; however, this limitation has determined the boundaries of critical discussion and has subsequently ensured that lines of questioning outside of privacy rhetoric are absent or ignored. The framing of BWV in these ways creates the necessary preconditions for turning officers into cameras tasked with collecting visual evidence.

Although the frames that I have identified are not unrelated, each of them distinctly adds to our understanding of the discursive context in which BWV is emerging as a popular solution to issues of policing. Additionally, each of these frames has contributed to the definition of the discursive parameters surrounding BWV; they have determined where the conversation can and cannot go. Given that BWV technology has been available for years and is only now being considered a necessary policing tool, it is essential to understand the context in which this particular technology is surfacing in order to answer the questions: Why now? How? For what purpose? With what consequences?

\subsection{BWV as a "Natural Progression" in Surveillance and the Future of Policing}

Much of the discussion surrounding BWV has positioned the adoption of the devices as a natural progression in state surveillance, a version of progress that is common when adopting new technologies (Feenberg 2010; Marx 2010; Winner 1988). This narrative positions BWV as an easy choice, even an inevitable one. In the case of surveillance technologies, the characterization of new, more invasive and intimate technologies as a natural choice falls within the existing social discourse of risk management. The existing 
logic of more technology, more data, and more cameras in order to ensure that we avoid risk provides actors involved in the BWV discussion with an existing rhetorical framework to use in shaping the discussion.

The prevalence of risk discourse in policing contexts is particularly noteworthy as predictive policing becomes the standard. As Ericson and Haggerty suggest in Policing the Risk Society (1997), "policing today is not a matter of order maintenance, law enforcement, or social service as ends in themselves. Rather, coercive policing is underpinned by surveillance devices that facilitate the governance of territories and population" (p. 148). The kind of policing outlined here is predicated on risk management, which requires extensive collection of data so that police are better able to predict criminal behaviour and mitigate risk. This predictive policing is also reminiscent of Gandy's (1993) panoptic sort in that policing now involves the use of data collected from various locations to make predictions regarding criminality, impacting strategy and resource allocation. The use of data in this way is an example of what Gandy considers cybernetic triage, as it filters groups of people, determines their level of risk, and responds accordingly. As we continue, as a society, to make decisions predicated on maximizing our ability to identify and avoid potential risk, the expansion of surveillance prevails as the popular response. The result is that we have come to see surveillance technologies and the data and footage they curate as a key tool in this risk management project- a natural next step.

News media have routinely categorized the issue of BWV as a natural progression in state surveillance that will provide protection from the risk of officer misconduct. Framing the discussion in this way locates BWV in a history of surveillance becoming 
increasingly mobile. Starting with surveillance cameras mounted on buildings, police surveillance slowly extended to the dashcam, allowing for a slightly closer recording of interactions between law enforcement and the public. Much of the media coverage of BWV suggests that these devices are a natural extension of this move toward closer, more intimate records of these encounters.

Discourse that situates BWV as a natural progression in state surveillance has tended to take one of two distinct positions. The first position holds that previous tools of state surveillance, such as the dashcam, have their limitations and makes the suggestion that BWV will be a more useful tool. Of course cameras mounted to buildings and other such infrastructure are limited to recording from a distance and rarely record audio; often making the footage they generate difficult to interpret, which becomes a particularly troublesome limitation when it comes to using video footage as legal evidence. In addition, footage recorded by devices such as CCTV cameras is limited to areas that have cameras - although this is becoming less of an issue as the number of public area surveillance cameras continues to expand (Wall \& Linnemann, 2014).

While the dashcam does bring the gaze slightly closer to the encounter, it is still bound by its position on the police cruiser. Bringing the gaze closer and making it more mobile has produced some compelling footage; however, an event can only be recorded if it occurs in proximity to the vehicle, within the scope of the camera. As one Canadian journalist aptly pointed out, "dash cams have been in use for well over a decade and have been invaluable as an investigatory and evidentiary aid. The problem is they are only effective with whatever occurs directly in front of the police vehicle" (Knight, November 13, 2013). Given these limitations, it is not surprising that BWV, which mounts to the 
body and goes where the officer goes, would be characterized as a solution to the shortcomings of these less mobile alternatives. The Globe and Mail has reported that, "most police forces have long had dash-mounted cameras in police cruisers - and putting cameras on officers' lapels is merely a logical extension of the cameras in officers' cars" (May 21, 2015).

Similarly, many police have described BWV as the logical next step in the evolution of policing. The Calgary Herald quotes acting Staff Sgt. Todd Robertson: “equipping front-line officers with cameras is a 'logical step' forward” (Stark, November 27, 2015). Robertson also suggested, "that the equipment acts as another way of gathering evidence, not unlike note-taking and the dashboard cameras in police cruisers" (Stark, November 27, 2015). Chief of Toronto Police, Peter Sloly has made similar comments and on one occasion stated that, "the potential use of body-worn cameras is a 'natural progression'. Toronto police installed cameras in booking halls in the 1990s, followed by interview rooms and dashboard cameras on squad cars" (McDiarmid, February 18, 2014).

The tendency to characterize BWV as a natural progression plays into logics of risk management and is a manifestation of our societal preoccupation with avoiding uncertainty, particularly when that uncertainty pertains to our safety and security. Some even argue that we have become a 'risk society', defined by our compulsive need to mitigate risk (Ericson \& Haggerty, 1997). To accomplish this we have implemented countless technologies that track and sort, such as biometrics, surveillance cameras, and immense, integrated databases that work together to create a larger picture. The framing of BWV as a natural step in the evolution of state surveillance reflects this mentality, as it 
nonchalantly assumes that there will be evermore technology tracking and watching us in order to provide a level of protection.

The second position taken by those that characterize BWV as a natural progression of state surveillance is that these devices are the inevitable future of policing. Similar to claims that BWV is a logical next step, these actors claim that these devices are not only a natural choice, they are an inevitable one. The belief that the adoption of BWV by police is natural or inevitable was found throughout Canadian news coverage and was also present in the report produced by the Edmonton Police Service (EPS), demonstrating that this frame is popular among both journalists and police. Former Chief of the EPS Mike Boyd has argued that, "some form of video is the way of the future ... We believe the way of the future leans toward the video that's worn on the body of the officer" (Wittmeier, July 24, 2010). Another law enforcement official, former Chief of Calgary Police, Rick Hanson has echoed his colleagues, stating, “I don't think there's any way to avoid this" (Logan, October 1, 2014). Similarly, professor Chris Schneider - an often critical voice on the topic - told Marcia MacMillan of CTV Canada AM that, ... in the future I think the expectation will be that we're always being recorded in all of our interactions with police officers. I think this is probably the future of policing, that way we can predict in the next decade or so that all officers will be wearing body-mounted cameras (April 10, 2015).

It is clear based on the statements above - and the countless additional ones that can be found in nearly all of the Canadian news coverage of BWV - that the media and law enforcement professionals see BWV as an inevitable new reality of policing. Additionally, even those who are critical of the potential implications of BWV are reproducing the rhetoric that suggests the devices are inevitable, perpetuating a teleological understanding of technological change. 
It is worth noting that when discussing BWV, Deputy Chief of the EPS, Danielle Campbell, publically stated that, "video is the way of the future" (Estabrooks, June 23, 2015). Considering that following a very thorough BWV pilot program the EPS chose not to equip all of its officers with the devices, it is interesting that their official position would remain that BWV is the future of the job. Even after opting not to adopt the devices for its front-line officers, the EPS continues to reproduce the dominant rhetoric that these devices are the future of policing. This demonstrates the resiliency of discourse that claims a natural technological evolution and the tendency to cling to existing logics when discussing these technologies.

BWV manufacturers have also contributed to the discussion of the devices in terms of being the future of policing. First, these devices are being presented by their manufacturers as able to solve issues in the future. They do not claim to solve the current state of public disapproval that police are facing; they assert that they can save police from PR nightmares going forward. The screenshots below reflect claims made by Digital Ally and Reveal Media that their BWV products can solve a range of problems from occurring in the future.

\section{WHY VIDEO?}

Reduce Frivolous Law Suits - Minimize Agency
Liability - Increase Officer Safety
Improve Community/Media Perception of Police

- Secure Evidence

\section{True Video Solution}

Police Cameras have existed for many years but Digital Ally ${ }^{\mathrm{TM}}$ is the first to bridge the gap bringing together software and hardware to create a true video solution for Law Enforcement \& Security Agencies. We are the only video company that can connect In-Car Video, Body Cameras \& the back office software into one complete solution.

(“Digital Ally, Inc.”, 2014). 


\section{Body worn video is world-changing technology Provide compelling evidence}

High-quality video and audio footage of an incident make it clearer what happened, when, and who was there.

Protect workers by deterring crime

Making the camera obvious to the public has an immediate impact by demonstrating that actions are being recorded; leading to fewer assaults on frontline workers, for example

Fewer complaints

False allegations are immediately negated and the overall conduct between the two parties involved are improved, reducing the likelihood of a need to complain

\section{(“About Body Worn Video", n.d.).}

TASER goes even further, stating in the image below that their product is a, " ... future-proofed video solution for police officers" (“TASER”, n.d.). In other words, BWV is not only the way of the future and a solution to future problems, it is "future-proofed" suggesting that BWV can solve anything the future can throw at police. This positions BWV as a solution that cannot be undermined; it cannot fail.

\section{Beyond a Camera and Beyond Compare}

Behind the simple camera design lies a platform capable of performing virtually anything you can imagine. The hardware supports full wireless connectivity for triggering, streaming, and integration with the industry-leading suite of mobile and cloud applications. With feature improvements and updates every 30 days, Axon Body 2 is a scalable, future-proofed video solution for police officers.

("TASER", n.d.).

The characterization of BWV as the future of policing frames the adoption of these devices as a straightforward choice and perpetuates a discourse of social science fiction by bringing the future into the present. This fits nicely with the assertion that these 
devices are a mere extension or evolution of existing state surveillance technologies; however, this is a very passive way of framing BWV. By framing BWV as an inevitable reality of policing, the discussion is constructed in such a way as to suggest that there is no choice to be made regarding whether or not these devices are integrated into police work. This is not the case. BWV is not being rolled out in universal national projects, the decision to adopt or to forgo this technology is up to individual cities; some have jumped right in, others are carefully considering BWV; and some have opted not to invest time, money or resources into the devices. For example, the EPS has decided not to equip all front-line officers with the devices while cities like Calgary will be implementing the cameras service-wide (Stark, November 27, 2015).

The conception of BWV as the future of policing is perhaps a ramification of its quick adoption, particularly in the United States. As countless American cities continue equipping officers with BWV, it might seem as though the officer of 2016 is one who has their eyes and ears mechanically enhanced. Despite the rapid spread of BWV in the American context, adoption has been much less hasty in Canada with fewer cities adopting the devices and those who have generally doing so following structured pilot programs.

The Edmonton Police Service opted not to equip regular officers with BWV following what is arguably the most structured, methodical pilot program in Canada to date. In fact, the 241-page EPS post-pilot report makes two fundamental recommendations. The first being that, "the EPS should wait before investing further in BWV, and monitor ongoing Canadian initiatives by the RCMP, and the Calgary, Amherstburg, Ont., and Toronto police services" ("Body Worn Video: Considering the 
Evidence", 2015, p 5). This recommendation is followed by, "with caution, EPS management should consider the viability of a BWV program for specific EPS units where potential benefits might merit the financial investment" ("Body Worn Video: Considering the Evidence", 2015, p 5). What both of these recommendations suggest is that after careful investigation, BWV might not be a valuable investment for police organizations as a general practice. The EPS report offers a resource for counterdiscourse; however, any critical points made in the report have been largely ignored in favour of examples that reinforce the claims being made by the dominant discourse.

By characterizing BWV as part of a natural technological evolution, actors are able to present the adoption of these devices as an obvious choice. This method of framing the discussion turns what might be perceived as a very invasive 'Big Brother' type technology into a non-threatening one. This discourse positions BWV as nothing new and suggests that it is just an extension of the risk management practices and technological devices the public has already become accustomed to. As described by Ericson and Haggerty (1997),

risk is an invention based on imagined fears and on imaginative technologies for dealing with them. Indeed, the concept of risk is a construct of insurance technologies. It turns people, their organizations, and their environments into a myriad of categories and identities that will make them more manageable (p. 54).

We see this playing out in the marketing material for BWV included above, as manufacturers focus on risk and position their products as an insurance technology that will give police the tools necessary to deal with any risk they might encounter. As we continue to prioritize the mitigation of risk, the familiarity attached to BWV when it is framed as a natural extension of our risk management tools serves to ease public concern 
and avoid critical lines of questioning that might undermine the deployment of these devices.

\subsection{Responding to Camera Ubiquity}

The politics of staring down the state increasingly plays out most powerfully when an unauthorized gaze photographically "shoots back", so to speak, directly at uniformed police agents with cellphone cameras and other visual prosthetics (Wall \& Linnemann, 2014, p. 134).

The statement above, taken from Wall and Linnemann's article, "Staring Down the State: Police Power, Visual Economies, and the "War on Cameras"', describes the environment in which police now work, constantly at risk of being filmed by high quality videocapable smartphones wielded by almost every citizen they encounter. It is in this environment that recent videos depicting police brutality have been circulated internationally. Footage like that of Baltimore police officers arresting Freddie Gray, ignoring his inability to walk and his cries of pain has become increasingly commonplace as members of the public continue to film officers doing their jobs, documenting the mundane to the extreme (The Telegraph, April 28, 2015).

As officers attempt to navigate an environment that they suggest is plagued with cameras waiting to catch misconduct, many have argued that the adoption of BWV will put officers on an "even playing field" with the public by giving them their very own cameras. The media, officers, and law enforcement experts alike have taken to framing the adoption of BWV as a response to the contemporary ubiquity of cameras. With the number of private cameras recording their interactions, police rarely have control over footage filmed by bystanders and uploaded to the internet or broadcast by media outlets, a consideration that would have been much less important before the proliferation of smartphones. Increased visibility coupled with this lack of control has removed police 
from the top of the hierarchy of visibility and repositioned them within the surveillant assemblage. Given that police organizations have historically worked to maintain a tight grip on their visibility (Feuille \& Juris, 1976), their relocation from outside the assemblage to squarely in the line of its vision is a particularly uncomfortable move. On the surface, the argument that officers should adopt their own cameras as a response to camera ubiquity plays into logics of risk; however, also at work here is an attempt to regain control over visibility by setting the groundwork to discredit external sources of footage.

The Canadian news media have been quick to support the argument that police officers should have their own cameras to record events from their perspective. Specifically, the media reproduces the narrative that officers are somehow the victims of citizens with smartphones. As one Victoria Times Colonist story stated, "as is often the case these days, someone nearby had a video camera and recorded much of the encounter. The arrests, and the tactics used by police to stabilize the situation might have been forgotten by now if the 56-second video had not been made" (March 25, 2010). The Calgary Herald went even further: "when everyone has a cellphone cameras, it is only fair officers should also be able to video events that might offer a different viewpoint" (January 19, 2015). It is important to note the language of fairness. This is the crux of the problem with painting BWV as an attempt to put officers on equal footing with the public and its smartphones. This rhetoric implies that it is somehow unfair that officers are being recorded by the public, positioning officers as victims and the public as perpetrators that are misrepresenting police. The tendency to position officers and citizens in this way is particularly worrisome when we consider that the reason the public is recording its 
interactions with police officers is because of cases of misconduct and brutality. By framing the discussion this way officers get to both escape the consequences of their misbehaviour and demand our sympathies. Additionally, characterizing BWV as a response to unfair scrutiny suggests that citizen activism itself is unfair. Further, this way of framing BWV constructs camera technology as neutral, implying that the user is what makes the difference - allowing officers to claim that their footage will be superior to that recorded by motivated bystanders. This lays the groundwork for the privileging of BWV footage.

Furthering the discussion of BWV as a response to camera ubiquity, the Waterloo Region Record noted that, "in an age where almost everyone has a camera on their smartphone, a growing number of police services are looking to arm their officers with a recording device of their own” (Shingler, Jan 21, 2014). Similarly, professor Christopher Schneider commented that, "the proliferation of cameras in the public's hands means police are under more scrutiny than ever before. Arming officers with body cameras can help to level the playing field, providing and official recording of the situation" (Davis, May 21, 2015). First, these statements are interesting from a linguistic perspective, as the term 'arm' invokes notions of war, which is consistent with, and reinforces, the discussion of BWV within an ongoing war on visibility. Second, statements like these fail to consider that officers already have their own cameras in the form of CCTV surveillance and dashcams.

In addition to constructing the conversation about camera ubiquity as detailed above, the media reproduce a sense of inevitability regarding accountability:

In an era when ubiquitous cellphone cameras are used to capture - and even post online - contentious interactions between police and civilians, the move by law 
enforcement agencies to equip their members with body cameras might be considered the inevitable next step in the evolution of public accountability (Saskatoon Star Pheonix, December 20, 2014).

There are many frames at work in this particular statement, but first I would like to call attention to the use of the problematic term 'capture'. This particular statement is not unique in its use of the term, as various journalists, police officials, and manufacturers have claimed that BWV 'captures' events, details, perspectives, accounts, truth, etc. The use of capture is worth noting, as it is a term that implies that what BWV records is a static, fixed, and complete truth; the result is that BWV truth-claims are reinforced and the subjectivity of video technology is overlooked. This is reinforced by the implication that citizen footage does not provide public accountability, unlike police footage. Citizens are recording officers - public representatives - in an effort to produce accountability; they are quite literally providing public accountability, despite the unorganized and unsystemic nature of their efforts. However, the media and various other actors do not validate these actions as legitimate public scrutiny. Instead, official footage is validated as legitimate. The addition of police cameras and the discrediting of external sources of video footage is a necessary step in establishing a privileged position within the surveillant assemblage.

Media are not the only players framing the adoption of BWV as a response to camera ubiquity. Experts in the fields of law and policing have also consistently characterized BWV devices in this manner. Scott Greenwood, a constitutional lawyer in Cincinnati told the Globe and Mail that, "During the average interaction between a police officer and a subject in an urban area in the United States, there's something like seven external sources of video already. Most of them are on cellphone or on security video on 
buildings - that sort of thing” (Greenwood in Scowen, October 26, 2013). Greenwood also stated:

You've got an incident in Toronto: the [Sonny][sic] Yatim case. There are apparently 12 different sources of video on that, but they're all external. They're cellphone video or fixed-building video. We don't know what happened inside the streetcar. That's a perfect example of where the use of an on-body recording system, particularly at eye-level, either mounted on the glasses or the epaulettes or the collar, would show us what actually happened (Scowen, October 26, 2013).

Statements like this are common and paint the already existing footage as a negative. By framing "external" footage in a negative manner, actors are able to position the possibility of police footage as a solution, as internal and therefore superior. Further, as BWV can be considered an extension of the eyes, ears, and memory, it is intimate to the body. Therefore, the characterization of the negative external with the superior internal is in many ways a characterization of the disembodied camera as deficient and the embodied camera as the solution. The privileging of embodied cameras and the telos of "internal" being constructed in the dominant discourse is creating a framework in which to build the technologically extended cyborg officer, an idea I develop in the next chapter. It is worth noting that by framing the adoption of BWV as a response to camera ubiquity and subsequently discrediting cameras that are disembodied, the discourse has created an environment in which technologically enhanced officers are normalized.

Howard Burns, President of the Calgary Police Association Board stated that, "The reality is, everyone out there has a phone and a camera ... The police probably should have a camera as well" (Stark, October 2, 2014). This call for cameras that record the officer's perspective is echoed in the way that these devices are being marketed to law enforcement agencies. The following screenshot of the TASER website asserts that BWV ensures that the officer's perspective has a witness. Not only does this imply that 
the officer should have their own camera to record an event from their point-of-view, it also uses the term 'witness' which implies that this perspective is official and will act as corroboration of the officer's story.

\section{Your perspective has a witness.}

The actions of law enforcement are being scrutinized like never before. Bystanders can record their perspectives of unfolding events and broadcast their reactions with ease. The Flex was created to protect truth, not opinion. It provides an indisputable record of the officer's perspective, helping stop complaints and allegations before they escalate.

(“TASER", n.d.).

It is clear here that experts are contributing not only to the overall discourse that paints BWV as the solution to problems in policing, but they are also framing the discussion as a justified response to a public that is toting its own cameras. The result is a conversation that is largely limited to assumptions that additional cameras will solve the ongoing issues in policing. However, the solution is not the addition of just any cameras, it is the addition of police cameras. Subsequently, by assuming that the answer is to give officers their own cameras - an account of the event from their own perspective - the implication is that the officer's perspective will be better than the alternative citizen footage. This discrediting of other sources of video is a precursor in the transition from police with cameras to police as cameras. By establishing the officer's footage as privileged and superior, the officer becomes more than just an individual with a camera; the officer is the camera.

The framing of BWV as a response to the ubiquity of cameras and the implication that the addition of police cameras will serve to clarify what really happened is 
predicated on the assumption that police cameras will tell the truth, characterizing citizen footage as the opposite, untruthful or dishonest. What makes these devices so appealing to law enforcement and lawmakers is that they are owned by the state and provide what can be considered the official account of what occurred. As the police continue to resist their increasing visibility, the adoption of their own cameras as a response to camera ubiquity can be considered an attempt to control the gaze of the surveillant assemblage by privileging the cameras they own over those that they cannot control. This positioning is reinforced by BWV's status as what Jessica Silbey calls evidence verité, which refers to evidence produced by the state and those that represent it (2010, p. 1257). Evidence verité, as Silbey argues, often overwhelms other evidence as a result of its perceived reliability - a claim that aligns with the effort to portray BWV footage as official (p. 1257). What is more, this response positions the situation in terms of 'us versus them,' with officers on one side and the public on the other. Further, the characterization of BWV as an opportunity to put police on the same level as camera wielding citizens totally neglects issues of misconduct that initially ignited the BWV conversation. By painting the citizens filming them as miscreants, police become the victims in a conversation that began with their own acts of alleged brutality.

\subsection{Pressure to Adopt BWV as a Mechanism of Accountability}

When examining the historic drivers for change in the professional status of policing, a clear pattern emerges. Policing has a long history of reform driven by response to community outrage and expectation. Police abuse of powers, allegations of corruption and lack of community support have driven various authorities over time to review and recommend changes to the police in these times of crisis (Green \& Gates, 2014, p. 80).

As Green and Gates (2014) aptly point out, law enforcement organizations have a history of requiring public outcry and political pressure in order to provoke any meaningful 
change to their methods. Taking law enforcement's history of requiring substantial external pressure in order to make any alterations in the field of policing, it is not surprising that the adoption of BWV is regularly framed as a response or solution to recent incidents of officer misconduct. Given the speed with which many cities are adopting these technologies following unfavourable encounters caught on camera, it is clear that BWV has become the solution of choice when dealing with this mounting pressure.

The deaths of individuals including Freddie Gray, Walter Scott, Michael Brown, Eric Garner, Tamir Rice, and Sammy Yatim received significant attention in the mass and social media in large part because of the videos that accompanied their deaths. Visuals like that of Tamir Rice, a 12-year-old boy from Cleveland, who was playing in a park with a toy gun when police fatally shot him before even stopping their squad car, have tremendous affective impact and have thus dramatically influenced the public's perception of police (The Hamilton Spectator, October 9, 2015). Cities that have experienced this level of police misconduct and those around them have seen surges in public demand for additional oversight and accountability for police. In many cases, the police departments responsible for these fatalities have responded to outcry in part by introducing BWV. Additionally, many cities that have not faced scrutiny as a result of damning video footage have opted to adopt BWV as a pre-emptive measure to avoid future scandal. This pre-emptive response to the possibility of public scrutiny is reflective of an internalization of the risk mentality previously discussed. Not only has the act of policing become pre-emptive, predictive, and predicated on mitigating risk, police organizations themselves have adopted a risk management framework to protect 
themselves from uncertainty. As described by Ericson and Haggerty (1997), Manning suggests that, "organizations are 'resources for conceptualizing, assessing and coping strategically with perceived threats from the posited environment and in many respects therefore are political entities"' (p. 310). The precautionary adoption of BWV by these organizations reflects this kind of strategic coping, as BWV provides officers with a level of renewed control over the uncertain and the risky.

Eugene O'Donnell, a former NYPD officer and prosecutor turned professor of criminal justice, states, "the technology has existed for several years now and there is simply too much pressure not to adopt it” (Miller, October 9, 2015). What O’Donnell is touching on is the substantial pressure coming from politicians, including President Barak Obama, to expedite the adoption of these devices. In fact, the US President has devoted \$75 million to funding BWV programs across the United States (Edwards, May 1, 2015). In addition to prominent politicians pushing for the adoption of BWV by police agencies, civilians, including the family of Michael Brown, have been lobbying for the adoption of BWV in hopes that the use of excessive force will decrease (Sanburn, November 25, 2014). A statement released by Brown's family calls on Americans to, “join with us in our campaign to ensure that every police officer working the streets in this country wears a body camera" (Sanburn, November 25, 2014). With such highly publicized appeals to address issues of police misconduct by equipping them with cameras, the pressure is mounting for police organizations to comply.

The adoption of BWV as a result of these pressures has been a consistent way of framing this issue and is certainly not a unique way of constructing the conversation, as much of the Canadian news coverage has echoed the rhetoric of pressure too. Further, 
this logic is not specific to the American context; similar claims have been made about the ongoing Toronto pilot program, as it has been largely attributed to the need for oversight following the shooting of Sammy Yatim in 2013. As stated by the Windsor Star, "Pressure is growing for officers to be outfitted with body-worn cameras following several high-profile interactions in the United States between police and civilians" (Kotsis, December 24, 2014). Echoing this rhetoric, the Hamilton Spectator and the Ottawa Citizen argued, respectively, "Pressured by politicians and an angry public, departments from Los Angeles to New York have begun equipping cops with body cameras" (October 9, 2015); and, "Calls for police to adopt recording technology have been growing across North America following high-profile cases in which excessive force was used" (Quan, January 9, 2015).

The media's framing of the adoption of BWV as a response to external pressure serves as a way of correlating the adoption to particular instances of brutality. In doing so, the media has framed police adoption of BWV as an active attempt by police to solve a very serious problem. This positions the police as progressive rather than problematic, reframing the situation in a way that paints police as being responsive to calls for accountability and oversight. However, the reality of BWV is that it can only be effective as a measure of accountability if it is being used and controlled by those who really value that level of accountability. The lack of discussion regarding solutions at the institutional level, like overhauling a problematic occupational culture, suggests that there will be no real accountability despite the implementation of BWV (Chan 1996, 1997; Green \& Gates 2014). 
Reporter Scott Laurie underscored the suggestion that external pressure resulting from instances of brutality has resulted in the adoption of BWV. In his report on BWV for the CTV National News, Laurie stated, "For some, the issue has become an urgent call, get the cameras out there. Streets in the US have been seething after two officers were not charged. One shot unarmed black teenager Michael Brown. Another in New York killed Eric Garner with a chokehold" (March 1, 2015).

Framing the adoption of BWV as a response to pressure from both leaders and the public does provide key information regarding the political context in which these devices are emerging and effectively links the adoption of BWV to various cases of misconduct. However, by correlating the adoption of the technology to recent events including the deaths of Michael Brown and Eric Garner, there has been little to no consideration of the fact that both these devices and police brutality have existed long before the recent adoption of BWV. By failing to consider that police misconduct is nothing new, the media and experts have placed too significant an emphasis on the connection between recent events and the adoption of BWV while failing to consider what has made these particular devices so appealing as a solution to a longstanding problem.

As discussed in the preceding literature review, many of the characteristics of police culture have continued to be deeply problematic for decades. Of the core characteristics of police culture, the defensive nature that results from feelings of isolation from those outside their organizations is perhaps the most important to consider when it comes to claims that BWV will foster accountability among police. The guarded nature of this particular occupational culture makes it difficult to provoke meaningful 
changes to its practices both from within or externally (Chan 1996, 1997). Although BWV is presented as a tool that will facilitate additional accountability, it is more likely that police organizations see these devices as a means to avoid meaningful reform. Rather than a solution to a lack of transparency, BWV offers police the opportunity to take back a level of control, a well-established goal among police organizations (Feuille \& Juris 1976; Green \& Gates 2014). This solution in no way calls for changes to police culture or behaviour, it will only provide an official account of the continuing state of police practices.

In fact, claims that BWV will provide accountability are being undermined by the way the technology is being implemented, specifically in discussions of when officers should and should not be hitting record. If BWV were truly being implemented for purposes of accountability, all of their interactions, including the mundane, would be recorded in order to ensure that they are not acting inappropriately. Rather than recording their work, BWV is being implemented to record events; meaning the devices are there to record situations where criminality is occurring and witnesses are required. The implementation of these devices is making it clear that they are meant to be witnesses rather than mechanisms of accountability. Further, as these cameras are worn by the officer, record from the officer's point-of-view, and are owned by the state, these are witnesses that are meant to support the officer.

By adopting BWV, police organizations do face a certain level of visibility, but this visibility is on their own terms and supersedes the external gaze. Bowing to the use of BWV means having more control over their visibility with the additional advantage of not having to address any kind of systemic change. By agreeing to be visible in this way, 
police organizations are actually creating the conditions under which they are able to manage that visibility, thereby assuming a level of governance in the assemblage. In addition, this way of framing BWV allows various actors to gloss over any considerations of how these technologies are going to impact policing; they may or may not solve issues of misconduct, but we should consider what new issues may emerge as we turn police officers into cameras.

\subsection{BWV as a Panoptic Tool}

There is an air of panopticism as the media, officers, and experts frame the adoption of BWV as a tool to ensure that both police and the public remain civil during their interactions. The assumption being made is that when individuals are aware that they are being recorded they will act more appropriately than they would otherwise. However, despite suggestions that panopticism fails to correct issues of misconduct long-term (Nasiopoulos et al. 2015), we continue to discuss BWV - a markedly non-panoptic technology - as panoptic. The continued attempt to classify BWV as a panoptic tool has been underscored by those who cling to the experience of officers in Rialto, California. Particularly prevalent in the Canadian media coverage of BWV is the use of findings from the Rialto Police Department BWV study, which saw a drastic drop in both use of force and complaints. The Rialto Police department reports that for officers wearing BWV during the study, use of force declined by $59 \%$ and complaints against officers fell by $87 \%$, an example that has been repeated in nearly all media coverage of BWV despite arguably being an anomaly (Quan, January 9, 2015).

While the results experienced by officers wearing BWV in Rialto appear to be significant, few cities have seen that kind of dramatic change as a result of using these 
devices. In fact, the Edmonton Police reported that, "the pilot found no quantitative evidence that BWV had an impact on complaints," and, "there is no statistically significant evidence that the presence of BWV reduced use of force" ("Body Worn Video: Considering the Evidence", 2015, p. 8). Despite the inconsistency in findings, the media continue to frame the adoption of BWV using the panoptic frame. "For the most part, it sounds like the cops with cameras acted like all workers do when there's a change the boss might be watching: They were on their best behaviour" (Platt, June 24, 2015). Similarly, the Victoria Times Colonist reports,

It is likely they [BWV] would reduce the number of complaints about police impropriety. Members of the public might be less prone to make dishonest claims about police behaviour if they knew there was video evidence that would back up an officer's version of events. Officers might be more careful if they knew their actions were being recorded (March 25, 2010).

The panoptic potential of BWV is present in The Globe and Mail's assertion that, "we know from the studies that have been done that on-body recording systems reduce complaints. We know they reduce uses of force. Everybody is better behaved when there's video involved" (Scowen, October 26, 2013). These common sense claims have also been echoed by EPS officers, "I found that the BWV de-escalated a lot in these instances ... a lot of people who were acting up or irrational, once they realized they were on video they changed their attitude and become more co-operative" (Platt, June 24, 2015). BWV is not only being positioned as a panoptic technology it is an evidence based panopticism where subjects (police and citizen alike) are aware both of being watched and that there is a legal record should they fail to self-police.

By framing BWV as a panoptic tool that will improve the comportment of both citizens and officers, the implication is that police require the gaze of an electronic eye in 
order to behave themselves. Essentially, actors involved in shaping the dominant discourse have suggested that the police culture and practices that have led to incidents of misconduct cannot be fixed; they can only be recorded in the hope that that will be enough to deter, and if it is not, at least there will be visual evidence to take action after the fact. Given the current reputation with which police organizations are struggling, the positioning of BWV as a means of creating additional oversight and accountability is unsurprising. However, framing BWV as the solution for police misconduct actually works to suggest that officers cannot be fixed in the present, but BWV will deter/catch them in the future. Solutions that would fix problems of misconduct in the present would include overhauls of police training, tackling entrenched shortcomings and biases in police culture or creating a body of oversight that operates at arm's length. These organizational solutions are not being discussed, suggesting that officers will remain consistent and unchanged; we will just catch the few "bad apples" on video.

Despite the characterization of BWV as panoptic, these devices do not conform to the model of deterrence that panopticism is predicated upon. Rather than working to deter officers and citizens from behaving badly, BWV reflects a desire to pre-empt negative interactions. It is not about self-policing, it is about being stopped before the point of needing to self-police. The discourse might suggest that BWV are panoptic devices that will produce the desired behaviour among officers and citizens; however, if being watched were enough CCTV and dashcams would have already corrected issues of misconduct. BWV are artefacts of the risk society and they fully embody the need to mitigate risk; rather than being there to deter, they are there to pre-empt - a notable shift away from the panoptic model. 
Further, framing the discussion in this manner also fails to question the fact that this footage will be controlled by police, undermining the potential for BWV to act as a tool of accountability. It is incredibly counter-intuitive to give control over a mechanism of oversight and accountability to those under scrutiny. In addition, as discussed by Nasiopoulos, Risko, Foulsham, \& Kingstone (2015), the panoptic effects that initially result from knowing that a tracking device is recording one's activities are susceptible to habituation and often dissipate as wearers become accustomed to the technology (p. 214215). Therefore, claims that suggest that BWV will inspire both officers and the public to behave in a more desirable manner are likely overstated and are being used to shield police organizations from any real consequences.

What is more likely the case is that even if BWV inspires panoptic effects initially, they will begin to fail as officers become accustomed to the camera's presence to the point where they all but forget the devices are there. What will likely linger is the anxiety felt by citizens who are cognizant that, not only is BWV watching them, they have no authority over the footage. Additionally, any footage the citizen produces will be undermined by the existence of an officer's BWV footage. It is important to remember that the adoption of BWV gives officers back a significant amount of control, suggesting that any traditional panopticism that impacts the officer will likely be very short-lived. By wearing the devices directly on their bodies, officers are able to internalize the technology to the point where it is no longer an invasive gaze, but rather their own gaze. This full embodiment and internalization of BWV is another important milestone in the process of turning officers into cameras. This embodiment is also the reason for panoptic failure. Panopticism is predicated on external watching, as a technology of full 
embodiment, BWV involves a more intimate internal watching. However, the example of BWV provides a glimpse of what could be categorized as a more active version of panopticism, as officers are becoming hyperaware of their visibility and modifying their behaviour to regain control. Despite this new iteration of panopticism, the aspirations being used to frame the dominant public discourse do not adequately address what is happening as police organizations implement BWV.

\subsection{Privacy Concerns}

The ways that actors involved in the discussion of BWV have framed the issue not only largely constructs public understanding of the devices and the role they will play as a policing tool but also drastically limits the range of counter discourse or alternative frames. The limited parameters for discussion that have resulted from the way BWV has been framed leaves room for only one kind of critical question: those related to privacy, and subsequently, the policy that will address privacy concerns. Framing critical discussion in terms of privacy turns the response towards the conditions of implementation and execution, rather than questions that challenge acceptance of the devices. As a result, critical voices on the subject have been almost entirely limited to how the use of BWV will violate traditional conceptions of privacy and what policies can be enacted in order to limit this disruption.

The Canadian media have been some of the most aggressive proponents of this way of framing the potential downside of BWV, publishing titles like "Privacy fears at the fore amid body-worn camera pilot launch", "Privacy concerns dog police-worn cameras", and "Body-worn cameras raise issues of privacy". According to Brian Beamish, Ontario's information and privacy commissioner, 
It is not clear that recording informal interaction is necessary for any law enforcement purpose, including the purpose of enhancing police accountability, bias-free policing and public trust. On the other hand, it is clear that recording all such encounters would have a significant impact on personal privacy (Gillis, September 12, 2015).

Echoing Beamish's concerns, The Globe and Mail's Diana Mehta notes, “the country's federal and provincial watchdogs recently released a guidance document on the cameras, saying police should consider whether the expected benefits of the devices outweigh the impact on privacy and personal information” (May 16, 2015).

Discussions of privacy are predicated on the assumption that the devices will be adopted. Failing to question whether BWV should be adopted, these questions make the assumption that the problems come after adoption. These are not critical lines of questioning; they are pragmatic ones and require pragmatic, policy-driven solutions. By narrowing the scope of criticism to these types of questions actors involved in constructing the conversation are able to avoid deeper lines of questioning that might undermine the adoption of the devices. However, there a number of important questions that should be asked before BWV is adopted, including questions regarding how these devices reproduce existing and often flawed power structures. The result is that the rhetorical apparatus is moulding the conversation surrounding BWV in a way that only allows for resistance and criticism that is unproductive and of limited relevance.

\subsection{Conclusion}

Despite historically occupying a privileged position at the top of the hierarchy of visibility, the surveillance functions afforded by smartphones have removed police organizations from the top of the pyramid. Haggerty (2006) predicted this levelling of the hierarchy by the omnipresent gaze; however, what may have been unforeseen was the 
effort that police organizations would put into maintaining their limited visibility. Of course re-establishing the status quo of the hierarchy will require more than the adoption of BWV; it is not enough to have their own cameras, officers must become the camera. The adoption of BWV should not be seen as an attempt to curb misconduct; rather, it is an attempt to subvert the surveillant gaze from within the system. Police organizations are using their own cameras as an attempt to achieve a strategic and controlled visibility. By constructing the parameters of the dominant public discourse in the ways outlined in this chapter and limiting criticism to questions that can be answered with policy solutions, police organizations have created the necessary preconditions to turn officers into cameras with particular access to the truth. The result is that police are positioned well to reclaim much of the control that is lost during their incorporation into the surveillant assemblage.

Providing a glimpse of these underlying motivations of control, professor Christopher Schneider, an expert in the area of police and technology, explained to several media outlets, "police are rolling out these cameras so that when they have the recording on their chest, this becomes the official or authorized recording of the situation" (Mehta, May 16, 2015). Schneider goes farther, "in a world where cellphone videos of police interactions with the public can be placed online within minutes, bodyworn cameras might offer authorities a way to regain control of the situation's narrative" (Mehta, May 16, 2015). Comments like Schneider's give us glimpses of how the "war on visibility" is motivating the adoption of BWV and attempting to ensure that those who represent the state remain exempt from the negative implications of their place in the surveillant apparatus. 
These infrequent glimpses of underlying motivations allow for an entirely different interpretation and line of questioning with regard to these devices. These comments point to a systemic attempt to control video footage of police encounters and the subsequent conversations that result from that footage. Rather than viral citizen video, the footage of police organizations will be privileged evidence verité, giving them authority to determine what is considered 'official'. Police organizations will be able to frame the conversation surrounding their footage in a way that that paints the police as favourably as possible. With current public perception of police perhaps at its lowest point in decades (Jones, 2015), having control over the visual evidence of their public interactions and conversations will give the police the opportunity to reframe how they are perceived. The result is that police organizations are embodying the technologies and techniques of the assemblage in order to impact it from within. 


\section{Building the RoboCop: The extension and protection of officers}

"Part man, part machine, all cop" (Verhoeven, 1987).

The futuristic film RoboCop may have seemed improbable at the time of its 1987 release, but the film's prediction that the cyborg cop was the "future of law enforcement" now feels eerily accurate (Verhoeven, 1987). The contemporary officer may not share the Hollywood robotic exterior sported by Murphy, but police bodies are nonetheless being extended and transformed by technology. Murphy is a mechanically perfected officer created to deal with a public that is framed as aggressive and prone to crime. He sees the world through mechanical eyes and glimpses of his point-of-view are reminiscent of a recording device, complete with prompts in the corner of the screen that read 'recording', 'arrest mode', etc. Murphy has heightened reflexes and is plugged into police databases, able to access any information he might need. Finally, Murphy decides which interactions will be recorded through his eyes and which will go undocumented.

The adoption of BWV devices that are attached directly to the officer's body and designed to record their interactions from a first person perspective is perhaps the most potent example of the transition to the RoboCop. As discussed in the previous chapter, the adoption of these devices can be understood in terms of a "war on visibility" and should be seen as an attempt to shape the surveillant assemblage from within. BWV represents the embodiment of the surveillant assemblage and risk mentality, as officers become the camera in an attempt to mitigate future scrutiny. The officer of 2016 is not just a cyborg; his embodiment, and subsequent agency within the assemblage is deeply 
political and motivated, making the term RoboCop even more accurate. ${ }^{5}$ By discrediting external sources of video footage, the RoboCop claims a monopoly on truth, ensuring that the assemblage will see only what police want it to.

The discourse surrounding the emergence of BWV as a policing tool has constructed a narrative that positions the device as superior, objective, and neutral. Acting as an extension of the officer's eyes, ears, and memory, BWV is characterized as a purportedly objective solution to the fallible human. As the human officer increasingly falls short, the technologically extended officer becomes the alternative of choice. Not only is BWV characterized as an extension of the officer's body, but also as a shield that will protect them from the motivated gaze of citizen cameras. By framing the officer's footage as more objective than external video recorded by members of the public, the cyborg cop becomes the RoboCop - with a superior claim to truth and thus justice. These auditory and visual extensions are not neutral; they are political and defensive, a sign of weakening institutional control. The officer's extensions are positioned as superior to those of the citizen and they are being used to reclaim control over narratives about police, serving as protection - a shield - for officers and police organizations as a whole. The result is that BWV is a means by which police attempt to control their visibility within the assemblage. However, this process is not as smooth as the RoboCop mythos would suggest; in fact we are seeing a level of failure as the technology is unable to meet the challenge of flawlessly extending the body.

There are several factors that have contributed to the RoboCop narrative. First, the rhetoric suggests that BWV devices will extend the officer - enhancing and making them

\footnotetext{
${ }^{5}$ It is worth noting that the dominant discourse constitutes the RoboCop as a masculine figure that fits within a masculine culture, regardless of the individual officer's sex or gender. For this reason, references to police as RoboCops are accompanied by masculine pronouns.
} 
more efficient. Second is the sheer technical complexity of these devices which force the officer to become one with the device in order to ensure that its use becomes second nature. The complexity of these devices requires not only BWV's physical integration into/onto the officer's body, he must be extensively trained in order to build muscle memory that ensures the ability to quickly leverage the device in various environments. A third discourse woven into the conversation surrounding BWV centres around the discussion of the device's capacity to be used as a defence or protection for the officer. The suggestion that a technological extension can be used as virtual shield behind which officers can stand protected is also a nod to the RoboCop, as it provides a metaphorical equivalent to Murphy's gear. This logic is being perpetuated by all parties involved in the BWV discussion, as they consistently imply that the devices are both physically extending the officer's body and creating a sort of bubble around officers that serves as a protection from a malicious public.

Finally, the fourth frame constructing the contemporary police officer as RoboCop is the assumed truth-claim value attached to these devices. There has been almost universal praise of the truth-telling capacity of BWV, particularly in contrast to citizen footage, which has been painted as motivated, subjective, and inferior to the footage documented by officers. The positioning of police video footage as having a superior claim to truth adds to the construction of the RoboCop by characterizing the officer as a technologically augmented representative of the state who is objective, unmotivated, and concerned only with justice. Each of these dimensions of the BWV conversation supports the move toward the RoboCop, as the officer of 2016 becomes a futuristic collision between human biology and technology. 


\subsection{The Militarization and Cyborgization of Police}

In order to effectively create the morally superior RoboCop, police organizations have steadily taken steps to militarize and cyborgize their officers, creating the necessary preconditions for the emergence of an extended officer with a monopoly on truth. BWV clad officers offer the opportunity to render social risks more manageable, serving as a foundation in the repositioning of officers as soldiers with augmented capacities. This shift appeals to our need to mitigate risk - the augmented officer is better equipped to protect us.

Traditionally, the function of police has been distinct from that of the military. Despite adopting a military-inspired organizational structure, police required very different tools than the military. Police officers were not soldiers; their function was to maintain order among citizens within cities, a distinctly different function from those who protect the borders of a nation from outside threat. However, recent appropriation of more military equipment and dress has begun to blur the distinction between officer and soldier not only in terms of appearance but also function.

As discussed by Radley Balko in Rise of the Warrior Cop: The militarization of America's police forces, law enforcement organizations - particularly in the United States - have become increasingly militarized, making officers indistinguishable from soldiers in many ways. Balko (2014) questions how, "a country pushed into revolution by protest and political speech becomes one where protests are met with flash grenades, pepper spray, and platoons of riot teams dressed like Robocops?” (p. xiv). Balko's point is worth considering as we begin fitting officers with BWV devices, particularly in light of the context in which these devices are emerging. 
Police are increasingly using tools that would historically never have been considered viable for policing, including armoured vehicles and M-16 rifles (Apuzzo, June 8 , 2014). As police become more intimidating and mechanized, the addition of technologically complex extensions to their bodies will likely exacerbate the growing gap between officers and the communities they police. What we must also consider are the ways in which the shift toward militarized police forces changes the work that police do and what police mean in modern society.

Although the militarization of police forces is most obvious in the United States, Canada has not been immune to this trend. The movement toward arming police forces with military style tools and vehicles has spread across Canada with departments in almost every major city procuring militarized equipment. Recently, Winnipeg joined the list of Canadian cities that have purchased armoured vehicles for their departments, spending $\$ 342,800$ on its very own Terradyne Gurkha MPV, which, "weighs approximately 7,710 kilograms, seats eight and has eight gun ports" $(C B C$, December 9 , 2015). ${ }^{6}$ Toronto has also recently added to its military level tools, having purchased 51 military style rifles (Gillis, January 19, 2016). The growing popularity of military-grade tools among police organizations in Canada has sparked some criticism from individuals like Frank Cormier, a professor of criminology at the University of Manitoba. "People tend to feel more afraid when they see an armoured vehicle in the streets of their city, so these things can actually reduce the sense of safety" ( $C B C$, December 9, 2015).

The progression toward increasingly militarized police is one aspect of the creation of a superior police officer, able to take on anything. Where the military tools and vehicles enhance the officer's brawn by providing physical protection and weaponry,

\footnotetext{
${ }^{6} \mathrm{MPV}$ refers to a multi-purpose vehicle.
} 
devices like BWV physically extend the officer's body and mind. The adoption of military gear is just one manifestation of the transition from officer to soldier and the fact that cities are allowing departments to purchase military-grade equipment suggests that this transition is being accepted. This acceptance is concerning, as it shifts the logic and function of officers, redefining notions of public space, civil protest, and the citizen. The result is that officers are primarily defending the state against citizens, rather than protecting citizens from malice - blurring the lines between police and the military.

The militarization and cyborgization of police officers combine to produce contemporary officers as RoboCops. The integration of BWV with the officer's body provokes a transition from rigid distinctions between human and machine to a much more obscure line between the two, invoking the cyborg. As discussed earlier, the term cyborg - or cybernetic human - refers to a human-machine hybrid, an organism that is not entirely human, nor entirely machine; rather, the cyborg is a combination of both. However, this cyborgization produces a number of consequences, as the RoboCop is a political actor with superior claims to truth, information, and justice. These officers are not simply being extended technologically they are being enhanced. The RoboCop is the embodiment of political project of justice and his 'truth' cannot be challenged. Through their technologically induced monopolies on truth and justice, officers move closer to popular dystopian conceptions of the RoboCop.

As we continue to integrate more technological tools into police work, officers become increasingly connected. Their minds are extended by vast databases that not only have the capacity to hold information indefinitely, but can also extrapolate that data, combine it with information from other databases, and make informed predictions at a 
level that would be incredibly difficult - if not impossible - for the human brain. The brain could never rapidly sift through and pinpoint a suspect the way that a database linked with CCTV and biometric software can. The interconnected, rapid interpretation of data offered by these extensions are an example of Gandy's (1993) panoptic sort at work; sifting through information and piecing together data doubles in an effort to preempt crime. In addition to extensions of the brain, the adoption of new policing tools has extended various other parts of the officer's body. The squad car, the gun, the stun gun, the two-way radio, and various other devices used in policing already extend the physical capacities of the officer's body and push the boundaries of its limitations. However, these devices do not become part of the officer. They are separate; they are external. The result is that officers have become responsible to for the cybernetic triage that Gandy (1993) argues limits the opportunities of those being sorted. As officers are extended, they are increasingly in a position to decide who will suffer limitation as a result of the information passing through the panoptic sort; essentially becoming panoptic gatekeepers.

As officers are militarized and technologically enhanced, discussions of officers in terms of the cyborg become increasingly relevant. The cyborg offers an alternative way of imagining the body that is particularly helpful when considering the continued additions of technological extensions to the body that are becoming ubiquitous. The cyborg has emerged as a useful representation of the continually altered and surveilled body of postmodernity. The privately controlled body of modernity has been replaced by a body that is no longer privately governed but is rather subject to intrusions, including the addition of technological devices that challenge the body's physical limitations. 
The reimagining of the human body as no longer private, but a largely public entity, normalizes the invasion of the body by external sources including technological extensions. The adoption of BWV by law enforcement organizations is certainly an example of this type of invasion. Not only are officers' bodies being extended by BWV, those that are being equipped with these devices are generally not given a choice. Regardless of whether or not officers are in favour of adopting these devices, the cameras are being purchased and implemented by police administrations and distributed to their subordinates. The result is not only the extension of police bodies but bodily extensions that are potentially invasive and a violation of the resilient conception of the body as a private entity.

It is this redefinition of the body that allows for discussions of the techno-human or cyborg. Although traditionally conceived of as fictitious, futuristic beings, the cyborg is becoming a reality as we continue to blur the distinction between human and machine. As our adoption of advanced bodily extensions become commonplace it can longer be said that the cyborg is strictly fictitious. As Anne Balsamo (1996) argues,

Cyborg bodies, then, cannot be conceived as belonging wholly to either culture or nature; they are neither wholly technological nor completely organic. In a similar sense, cyborg bodies cannot be completely discursive. Cyborgs are a matter of fiction and a matter of lived experience (p. 33).

By continuing to extend our bodies using the latest technologies, Balsamo's conception of the cyborg as both fiction and reality is increasingly accurate and useful to discussions of what it means to build the techno-human.

In addition to the conception of cyborgs as a useful ontology for the postmodern body, Jennifer A. González (2000) points out, 
The image of the cyborg has historically recurred at moments of radical social and cultural change. From bestial monstrosities, to unlikely montages of the body and machine parts, to electronic implants, imaginary representations of cyborgs take over when traditional bodies fail. In other words, when the current ontological model of human being does not fit a new paradigm, a hybrid model of existence is required to encompass new, complex and contradictory lived experience (p.61).

Although González is speaking to the use of the cyborg in visual art, her assertion that the cyborg is a recurring image during moments of social and cultural change is relevant when considering the ways in which BWV is being discussed. Not only are we currently in the midst of large-scale cultural changes resulting from our being increasingly 'plugged in', BWV is also emerging during a time of deep dissatisfaction and mistrust when it comes to police authority.

However, the addition of BWV to police bodies is not merely an example of the cyborgization of police, it demonstrates a shift toward the RoboCop. This distinction is important, as it highlights the political motivation infused into the adoption of BWV as a policing tool. The cyborg implies a neutral extension of the body - an aid - whereas the RoboCop is the result of a surveillant assemblage that seeks to extend its gaze infinitely in the project of "justice". The RoboCop is political, as it is located in particular claims to truth and justice - it is a state cyborg that is physically and morally superior to the citizen.

\subsection{Marketing BWV as a Law Enforcement Tool}

Underscoring the trend of the militarization and cyborgization of police, manufacturers including TASER, Safety Vision, Reveal Media, and Digital Ally are marketing their devices directly, and in some cases exclusively, to law enforcement agencies. As stated in the user manual for the TASER AXON body ${ }^{\mathrm{TM}}$,

The AXON body ${ }^{\mathrm{TM}}$ camera is a wearable camera system incorporating an audio and video recording device. This camera is designed for use in tough 
environmental conditions encountered in law enforcement, corrections, military, and security activities (TASER AXON body ${ }^{\mathrm{TM}}$ User Manual, 2013 p. 4).

This particular statement not only makes it clear that BWV is meant for law enforcement but it also makes the explicit link to the military. The following screenshots represent a small sample of the countless visual appeals made directly to law enforcement in BWV manuals product websites.

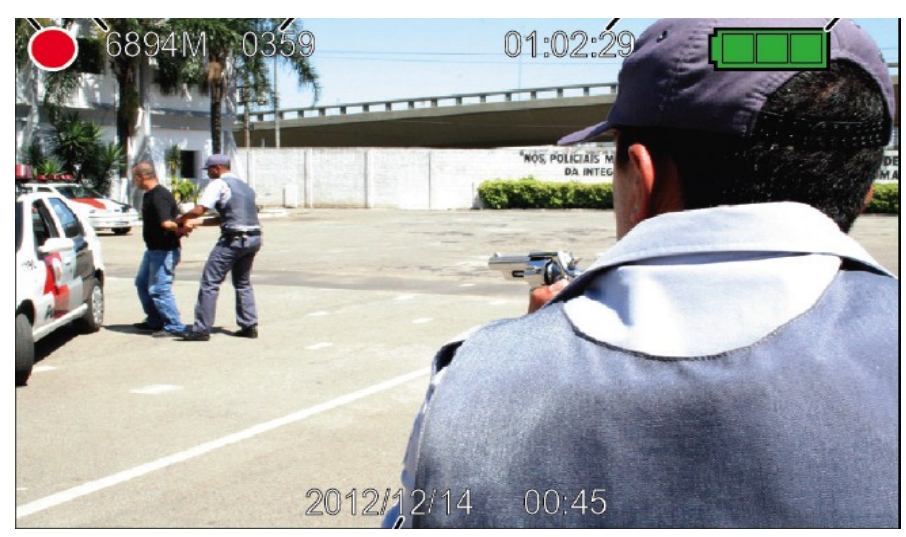

(Prima Facie User Guide, 2012, p. 7).

The image above is taken from the Prima Facie user guide and not only includes two figures that look like officers contrasted with what looks like a criminal, the image also includes a squad car: all the tell-tale markings of a police scenario.

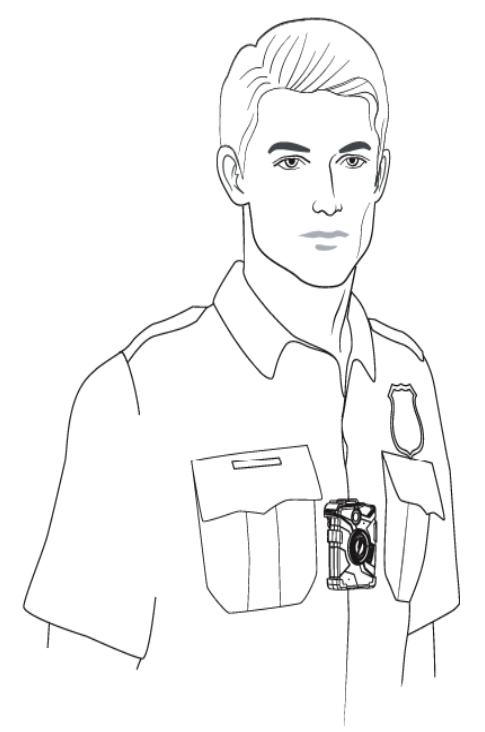

(TASER AXON body ${ }^{\mathrm{TM}}$ User Manual, 2013, p.7). 
The silhouette above is a simple outline of a person wearing a BWV device; however, it is immediately clear that this individual, despite little detail, is meant to be read as an officer. Although there is an absence of detail in this outline, the details that are present are specific. The outline of the characteristically shaped badge and the stiff uniform both tell the audience that this is a police officer. In addition, the figure reflects the traditional male officer with short hair. Further, the BWV device is actually bolder than the rest of the outline, emphasizing the place of BWV on the officer's body. The image below reinforces these claims as it appears in the blue that is characteristically associated with police and the text is positioned over a squad car.

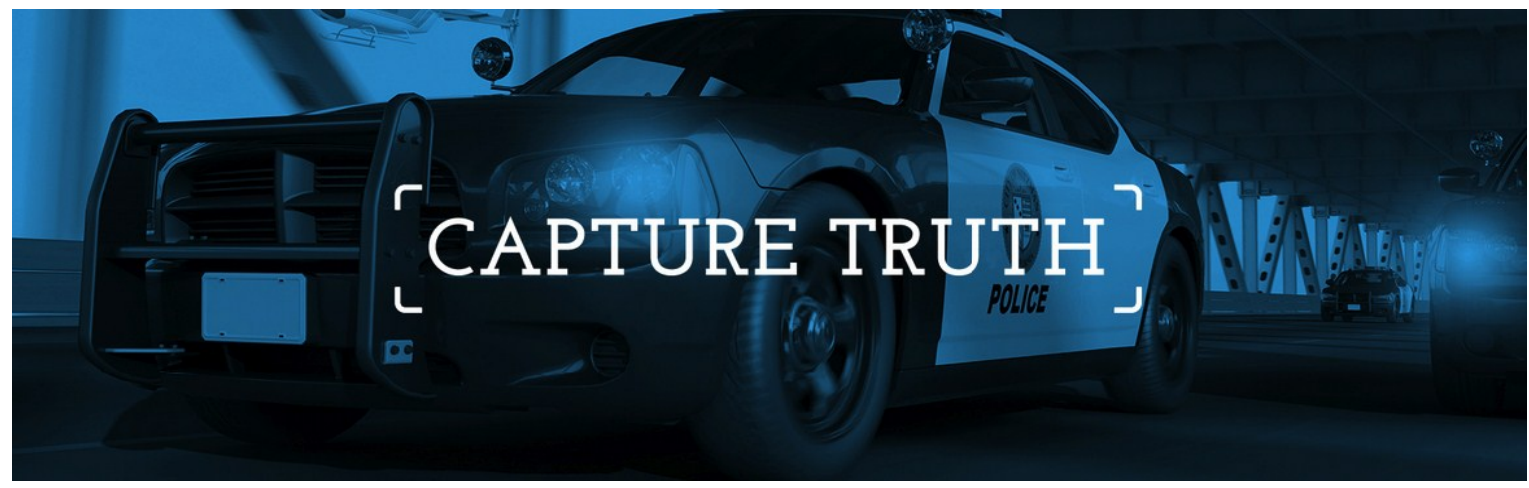

(“Digital Ally, Inc.", 2014).

It is clear that these manuals websites offer both images and text that explicitly reference the use of BWV as a policing tool. In some cases they even make claims that BWV products were created specifically with law enforcement in mind. For example, the storage platform that corresponds to the AXON body ${ }^{\mathrm{TM}}$ is called Evidence.com. The use of police/legal terminology sends the message that this product is specifically meant to be consumed by police officers. Additionally, the language used in Digital Ally's Law Enforcement Catalogue explicitly references police officers. The example below illustrates how BWV will help save officers' time by freeing them up from paperwork and file preparation. Given that research on police culture has found that officers crave 
excitement and 'real' police work, the opportunity to spend less time doing paperwork is likely an effective plea (Loftus, 2009). The claim that officers will be free to do more "real" police work if they adopt BWV works toward positioning the officer of 2016 - the RoboCop - as one that does not do office work. The technologically extended officer is not a secretary; he is a cop.

\section{Officer Time}

The UK Home Office's Guidance for the Police Use of Boch-Worn Video Devices (Goodall 2007)

Quicker resolution of cases, due to video evidence, led to a $\mathbf{2 2 . 4 \%}$ reduction in officer time devoted to paperwork and file preparation along with an $9.2 \%$ increase of officer time spent on patrol.

(“Digital Ally, Inc.”, 2014).

Finally, and perhaps the most obvious appeal to law enforcement, TASER will only allow sworn law enforcement members to buy their BWV products online. In other words, TASER offers an exclusive deal enjoyed only by officers, further enticing police to buy into BWV.

\section{BUY ONLINE}

A number of TASER products and accessories can

be purchased directly through our online store, which is open to sworn members of law enforcement only.

SIGN IN $\rightarrow \quad$ REGISTER $\rightarrow$

(“TASER", n.d.).

The marketing of BWV devices directly to police organizations is not surprising given that there is clear demand for them in the policing context. However, this can also 
be considered in terms of the growing trend toward police militarization and cyborgization. We are witnessing a growing shift toward equipping officers with increasingly complex tools and it is clear that the manufacturers are capitalizing on this by marketing the futuristic police officer as more efficient and better protected. The result is that this market is perpetuating a narrative that suggests that new devices can solve all of the issues that police are facing, from negative public opinion to bringing down criminals; all they have to do is build the perfect RoboCop.

\subsection{Extending the Officer}

As mentioned, BWV has been regularly characterized as capable of extending the officer in ways that will compensate for their bodily limitations. Framing the discussion of BWV in this way conjures the image of the ultimate protector. However, unlike the flawless cyborg officers that often appear in works of fiction, the use of BWV as an extension of the officer's physical and mental capabilities has been anything but straightforward. Nevertheless, BWV manufacturers, politicians, and journalists alike have continued to characterize BWV as a tool that will give officers extended competencies.

Canadian news outlets have been keen to characterize BWV as a tremendous extension of the body. The London Free Press has referred to BWV as an extension of the officers' visual and auditory capacities, stating that "In the biggest Canadian study of its kind, Edmonton police are testing a body-worn recording system that gives cops an extra set of eyes and ears" (October 10, 2012). Similarly, the Toronto Star reported, "some Canadian forces are already testing the body cams, and many see the officer of the future as a plugged-in, patrolling monitor, whether in a car, on a bike or walking the beat" (Stancu, August 3, 2010). Both statements position BWV as an extension of the 
officer's body; however they do so in different ways. The first asserts that BWV can be considered a physical extension of the officer's eyes and ears, recording what the officer sees and hears in a heightened, more reliable way. The second refers to the officer of 2016 as one who is plugged into various extensions that allow them to accomplish their job more efficiently. Although these statements reference the bodily extension of officers in different ways, both are indicative of a broader tendency to construct BWV as useful extensions of the body.

Similarly, Spencer Chandra Herbert, member of the New Democrats in British Columbia has stated that, "body worn video cameras remove the need to rely on people's memories or notes" (Burgmann, February 24, 2015). Herbert echoes the media's claims that BWV will act as a solution to human limitations. By claiming that BWV is an attractive alternative to the fallibility of our memories and the subjectivity of an officer's low-tech notes, Herbert is reinforcing the suggestion that BWV will serve as a means of overcoming the body's physical and mental limitations. Discussing BWV in this way positions humans as flawed, and by contrast, technologies as superior.

Officers themselves have taken to characterizing BWV as useful extensions of their bodies. Greg Hallgrimson, Chief of Police at Greenwood Police Department, states in a testimonial on the Digital Ally website,

We're able to spot evidence, even in the videos. Every once in a while we'll see something in the vehicle that the officer didn't see. So they're great for us. If there's any dispute later, or somebody recants on the statement that they give, we have it right there on video ("Digital Ally, Inc.", 2015).

Hallgrimson's discussion of how BWV can sometimes pick up on details that the officer did not notice is reminiscent of the characterization of these devices as a more complete extension of the officer's eyes and ears. However, discussions of how BWV will act as 
helpful extensions of the body are perhaps idealistic or premature, as the reality of the transition toward using BWV is much less smooth.

Although these statements regarding BWV seem to reference the devices currently being adopted by police organizations, what they are really discussing is the BWV of the future. These idealistic characterizations of bodily extensions that are noninvasive, helpful, and objective are just that: idealistic. The BWV of today has countless shortcomings, particularly in the policing context. Although these devices have been available for years, their widespread adoption by police is fairly recent and the devices require additional tailoring before they can become the superior devices being constructed in the discourse.

The tendency to discuss BWV in a futuristic form that has shed its current limitations can be considered a work of social science fiction. Coined by William Bogard (1996), social science fiction refers to a kind of “... future history. It is not 'true,' nor is it exactly a prediction. Instead it chronicles how a fantastic machine might recount its past, a past that haunts our own technological present and, like some displaced recollection, precedes it" (p. 7). The tendency to discuss BWV as it might exist in the future, rather than as it really exists today is a clear example of the discourse of social science fiction. The BWV being characterized by the media, politicians, police, and manufacturers as a superior extension that simply attaches to the body and replicates reality is fictitious. Bogard (2003) goes further in stating, "everything today is obscenely visible and immaculately packaged, totally coherent, controlled in advance by models and codes and simulations that disguise the absence of anything remotely or nakedly real anymore" (p. 178). This perfectly applies to the construction of a BWV that does not 
truly exist but is perfectly packaged and controlled by the dominant discourse. The social science fiction of BWV is undermined by the experience of officers that have actually used BWV, as their accounts demonstrate a very different, and much more flawed, device.

The reality of BWV can be read between the lines, as officers and police organizations chronicle their lived experience with the devices. As stated in the EPS postpilot report,

In use of force situations the camera almost always became partially or fully dislodged. At a minimum, the force of the action was disrupted. On several occasions the camera flew off and was 'lost' without the wearer realizing it. It was retrievable in the training context, but in operational use this would be difficult ("Body Worn Video: Considering the Evidence", 2015, p. 17).

This experience recounted in the EPS report paints a very different picture of BWV. Characterized as non-invasive, streamlined extensions of the body, the real BWV falls off the body and is unknowingly lost. The inability of these bodily extensions to remain attached in dynamic situations is just one example of how the actual performance of the BWV has been underwhelming. In their review of the RS3-SX, one EPS officer that participated in the pilot program raised concerns about the beeping that these devices make when their battery is nearly drained. The officer suggested that these indicators are problematic, as they have the potential to be distracting in precarious situations. The officer stated that, "at a priority event we do not have time to change the battery. The beeping on low battery is loud and distracting and could negatively influence a fragile, delicate situation" (“Body Worn Video: Considering the Evidence”, 2015, p. 21).

These assessments from the EPS post-pilot project report suggest that what are supposed to be helpful bodily extensions are proving to be more difficult to integrate than 
the discourse would suggest. The fact that officers struggled to ensure that their BWV remained attached to their bodies means that even at their most basic level these technologies are falling short. The RoboCop's gear is not meant to fall off or underperform; the entire point of the cyborg cop is technologically extended, superior performance. The rocky transition being experienced by officers adopting BWV stands in direct contrast with claims that these extensions are appealing because of their ability to compensate for human limitations.

As BWV performance continues to be flawed, the coherence inherent in the RoboCop is broken and risks failing; however, these failures are being neglected by those shaping public discourse. The absence of criticism directed at the current BWV and its underperformance is a necessary practice of social science fiction; as these devices fail, their status as solution must be reinforced by supplementing their present iteration with a superior future one. By clinging to a BWV that does not yet exist, the actors involved in this conversation have framed the discussion in such a way that positions BWV as a desirable choice, with few technological shortcomings in need of consideration. Those calling for the adoption of BWV are then able to offer a simple solution to public outcry as well as justify the substantial financial investment necessary to adopt these devices.

\subsection{The Technologically Savvy Cop}

In addition to enhancing the officer's body, BWV should also be considered from the perspective of its sheer technological complexity. These devices are not simple, they require extensive training in order to build the muscle memory necessary to use them in fast-paced situations. By mounting these complex devices directly onto the officer's body he physically becomes more technologically complex. As described in the EPS report, 
"there is a need for specific tactics training to develop muscle memory and integrate the use of the devices with other equipment" ("Body Worn Video: Considering the Evidence", 2015, p. 10). This suggests that officers require extensive training to fully integrate the technology into their bodily movements. Further, the report states,

The pilot training package was comprehensive and well-conceived, but it didn't deliver the desired outcome -- consistent and uniform BWV practice by pilot participants. They (and their supervisors) suggested adding a major training component: intensified BWV tactics training to develop muscle memory and integrate the technology with basic police training on other tactics and equipment ("Body Worn Video: Considering the Evidence", 2015, p. 86).

Despite considerable training, the officers that participated in the pilot program were still unable to standardize their BWV use. The following statement from the EPS report furthers the discussion of BWV's technical complexity, even suggesting that the result was confusion among officers.

Training for operating the BWV device is more complex than merely learning how to turn on and off the recording function. Members must have confidence in their ability to fit these actions into their previous tactics training for positioning and prioritizing the use of all their other equipment. Without careful consideration at the organizational level of how BWV integrates with all police tactics and equipment, confusion about how and when to use it will be likely to result ("Body Worn Video: Considering the Evidence", 2015, p.88).

As a result, the EPS has made recommendations that to successfully train officers to the point where BWV becomes second nature, any training plan must include, "tactical training on physical operation of the cameras", "learning modules for the operational procedures", and "ongoing 'refresher' training reviews" (“Body Worn Video: Considering the Evidence”, 2015, p. 10).

The complexity of BWV devices stems from multiple aspects of the technology the most prominent being their miniature size. These devices are the product of a history of miniaturization that has worked to create increasingly discrete devices (Mills, 2011), 
an important factor in the creation of a RoboCop whose success requires discrete, uninvasive, and functional extensions. However, the lack of space on these miniature devices means that a single button must control multiple functions, requiring officers to press them in different ways and for varying lengths of time in order to initiate the function that they desire. In the case of the TASER Axon body ${ }^{\mathrm{TM}}$, the user manual specifically indicates that the EVENT button is, "used to start and stop recording. (Double-press to start; hold for 3 seconds to stop recording)" (TASER AXON body ${ }^{\mathrm{TM}}$ User Manual, 2013, p. 6). Although this might sound straightforward, these officers are recording in fast-paced environments where remembering to double-press rather than hold a button for 3 seconds might be overly complicated. Further, in its discussion of the Reveal Media RS3-SX the EPS report states that, "standby and recording functions run by pressing a button on the front of the battery pack; varying the number of button presses chooses the specific function" ("Body Worn Video: Considering the Evidence", 2015, p. 15).

In addition to the TASER and Reveal Media products, Safety Vision's Prima Facie also requires that officers learn to use the same buttons for multiple purposes. As outlined in the Prima Facie user manual, "To record video:

1. Ensure the unit is on. Press the Power button. When powered on, the Status LED displays solid green.

2. Press the Video Record button on the front of the unit. The unit beeps once. The status LED blinks red (unless in Stealth Mode).

3. Point the unit in the direction of the object or event you want to record.

4. To stop recording, press the Video Record button on the front of the unit again.

The unit beeps twice.

The Status LED returns to displaying a solid green"

(Prima Facie User Guide, 2012, p. 10). 
Much like the AXON body ${ }^{\mathrm{TM}}$ example, the Prima Facie requires officers to use the Video Record button to both initiate and end recordings. This is not in and of itself overly complicated; however, again we must consider the contexts in which officers will be using these devices. Requiring officers to internalize the various ways in which these devices communicate what mode they are in or how much battery life is left is very demanding given the types of situations that would prompt the use of BWV.

In addition to the complexity of the buttons and functions on BWV, these devices also have an overwhelming number of LED colors that indicate various system statuses. In order to properly use BWV, officers will require a thorough understanding of what each of these indicators mean. The following chart has been pulled directly from the TASER AXON body ${ }^{\mathrm{TM}}$ user manual. These charts detail the plethora of visual indicators that users must internalize in order to properly understand and use their BWV devices.

At first, the LED on the bottom of the camera will display red, but the color will change to indicate the camera's stage in the uploading process.

\begin{tabular}{|l|l|}
\hline System Status & Camera Bottom LED Indication \\
\hline Uploading Data. & $\begin{array}{l}\text { Blinking Yellow } \\
\text { DO NOT Remove the Camera from the ETM. }\end{array}$ \\
\hline Device Ready (All Videos Uploaded Successfully). & Solid Green \\
\hline In Queue Awaiting Upload & Solid Yellow \\
\hline Initial Connection (Momentary). & Solid Red \\
\hline $\begin{array}{l}\text { Device Not Assigned, Agency Mismatch, or } \\
\text { Camera Set In The Offline Mode. }\end{array}$ & $\begin{array}{l}\text { Blinking Red } \\
\text { Consult ETM Support Page. }\end{array}$ \\
\hline ETM Has No Communication With Camera. & LED Off \\
\hline $\begin{array}{l}\text { Firmware Update, Internal Battery Charging, or } \\
\text { Memory Full. }\end{array}$ & $\begin{array}{l}\text { Blinking Red and Yellow } \\
\text { DO NOT Remove the Camera from the ETM. }\end{array}$ \\
\hline Network Error. & Blinking Red, Yellow, and then Green \\
\hline
\end{tabular}

(TASER AXON body ${ }^{\mathrm{TM}}$ User Manual, 2013, p. 15).

As if the LED indicators above are not exhaustive enough, the chart below outlines the LED indicators for the TASER AXON body ${ }^{\mathrm{TM}}$ battery status. TASER is not 
the only manufacturer whose product requires the user to memorize the various prompts that indicate the percentage of battery life that is left, each of the BWV devices indicates in one way or another that the battery is dying.

8 Battery LED - When lit, momentarily indicates the remaining battery capacity (it does not indicate the operating mode).

\begin{tabular}{|l|l|}
\hline Battery Status & Battery LED \\
\hline Battery Capacity is 41-100 Percent. & Green \\
\hline Battery Capacity is 20-40 Percent. & Yellow \\
\hline Battery Capacity is Less Than 20 Percent. & Red \\
\hline
\end{tabular}

(TASER AXON body ${ }^{\mathrm{TM}}$ User Manual, 2013, p. 6).

What is interesting about the TASER battery status and corresponding LED indicators is that the colors align with pre-existing standards for coloured indicators. Any technologized individual is familiar with the green means go, red means stop framework for visual prompts. Despite adhering to a pre-existing framework of knowledge that officers are likely familiar with, the requirement that officers internalize what the corresponding percentages make what could have been simple more complex.

In addition to complicated LED prompts, officers using BWV must also internalize various other indicators. As mentioned, these devices often have beeping prompts that officers have found to be problematic in precarious situations. However, additional consideration must be made to the complexity of what the various beep sequences signal. The table below outlines the five distinct ways that the TASER product communicates with its user through sequences of beeps. 
The AXON body camera emits beeping sounds called "audio prompts" to notify you of the system status. These audio prompts usually occur after you perform an action with the body camera.

\begin{tabular}{|l|l|}
\hline Operating Mode & Audio Notification \\
\hline Powering On or Off. & One Beep \\
\hline Recording an Event. & Two Beeps (Every Two Minutes) \\
\hline $\begin{array}{l}\text { The Device is Ending an Event and Returning to } \\
\text { BUFFERING Mode. }\end{array}$ & One Long Beep \\
\hline The Battery is at 20 Percent Capacity or Lower. & Four Quick Beeps (Every 20 Seconds) \\
\hline The Camera Memory is Full. & $\begin{array}{l}\text { Alternating Frequency of Two Tones that Occurs } \\
\text { When You Double-Press the EVENT Button. The } \\
\text { Camera Will Not Start Recording. }\end{array}$ \\
\hline
\end{tabular}

(TASER AXON body ${ }^{\mathrm{TM}}$ User Manual, 2013, p. 19).

The officers that participated in the EPS pilot program reported various concerns and disappointment with the devices as a result of their complexity. Complaints ranged from the intricacy of the buttons to claims that the lights on the devices were counterintuitive. As outlined in the report,

The coloured indicating lights for operating the camera were counter-intuitive: instead of 'go' a green light meant 'buffering,' instead of 'stand by' (or buffering), an amber light meant 'disconnected wire,' instead of 'problem,' flashing red meant 'successful recording' and solid red indicated booting up. The various battery light options added to the confusion. The result was frequent failure to record ("Body Worn Video: Considering the Evidence", 2015, p. 20).

These complicated, counter-intuitive prompts underscore the failure of BWV to produce the effortless and intuitive cyborg technology.

In addition to the multiple lights, colors, and sounds that officers must learn and internalize they must also learn the complex processes that are a reality of these devices. As stated in the TASER AXON body ${ }^{\mathrm{TM}}$ user manual under the troubleshooting section,

if a reset occurs in BUFFERING mode, the camera will beep once while shutting down. The LED will go from blinking green (BUFFERING mode) to blinking yellow, and then it will turn solid red. The LED will then cycle back through solid red (booting). The camera will then beep once, and the LED will blink green (BUFFERING). This will repeat until the AXON system is booted up (TASER AXON body ${ }^{\mathrm{TM}}$ User Manual, 2013, p. 21). 
What should be a simple reboot process requires the officer to understand the sequence of various lights, colors, and sounds that the device will make when rebooting. In order to identify what the device is doing, what mode it is in, and various other considerations such as battery life, the officer must have an internalized understanding of the countless prompts that their particular BWV device produces.

Further, claims that BWV will offer superior evidence is also undermined by the fact that in practice the devices can lose track of date and time, potentially eroding its evidentiary possibilities. As stated in the EPS report,

An unacceptable problem arose with some batteries when they drained to low or empty; the date would reset to factory default. Although members' notes and upload time can support the actual time of an event, this failure could cause an incorrect metadata marking on the video, proving harmful to the evidentiary value of BWV footage ("Body Worn Video: Considering the Evidence", 2015, p. 22).

The prompts and functions indicated in this section are not the only BWV processes that officers must be aware of, they must also memorize BWV operations like those outlined in the following user manual excerpts.

Press the LCD/Stealth Mode button quickly to turn the LCD screen on and off. Press and hold the LCD/Stealth Mode button for 2 seconds to turn off the front Status LED and the IR illuminators. To exit Stealth Mode, press and hold the LCD/Stealth Mode button again for 2 seconds or cycle the Prima Facie's power (Prima Facie User Guide, 2012, p. 9).

Note - If the video recording is initiated while the unit is in Sleep Mode, preevent time is not recorded (Prima Facie User Guide, 2012, p. 9).

When we consider all of the functions, prompts, processes, and other operations outlined in this section it becomes clear that BWV devices are rather complex. These devices require that the user be extensively trained and able to internalize all of the operations of the device in order to properly use them. Of course the RoboCop is by its 
very nature technologically complex; however, the RoboCop is seamlessly complex - its technological extensions are advanced but there is an ease of use that the RoboCop requires. Additionally, the RoboCop requires uninvasive extensions that interact with the user and are intuitive enough to become fully embodied. Although BWV is miniature, attaches to the body, and is sensitive to touch, the technology is nowhere as uninvasive or intuitive as is required for officers to fully embody it. The reality of BWV is that they add bulk to an already weighed down officer and are prone to falling off the body; they are technically complex and often involve cords that can get in the way. Further, officers are not able to look at the devices because they are ironically located outside their line of vision. They are not meant to navigate it with their eyes; they must learn the device through touch and muscle memory, reinforcing the intimacy of BWV. As a result, we see a tension between the affordances necessary for RoboCop level embodiment and the technical limitations of BWV. However, these considerations are routinely being overlooked as BWV continues to be characterized as an idyllic extension of the officer. The technical aspects of the devices themselves are undermining the flawless transition to the RoboCop. It is not just a matter of purchasing a better mount so that the camera stays with the officer; the functions of the technology itself are difficult and regularly risk failure.

\subsection{The BWV Shield}

In addition to the potential of BWV to act as a helpful extension of the officer's body and the technological complexity of the devices, BWV has also been framed as a shield that can protect officers from unwanted visibility. BWV is routinely categorized as a tool that will be used to protect and defend officers against malicious allegations of misconduct. 
Framing the adoption of BWV as a tool of protection is reminiscent of the argument that officers should be equipped with cameras just because bystanders are. However, in this case, the adoption of BWV is specifically being framed as a potential tool to protect - or shield - officers from (false) accusations of wrongdoing.

By framing the adoption of BWV in this manner, politicians, police officials, manufacturers, and the Canadian media are implying that the public pose a threat to police. This is problematic considering that these devices are - supposedly - being adopted as a tool of police oversight and accountability. NDP justice critic Mike Farnworth demonstrated the framing of BWV as a mechanism of protection when he stated that, "it would also work vice versa, and show how the public is behaving toward the police ... the cameras could protect cops against false or mistaken claims of misconduct" (Smyth, March 1, 2015).

Suggestions that BWV will act as a shield that protects officers have also been echoed by the officers that participated in the EPS pilot program. As one officer stated, “it's the 'armchair quarterback' issue that really bothers me. It seems these days our word is not as valuable. I understand that the cameras are for accountability, but it's like we're not trusted anymore" (“Body Worn Video: Considering the Evidence”, 2015, p. 50). Another officer that participated in the EPS pilot stated, "I have had two complaints in recent months ... and BWV would have cleared them up pretty quick. To not have this technology is wrong” ("Body Worn Video: Considering the Evidence", 2015, p. 54). Similar sentiments are reiterated by many of the officers that participated in the pilot with another noting that, "there is a current threat of a complaint where a person ... [Was] combative and verbally abusive, including a personal tirade against me. He says he will 
complain ... I hope he does - I've had copies of the video burned" ("Body Worn Video: Considering the Evidence”, 2015, p. 60).

Further, the claim that BWV will protect officers from frivolous accusations of misconduct has also been voiced by police officers in their review of the devices themselves. The following testimonials are included on the Digital Ally website. Chris Morgan, of the Helena Police Department stated that, "it's a safety aspect for us and the public. You don't notice it's there, but you feel more protected when you have it with you because you have a constant (recording) of what you say and what the public says" (“Digital Ally, Inc.”, 2014). Similarly, Chad Wilderdyke, Sergeant at Clay County Sheriff's Department argued, "it's an invaluable tool. I love having the video. I would not want to work without one. It has exonerated me, [but] wearing it has never gotten me into trouble ..." (“Digital Ally, Inc.”, 2014).

Finally, Canadian journalists have also taken to reporting the adoption of BWV as a means of protecting officers from viral footage recorded by bystanders. "Conversely, police departments have argued in favour of cameras to protect officers against unfounded allegations of abuse, insisting grainy cellphone videos that find their way onto YouTube rarely tell the whole story" (Keller, October 15, 2014). This particular journalist is reproducing the popular police arguments that BWV will both protect officers from the public but also that bystander video does not tell the whole story. The suggestion being made here is that unlike videos taken by citizens, the footage from an officer's BWV will tell the whole story.

The positioning of what the officer records in direct opposition with citizen footage works to imply that the video technology itself is neutral and that it is the user 
that makes a difference to the value of the resulting footage. This type of logic positions the officer as morally superior to the citizen. The citizen's footage is motivated and thus subjective; the officer's is the objective truth. As representatives of the state, this positioning of officers as morally superior is actually a suggestion that the state is morally superior to civil society. The characterization of the technology as neutral produces a narrative that is fundamental to the popular suggestion that BWV is the solution to police misconduct. The reality is that there are already countless cameras recording a given situation and the truth-claims of those cameras must be undermined in order to make room for BWV's claims to superiority. If it were to be admitted that the technology is subjective, police organizations would not be able to suggest that their cameras or points-of-view are any better than those being used by the public. In order to use BWV as a shield, police must claim a monopoly over the truth, this is accomplished by suggesting that user that determines objectivity and the officer is the morally superior user.

The framing of the officer as morally superior changes the conversation from officers requiring cameras to keep them in line to officers needing cameras to keep the public in line. This narrative reproduces the hierarchies of visibility observed by Haggerty (2006). Haggerty argues that,

The multiplication of the sites of surveillance ruptures the unidirectional nature of the gaze, transforming surveillance from a dynamic of the microscope to one where knowledge and images of unexpected intensity and assorted distortions cascade from viewer to viewer and across institutions, emerging in unpredictable configurations and combinations, while undermining the neat distinction between watchers and watched through a proliferation of criss-crossing, overlapping and intersecting scrutiny (p. 29). 
Although Haggerty is right about modern surveillance undermining traditional hierarchies of visibility, undermining the neat distinction between watchers and the watched, his position seems far too optimistic as police organizations - likely followed by other institutions - are finding ways to control the surveillant gaze. Police have long been at the top of the hierarchy, a privileged position mostly exempt from the gaze. This privilege was the result of the officer's position as the state's eyes on the ground. However, as the discourse continues to position the officer's account as superior to the citizen's we can see the hierarchy re-emerging.

Additionally, as a result of framing the police as victims in need of shields, the discourse is flipped, taking the pressure for reform off of police organizations. It is not surprising that this narrative has emerged given that police organizations have a long history of fighting reform (Green and Gates, 2014). However, reversing the discussion and painting officers as requiring additional protection completely glosses over the advantage that the police enjoy. Officers and the public are not on equal footing, as the police represent the state and are the official authority - a privileged position that citizens do not share. Additionally, police organizations control resources far greater than those of the public and they already own the footage from CCTV and dashcams.

\subsection{Capturing Truth}

All the management of our lives depends on the senses, and since that of sight is the most comprehensive and the noblest of these, there is no doubt that the inventions which serve to augment its power are among the most useful there can be (René Déscartes in Jay, 1993, p. 21).

Déscartes was describing a privileging of the visual that remains a major stumbling block today; a phenomenon that Martin Jay (1991) refers to as ocularcentrism. Our tendency to privilege what we can see over experiences mediated by our other four senses is deeply 
tied to our understanding that what we see is the truth. Jay argues that this is the result of a visually privileged order of knowledge, where what we see rests at the top of the hierarchy (1991, p.23). Brennan and Jay (1996) specify that, "new attention has been paid to scientifically and technologically generated 'techniques of observation,' which are shown to be dependent on culturally inflected visual practices and able in turn to influence later ones" (p. 3). This last point is particularly important given that BWV is an example of the privileging of technologically generated techniques of observation, as these devices are technical replicas of the eye that are being hailed as superior to their human counterparts. Despite significant proof to the contrary, we continue to believe that what we see is a one true reality; however, it is more accurate to say that what we see is a unique interpretation that is founded in our individual experience of the world. The assumption that seeing is believing has contributed to the construction of BWV as a truth telling device, capable of capturing a universal reality. Subsequently, the officer wearing the device becomes the truth teller, undermining any competing accounts.

The truth-claims being attached to BWV have been a recurring favourite of officers themselves. Amherstburg police Chief Tim Berthiaume embodied this logic: "it's an excellent tool that provides an unequivocal account of what was said" (Jarvis, April 13, 2015). Similarly, Supt. Kevan Stuart has said that, "the cameras provide an objective account of good and bad police interactions" (Quan, January 9, 2015). Referring to BWV footage as an impartial account of an event, retired Saskatoon police officer Ernie Louttit argued that, "having a camera rolling when officers break up a fight, for example, would have shown an impartial view of what happened instead of relying solely on an officer's recollection of events" (Hamilton, November 26, 2014). Finally, Staff. Supt. Tom Russell 
noted, "we believe that body-worn cameras are a valuable piece of technology that will provide an unbiased, accurate account of our interaction with the public" (Mehta, May $16,2015)$.

In addition to police officials claiming that BWV will provide an objective account - a truthful account - of an event, BWV manufacturers have also repeatedly employed this assumption in their discussion and marketing of BWV. TASER spokesperson Steve Tuttle has said that, "it will catch officers making mistakes, sometimes egregious mistakes to full on errors. And that's OK because it captures the truth, and the truth is the truth" (Miller, October 9, 2015). The BWV manufacturers analyzed explicitly claim that their products are able to 'capture' the truth and leverage this claim in order to market their devices. Perhaps the most blatant example is Digital Ally's slogan, 'Capture Truth'. By making the claim of the capacity for their BWV to portray truth the central message of their company, Digital Ally has built their entire marketing strategy on this function, implying that this is the most important aspect of the device. Digital Ally is not the only manufacturer to claim its product can provide visual evidence of the truth, TASER makes similar claims about its AXON body ${ }^{\mathrm{TM}}$. TASER's website claims that,

The actions of law enforcement are being scrutinized like never before. Bystanders can record their perspectives of unfolding events and broadcast their reactions with ease. The Flex was created to protect truth, not opinion. It provides an indisputable record of an officer's perspective, helping stop complaints and allegations before they escalate ("TASER", n.d.).

This claim is particularly interesting as it paints the bystander's footage as an opinion and the officer's as fact. Additionally, Safety Vision's website includes the following image which not only directly appeals to law enforcement, it is also a clear reference to their 
device's ability to record a single truth and frames it in opposition to "false claims of injustice". As I have argued, the claims of mechanical objectivity attached to BWV are not attached to the technology universally but rather only in the policing context.

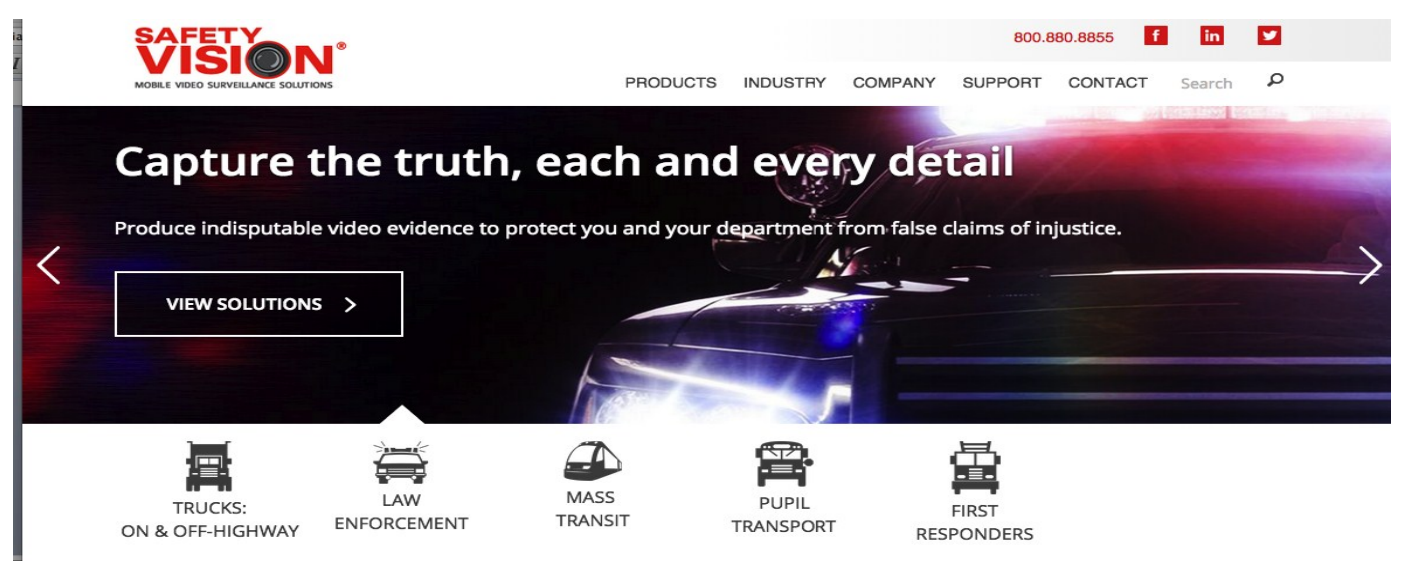

(“Safety Vision”, 2016).

The rhetoric of BWV as capable of capturing 'The Truth' is problematic for several reasons. First, the implication that BWV is capable of documenting the truth implies that other devices recording footage at the scene are capturing something other than the truth. The result is that the footage recorded by officers' BWV is positioned as better than that filmed by other cameras, thereby privileging the officer's perspective over alternative points-of-view. BWV devices will tell $a$ truth, not the truth. The officer's BWV will provide one perspective, the same way that a bystander's smartphone will. However, by claiming that BWV will record the truth, officers, manufacturers, and others are implying that the cameras currently filming police interactions are not capable of capturing the truth. Framing police BWV in this way paves the way to ensuring that the officer's account maintains the same privilege it has traditionally enjoyed.

Finally, Canadian journalists also reproduce this truth discourse. The Calgary Sun stated, "perfect, no. But bodyworn police cameras place an impartial set of eyes on what 
is increasingly a volatile and controversial job" (Platt, June 24, 2015). In the same vein, the City Centre Mirror reported that, "police say body-worn cameras provide an unbiased and accurate account of their interactions with the public" (May 28, 2015). Adding to the conversation, the Calgary Herald and the Waterloo region Record have made the following claims,

As a wise old cop once said, there are three sides to every story: your side, the other person's side and the truth. An innovative tool will help ensure the truth triumphs in disputes arising from altercations involving Calgary police officers and members of the public (January 19, 2015).

In Montreal, the request for the devices came from the police officers themselves, who say videos posted online and spread on social media often fail to show the full exchange in an intervention (Shingler, January 21, 2014).

All of these statements suggest that the technology itself is objective; however upon closer inspection it is clear that it is only the officer's technology that enjoys this privilege. The reality is that these devices are no more capable of capturing the truth than any other camera at the scene of an event. However, the repeated claim that BWV will provide a more complete truth than sources external to the police positions BWV as superior to other sources of visual evidence. As a result, the conversation surrounding BWV has framed the footage that will be recorded by officers' devices as the authority, standing above any competing footage.

Reinforcing my claim that these devices are being characterized as objective in order for officers to maintain their monopoly on truth, the EPS report makes several statements that suggest that in practice the mechanical objectivity being claimed by various actors is virtually non-existent. When detailing the realities of using BWV, the report makes the following statements, 
Perceptions about audio-video quality are highly subjective because of individual differences in sight, hearing, prior expectations and knowledge. This contrasts with widely held assumptions that video footage is 'factual' and indisputable ("Body Worn Video: Considering the Evidence", 2015, p. 9).

But - technical and film experts, and crown prosecutors, challenge these claims. There are several factors at play: how far the camera can see vertically and horizontally; how fast it is filming (frames per second); and variable light and sound conditions that must inevitably effect the quality of video. A BWV recording captures only what the camera can see and hear. This may not be the same was what the wearer sees and hears ("Body Worn Video: Considering the Evidence", 2015, p. 28).

Each of these statements acknowledges the subjectivity that is often neglected when new technologies are adopted. These devices are not inherently objective; lighting, sound quality, scope, etc., all contribute to the subjectivity of the resulting footage. Further, even if the devices themselves were objective, the texts they produce are subject to different interpretations by numerous viewers. In his discussion of law's growing dependence on visual evidence and the fantasy that is often attached to that evidence, Feigenson (2014) argues that "visual proof that takes the form of movies on screens persuades in part by appealing to largely subconscious desires for the ideal knowledge, self-coherence, and community, which it can never really satisfy" (p. 17). Feigenson's claims shed light not only on the deeply subjective nature of visual evidence, but also how our relationship with cinema can impact our ability to objectively interpret evidence in the form of film. Relatedly, it is worth noting that the EPS statements above - which clearly undermine claims to truth and mechanical superiority - are being made by a police department that has opted not to equip all of its officers with BWV after piloting the devices. In some ways the EPS report can be seen as a justification for opting out of a growing policing trend that to some feels inevitable. 
Its need to produce concrete examples of BWV failing has meant that the EPS

report is one of the few sources to meaningfully discuss the shortcomings of this

technology. The report continues on to state that,

Research refutes the assumption that viewers of a video clip see and hear the same things. The project team encountered this very issue when analyzing the interviews with pilot participants. Also, the project team members faced their own struggles to evaluate objectively the video clips gathered during the project ("Body Worn Video: Considering the Evidence", 2015, p. 28).

Not only is the EPS refuting the idea that BWV can document the truth, it is claiming that no video technology offers that capacity. As the report explicitly points out,

Even with the best controls and standardization, the rating exercise emphasized how subjective the viewing of video can be. This is an important finding and a significant consideration for evaluating the evidentiary potential for BWV footage ("Body Worn Video: Considering the Evidence", 2015, p. 31).

Going even further, the EPS gives an example of such a case,

A recent ruling from the Ontario Court of justice involving video taken by a security officer's cell phone is informative. Both parties agreed that the cell phone quality was good and that it provided an accurate and objective account, but the defence and prosecution differed on the details of what the account would support ("Body Worn Video: Considering the Evidence", 2015, p. 76).

It is not particularly uncommon for both the prosecution and defense to use the same video footage to support their competing arguments; by framing it in competing ways. The possibility of successfully painting a particular piece of footage in two opposite ways is only possible because of the inherent subjectivity of video.

As visual criminologists and filmmakers alike have demonstrated, there are many factors involved in constructing footage that affect what is recorded and how it is perceived. As legal scholar Jessica Silbey argues,

The camera always includes some images and excludes others. Films are depicted in artificial light and color. From the earliest emergence of film technology, filmmakers and critics recognized that the appearance of reality in films is an 
illusion based up on conventions of representation ... these conventions produce images that resemble and represent reality, but are not reality in fact $(2008, \mathrm{p}$. 102).

Keeping in mind all of the ways that video footage, not to mention the audio components, are subjective and open to interpretation, the claim that these devices are able to record truth is inaccurate. These devices do not provide a superior truth, they document the officer's truth and by suggesting that the officer's truth is the truth, the dominant discourse is suggesting that the officer's account is the one that matters. Again, this positioning of the officer's account as superior reinforces the RoboCop's monopoly on truth and exceptional morality, two fundamental steps in ensuring that police organizations are able to control what the assemblage sees.

\subsection{Conclusion}

When we consider the multitude of technological tools that police employ daily, including databases, dashcams, biometrics, and so on, it is clear that technology has been facilitating police work for decades. However, the adoption of BWV marks a distinctly different kind of extension - a physical, bodily extension that is much more intimate than predecessors that extend at a distance. BWV can be seen as an attempt to solve the physical limitations of the officer's body; an attempt to make the officer better, closer to perfect. Further, these devices are not just on the body, they are very much in the body as they work to enhance the officer's fallible memory and senses. This intimate bodily extension moves officers past the point of being extended, motivating them to become the camera in order to fulfill their role as RoboCops. The mounting of complex BWV devices to the officer's body is indicative of our increasing preoccupation with overcoming our bodily limitations and making ourselves more efficient; invoking 
discussion of the cyborg. Much of the rhetoric surrounding the emergence of BWV is constructing the image of a futuristic, enhanced officer; however, the cyborg cop is not just extended - it is superior. He is RoboCop.

Framing BWV in this way includes claims that it is extending the officer, making the officer more complex, offering them protection, and providing them with a monopoly on truth. However, a closer consideration of the ways that BWV is being framed exposes the various motivations behind characterizing the devices in the ways suggested above. Where the solution to misconduct and brutality is technological extension we can see the problem being constructed in such a way that officers cannot be changed, they can only be monitored. We also see that the technological complexity of these devices that is meant to enhance the officer is proving to be much more difficult to integrate than would be suggested by actors including manufacturers. The fractured integration of BWV threatens to undermine the RoboCop, risking failure. Framing of BWV as a shield that will protect officers suggests that officers must be protected from a motivated public that is out to get them. This treatment of the discussion sets the groundwork for the characterization of the devices as neutral and the officers as morally superior to citizens. The subsequent truth-claims being attached to the officer's device work to ensure that the officer's account - the state's account - is privileged over any others.

The creation of the RoboCop is a by-product of the continued expansion of police brawn that involves the militarization and technological enhancement of officers. The trend toward the cyborgization of police officers serves as a way of underscoring police superiority and gives police organizations the upper hand in the war on visibility. The RoboCop, the cyborg cop within a framework of the surveillant assemblage and the risk 
society, produces mechanical, objective truth, giving the officer of 2016 a monopoly on legal truth. The result is that police get to determine their own truth without risking any real external opposition; they are able to control what the pervasive assemblage sees. Our continued progression toward a RoboCop reality raises questions regarding the future of activism, dissent, and accountability in a world where the state's representatives increasingly control the only truth that is taken to matter. 


\section{A Different Kind of Shot: Redefining how police look}

"You don't take a photograph, you make it". Ansel Adams

The addition of BWV to the policing repertoire forces officers to take on new roles: photographer, videographer, and director. Traditionally, these are roles that would have been well outside the scope of what we expect of police officers; however, as we continue to equip them with first-person recording devices - expecting that they will gather quality visual evidence - officers must become intimately acquainted with practices of videography. Video footage is constructed in much the same way that Adams suggested we 'make' photographs; they are not reproductions of reality taken by an unbiased machine. They are pieces of reality constructed by both the limitations of the technology and the individual wielding it. In order to 'make' the video footage necessary to support future legal proceedings and protect officers in the event that they are accused of misconduct, officers must adopt a cinematic logic; they must think like the camera; they must become the camera.

Although officers have traditionally reconstructed events by describing them in their notes, these notes were never evidence per se, rather they served as a reminder for the officer should she or he be called to testify in a case. With the adoption of BWV, the officer must learn to construct the event in the moment by positing their body in such a way that the necessary footage is recorded. The result is that officers must learn the intricacies of film and start to consider factors such as lighting, sound quality, and angles in order to ensure their BWV footage is clear and provides useful evidence. Consequently, officers must become the directors of their own films, tasked with documenting their experience during an event and ensuring that they produce high 
quality, desirable footage, with a clear narrative. This a distinct departure from various other tools that have been added to the police uniform over time, as the skillset required to operate the embodied camera fall outside the realms of safety and security that have traditionally defined police work.

I have argued that the adoption of BWV by police organizations is a calculated response to their incorporation into the surveillant assemblage and an attempt to maintain a level of control over their visibility. The adoption of a cinematic logic is needed to properly leverage BWV and ensure tight control over the nature of their visibility. As this technology - like all technology - has its affordances and limitations, a tension of agency develops, where the officers' agency must become secondary to the agency of the device. The result is that in their resistance to the surveillant assemblage, police have conformed to it. The embodiment of BWV is both a surrender to the assemblage and an opportunity to shape it from within, prompting considerations of what happens to police officers when they are turned into cameras.

As police organizations continue to use BWV to win the war on visibility we are forced to reconsider our conception of the assemblage. The example of BWV suggests that the assemblage is no longer necessarily levelled and rhizomatic, it now includes nodes of centralized power where visibility can be controlled. These nodes are both exposed and shielded from the surveillant gaze; they are visible but they effect what it sees. It is important to consider that not only do police organizations influence their visibility, BWV gives them the opportunity to shape the perception of what is seen. Their concession to the gaze coupled with their ability to control what the assemblage sees is reminiscent of the panopticon, but a modified panopticon where the prisoner controls 
what the guard sees as well as how the guard perceives the prisoners' actions. Therefore, perhaps the surveillant assemblage is best modified by considering it an assemblage of small panopticons that both exist separately and together. Essentially, while our traditional conception of the panopticon proves inadequate given the level of surveillance today, the ability to impact the surveillant assemblage from within suggests that it too is no longer wholly accurate. Given these shortcomings, I suggest that we have actually transitioned to a surveillant apparatus that more closely resembles Gandy's panoptic sort; however, the current system is not only meant for cybernetic triage, it is also meant to pre-empt undesirable behaviour while giving some actors control over their visibility. The result is a combination of the panopticon and the surveillant assemblage: a panoptic assemblage.

This chapter will explore the various ways in which the adoption of BWV is changing the way that police officers approach and carry out their work. Of the many questions being asked as BWV continues to be rolled out by police organizations internationally, very little attention has been paid to how these devices will change the way that officers work and established methods of evidence collection. My intent here is not to make a normative judgement about BWV, but rather to raise some questions that have largely been overlooked in the discussion about these devices and to probe some of the ways in which turning officers into cameras might be problematic. Additionally, this chapter will explore in more detail changes to the surveillant assemblage that are provoked by the adoption of BWV by police organizations. 


\subsection{Officer POV}

Traditionally, state surveillance technologies - in fact, most surveillance technologies have produced what can be considered a third person perspective. These cameras record events from various external vantage points; they rarely tell the story of one particular actor from that actor's own perspective. What makes BWV fundamentally different from other surveillance technologies is the device's ability to document the user's perspective. By mounting BWV to the body, camera facing outward, the camera sees what the user sees. Of course this is not always as simple as I am suggesting, as factors such as height, the specific position of the camera on the body, field-of-view, etc. can hinder the device's ability to record exactly what the user is seeing. However, the footage is fundamentally from the user's point-of-view regardless of quality. By adopting BWV and mounting them to officers (prompting officers to fully embody the devices) police organizations have ensured that their point-of-view will be accounted for.

As described by the Leader Post, "RCMP officers across Canada could soon join Calgary police in donning small bodyworn video cameras to record from the officers' eye view virtually everything that happens during their shifts" (December 20, 2014). This particular statement reflects a common misconception that BWV will be recording the officer's entire shift when in reality the technology does not facilitate an entire shift worth of battery life. What is important here is that the device's inability to perpetually record means that police are prioritizing certain events and interactions over others. I have previously argued that these devices are not being implemented to watch officers' work, but rather to ensure a specific record of certain events. However, when we consider that BWV records from the officer's perspective, giving the officer discretion over which 
events are recorded, it becomes doubly concerning. Not only is the officer's perspective privileged over the citizen's, the police will also determine which events are worthy of record.

In the same vein, several police officials have made similar claims about the capabilities of BWV. Supt. Kevan Stuart of the Calgary Police stated, "This will give the police officer's perspective as to what they saw, what they heard and what they knew at the time of the event as opposed to a third party" (Stark, October 2, 2014). Echoing Stuart, then Deputy Chief of the EPS, David Korol stated, "It can move with the officer in terms of what the officer visualizes" (Wittmeier, July 24, 2010). These statements suggest that because BWV moves with officer that it will document their point-of-view. Further, paraphrasing Sgt. Greg Cox of the RCMP media relations section, the Victoria Star stated that, "BWVs not only provide increased transparency and accountability for everyone, it delivers a first-person view of what a police officer encounters, oftentimes in highly dynamic and tense situations" (Staples, March 5, 2014). In a testimonial on the Digital Ally website, Greg Hallgrimson, Chief of Police at Greenwood Police Department contributed to this way of framing BWV when he stated that, "You're going to hear exactly what he hears and see what he sees" ("Digital Ally", 2015).

In addition to the enthusiasm that many officers have about the opportunity to present footage from their own point-of-view and point-of-hearing, Canadian journalists have also been quick to applaud BWV devices for their ability to chronicle the user's perspective. Specifically, journalists have discussed the utility of footage that records an officer's interaction from their own perspective, as it might record details that would otherwise go unseen by cameras that are external to the interaction. 24 Hours Vancouver 
suggested that, "Body cams provide a cop's-eye view of the engagement with a suspect, such as the response to a drunken street brawl. The footage provides the context missing from the citizen journalist clips" (Knight, November 13, 2013). Additionally, while discussing a video taken by a bystander in Victoria, the Victoria Times Colonist stated that, "Most importantly, the video does not let us see what the police officers were seeing. Which is one more reason why body-worn video cameras should become part of the uniform for every officer on the beat" (March 25, 2010). Each of these statements implies that what the officer is experiencing is different from civilians involved in the interaction.

Although we each experience events differently, framing the adoption of BWV in this way implies that the officer's point-of-view in an instance of misconduct might reveal some kind of justification that the rest of us cannot see. By positioning the officer's experience as something fundamentally different from the bystander's, misconduct can be explained away or justified. It is almost as if actors are implying that if only we could see what the officer saw, we would understand their excessive use of force. In some rare cases this might be true; however, in many of the recent cases of fatal force the existence of BWV footage would not justify its use. This frame is addressed by The Globe and Mail,

What are the pros of putting body cams on police? They're almost limitless. The most important reason is it provides for the first time an unimpeachable view of what the officer actually sees. We've never really come close to having the ability to truly judge what an officer has done except through an officer's narrative and recollection, and eyewitness accounts (Scowen, October 26, 2013).

BWV manufacturers have arguably been the largest proponents of the first person perspective of these devices. These companies are directly marketing to law enforcement 
organizations and have been keen to point out that BWV records the officer's experience - providing footage that can potentially solve issues of public mistrust and negative public opinion. The following screenshot was taken from the Digital Ally website and specifies that the device will "ensure that the camera captures exactly what the officer sees during an incident".
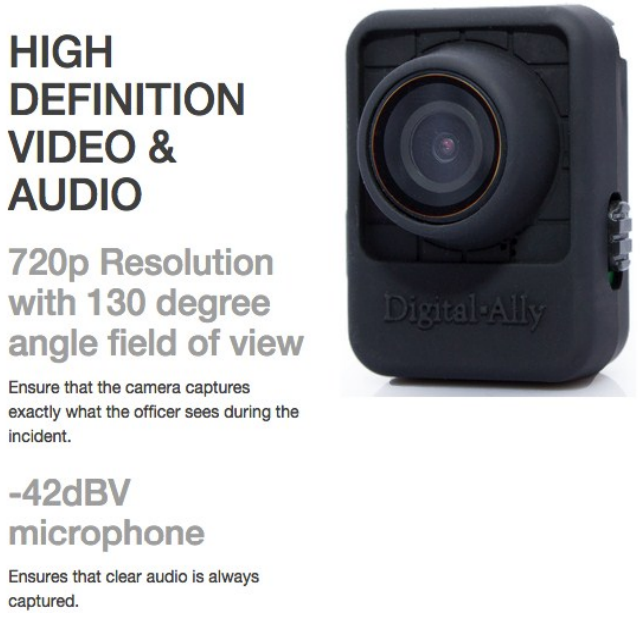

Digital Ally, Inc.”, 2014).

Taking this frame even further, Reveal Media claims that its RS2-X2 was actually designed from the officer's perspective. Positioning the device as being designed from the officer's point-of-view suggests that that is what officers need, a device that documents their perspective. This implies that documenting the officer's perspective is one of the core requirements of BWV, marking its other functions as secondary. Marketing the device in such a way places the officer's perspective at the top of the hierarchy of what BWV is supposed to produce, higher than other functions such as accountability. 


\section{Designed from your perspective}

Every aspect of our body cameras has been designed from the view point of the police officer. To record, just pull the big red sliding switch down. It's easy to operate with gloves and with no need to see it.

The RS2-X2 features a mark as evidence button, which means no interaction is required back at the station to categorize material, officers can do it all on patrol.

The 2.5 " screen allows high quality visual and audio playback without having to return to the station computer to view the material.

("Police Body Worn Cameras", n.d.).

TASER's website also reflects this kind of marketing as it claims that the Axon Flex can best document the officer's point-of-view because it can be repositioned in various ways to better record the officer's perspective. Additionally, TASER specifies that the ability to reposition their camera gives the officer added control over how to deploy it. This suggests that not only should the officer be given a camera that records their own perspective, they should also control what it records. Rhetoric of this kind produces the unintended implication that the cameras are only as objective as the officer, that the officer has the opportunity to decide what is and what is not relevant.

\section{Axon Flex: Adaptive, Point-of-View}

\section{Camera}

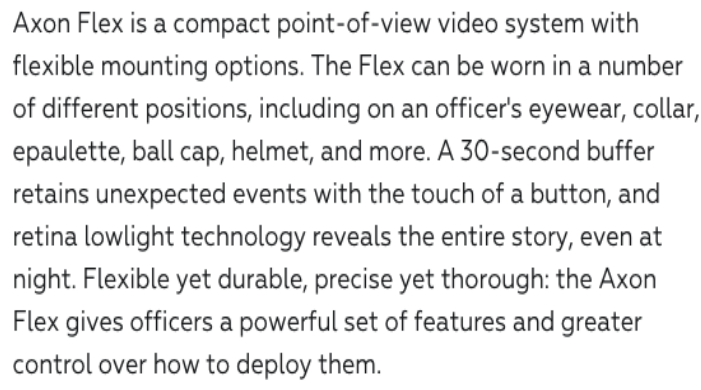

(“TASER", n.d.). 
Interestingly, manufacturers seem to be issuing claims to BWV's ability to recount an event from the officer's point-of-view in two different ways: the first suggests that the device documents what the officer sees, while the second implies it records the officer's experience. The distinction between the ability to document what the officer sees versus their experience of an event is an important one, as claims that the device conveys experience suggest that it will provide a deeper level of understanding with regard to the choices an officer has made: a complete picture. This positions BWV footage as though it were demonstrative footage, described by Feigenson (forthcoming) as, "evidence that can be understood to let jurors know, and not merely know about ..." (p. 2). The implication that the officer's footage will provide insight into their motivation assumes that what we see in alternate footage is incomplete and that through the officer's BWV we will be able to experience the event as it happened. In fact, the screenshot above actually states that TASER's product, 'reveals the entire story'. This is reminiscent of claims discussed in preceding chapters regarding the positioning of officers as truth tellers and citizens as motivated or malicious. Further, this suggests that seeing an event from the officer's perspective will change our perception of it in a way that non-police footage would not.

\subsection{Surveillance with Agency}

The adoption of BWV is inspiring many changes in the field of policing, but perhaps one of the key concerns is the tension between competing agencies: that of the officer and that of the technology. Although it can be argued that all technologies have a particular agency as a result of their design and implementation, BWV radically changes the nature of state surveillance by moving state cameras from the inanimate to bodies with agency. 
This distinction is important, as state cameras transition from indiscriminately documenting whatever they are pointed at to recording whatever the officer chooses. However, what we are seeing as officers actively learn and internalize the capacities of their devices is that BWV has agency of its own - and it is superseding that of the officer, as their mandate now requires that they gather quality footage. As I outline below, officers are wrestling with these technologies, trying to determine how to best use them to produce quality footage to support future legal actions. However, the volatile and mobile nature of the officer's agency gives them the opportunity to leverage the agency embedded in the devices. As a product of BWV's mobility, the officer is able to influence the footage it records - provided they do so within the confines of what the technology will allow. The result is that we see anxiety developing among some officers as they grapple with having to work within the parameters of devices that in many ways turn them into surveilled subjects, another uncomfortable reality in the struggle to limit their visibility within the surveillant assemblage.

Quality footage in this case refers to footage that will pass the necessary barriers to becoming viable evidence. The inspiration to adopt BWV comes from its perceived ability to gather a superior account to the smartphones wielded by onlookers, providing a claim to the truth. If these organizations want to control the narrative (in the event that misconduct occurs and otherwise) then they must be able to provide footage whose official status as evidence verité cannot be undermined. In order to accomplish this, the footage must be unambiguous; it must be shot from good angles, with good lighting and very little background noise, to name a few contributing factors. In other words, BWV's mechanical point-of-view is perceived as superior to the officer's, forcing the officer to 
prioritize the technology. As Feigenson (forthcoming) argues, computer-generated evidence is often perceived as 'inherently free from error' (p. 23). The burden of having to operate within the parameters of the technology in order to collect footage that can be used as proper evidence forces officers to prioritize the agency of the device over their own. The extensive training that officers go through in an attempt to fully embody the technology also serves to train them to submit to their BWV. However, the officer can stake a claim to the aura of the technology by understanding its agency and finding ways to incorporate their own.

The tension between the officer's agency and that of BWV is visible in the findings and interview dialogue outlined in the EPS report. The report makes several references to officers making decisions that fell outside the parameters of their BWV policy. The officers reported breaching policy in various ways, demonstrating an attempt to regain some of their own agency within the scope of what BWV allows. As stated by one EPS officer involved in the pilot, "On the radio strap, when I turned my head to shoulder check it hit my chin or face. Running up stairs (for example) I always knew it was going to hit me, so I really didn't like it. I would put it over my shoulder to get it out of the way" ("Body Worn Video: Considering the Evidence", 2015, p.18). Perpetuating this way of framing BWV, another officer stated that, "It was adequate as I used it. If I'd used it as per policy for every interaction, it would have been completely inadequate. But mostly it is adequate when used with discretion" ("Body Worn Video: Considering the Evidence", 2015, p. 21). Both of these officers are explicitly stating that they breached the EPS pilot protocol in order to use the devices in ways that were more convenient or comfortable for them. 
The most frequent disregard of policy and procedure was related to the EPS guidelines regarding when to activate the camera. The policy outlines that officers should be activating their BWV, "when arriving at the scene of a crime or incident if the camera is not already activated", during traffic stops, or any other situation where the member believes that recording could be beneficial ("Body Worn Video: Considering the Evidence", 2015, p. 222). However, the technological limitations of the BWV battery prompted officers to ignore this policy. As stated in the report, "Members adjusted their camera use to manage limited battery life, making choices about which interactions to record during a shift" ("Body Worn Video: Considering the Evidence”, 2015, p. 22). This demonstrates that officers are not only able to use their agency to decide what to record, but in some cases are forced to do so by the technological limitations themselves. This was echoed by another officer who stated,

As per policy I am not supposed to choose not to use my camera on 'low level' calls. Me saving the battery life so I have a camera that runs for a decent amount of time when I truly need it is technically breaching policy. Own discretion like any other tool we carry and use it at our own discretion would be nice (I do recognize the issues with that though as some would use their 'discretion' to never use the camera) ("Body Worn Video: Considering the Evidence", 2015, p. $82)$.

These statements suggest not only that officers are deciding when to turn their BWV devices on, and subsequently what gets recorded, it underscores claims that BWV is not meant to record their work, but rather events. This is reinforced by their position as evidence collectors and implies that what they are recording is not mundane; it is significant. It is crime.

Of course the officer's use of discretion regarding when and what to record in order to save battery life is an exercise of agency; where this becomes a real concern is in 
statements like, "I made decisions based on whether it would help me later. I didn't record ordinary day-to-day interactions" ("Body Worn Video: Considering the Evidence", 2015, p. 37). This particular officer is articulating that they consciously contemplated whether or not BWV in a certain situation would help them later on. The officer in question is acknowledging something very important: she or he knows that BWV can be deployed in such a way that it either helps or hinders them after an event. This suggests that officers are figuring out how to exercise their own agency within the confines of BWV.

Additionally, some officers have specifically characterized BWV in terms of discretion, with one officer stating that, "On the street, when something happens in front of us, BWV is not the first thought. The SOPs were changed to give more discretion as to when to activate. But what is 'discretion'? To you, to me, to others?" ("Body Worn Video: Considering the Evidence", 2015, p. 37). Although this officer acknowledges that discretion is highly subjective and problematic, the EPS report stated that, "Almost one third of the participants expressed a desire to be able to use BWV at their discretion, and likened BWV to that of other optional EPS tools such as a CEW (Taser) or carbine, both of which require special training" ("Body Worn Video: Considering the Evidence", 2015, p. 49). By suggesting that they should be able to treat BWV with the discretion afforded to them with other tools, officers are attempting to fit these devices into the same category as their stun guns, a resource that is optional rather than mandatory. Based on dominant rhetoric that suggests that BWV provides protection for officers in a context where they argue they are under unwarranted scrutiny, officers should want to embrace these devices. However, almost a third of participants undermine these claims by 
communicating their desire to use BWV at their leisure, suggesting that having to prioritize the device's agency over their own in order to gather usable evidence is unappealing to them. As their own agency must become secondary to that of BWV, officers in many ways become a surveilled subject. Given that these devices represent an attempt to maintain opacity, it is not surprising that feeling like the subjects of the gaze has officers looking for ways out.

The pushback among officers struggling to dominate these new devices is also evident as they verbalize their agency. As one EPS officer so aptly stated, "They can put in the policy as much as they like, but we are all individuals. This BWV was not standard from the day I was a recruit and it takes time to adapt" ("Body Worn Video: Considering the Evidence", 2015, p. 86). This officer is essentially stating that policing institutions can enact as many policies and rules as they would like but they cannot force the officer, in the moment, to follow any of them. Another officer similarly stated that,

On the job we often, technically breach the letter of policy in our day-to-day duty ... I don't ever know every item of the policies and procedures. We feel that we have "Big Brother" looking over our shoulder. It isn't just the user, but also the partner or other member who might not have the BWV on. Now will the video be used for disciplinary purposes? I can articulate the justification for what I do/did, but it is the headache of being called on it ("Body Worn Video: Considering the Evidence", 2015, p. 86).

The reference to 'Big Brother' is worth noting, as it reinforces my claims that the agency embedded in BWV is making officers very aware of their visibility, reinforcing the notion that some officers do not see the camera as an extension of their power, but a limitation to it. Therefore, despite an organizational move toward strategic visibility, individual officers are conveying that they are feeling very visible in their attempt to gather quality footage. This hyperawareness is exacerbated by the lack of control officers 
feel when being forced to operate within the confines of the technological affordances offered by BWV. Goold (2003) found that having interacted with CCTV surveillance some officers were, "acutely aware of how misleading camera footage could be, and of the need for police officers, lawyers, and the courts to become more wary when relying solely on CCTV evidence ..." (p. 196). This awareness is now being articulated by officers using BWV, as the knowledge that they could find themselves the subjects of unwanted scrutiny because their BWV footage is misinterpreted is motivating officers like those quoted above to find ways around the affordances of their devices - and in some cases are completely disregarding policy and protocol to do it. This anxiety suggests that officers equate visibility with vulnerability and are taking steps to learn their devices in order to minimize that vulnerability.

Focusing on the officer's agency, Jocelyn Simonson, assistant professor at Brooklyn Law School, has criticized the level of control that officers have over what to record and what to leave out. Simonson stated that, "The videos are taken from the point of view of police. The videos are in the possession of the state. And there is no guarantee that there is going to be public access to those videos, especially if the political climate doesn't shift" (Miller, October 9, 2015). The potential to leverage BWV to highlight positive officer interactions while opting not to record negative ones is exacerbated by the nature of police culture. The occupational culture in which BWV is being introduced often resists the adoption of new technologies, particularly those meant to monitor officers' actions (Chan 1997; Drover \& Ariel; 2015; Loftus 2009). As a result of the realities of police culture, BWV has been met with resistance by some officers who have used their agency to opt out of using the devices as instructed. As identified in the EPS 
report's suggestions, "Training must address organizational culture to create buy-in from members" ("Body Worn Video: Considering the Evidence", 2015, p. 10). The EPS has acknowledged the nuances of police culture and the need to convince officers to buy into the possibilities offered by the technology - adopting these devices would otherwise be futile in many ways, as officers are able to exert extensive control over the cameras.

The limited criticism of officer discretion with regard to BWV has been voiced predominantly by civil liberties activists. In particular, the Canadian Civil Liberties Association (CCLA) has been vocal about how officer agency undermines the goals of oversight, transparency, and accountability. Groups like the CCLA argue that giving officers the opportunity to decide when to hit record undermines the entire point of adopting BWV. As Abby Deshman, director of the public safety program at the Canadian Civil Liberties Association, has stated "giving individual officers control over what interactions to record, and which to leave offthe[sic] video record, would leave the technology open to abuse and circumvent the goal of impartial and transparent accountability” (Quan, January 9, 2015). As Deshman points out, BWV offers a lot of opportunity for officers to abuse and circumvent the policies and procedures outlined for the use of these devices. In addition, Nathalie Des Rosiers, general counsel with the Canadian Civil Liberties Association suggested that, "An officer could harass someone and then turn the camera on to show the subject acting aggressively or being verbally reactive, which in turn could be used to justify an officer's action" (Stancu, August 3, 2010).

All of the considerations raised by Simonson, Deshman, and Des Rosiers are valid; however, they limit critical discussion by reproducing claims that bad police 
officers will do bad things, a limited critique. The ramifications of adopting BWV are much more complicated, as these devices and the agency they exhibit are producing real, tangible changes to policing. Yes, officers do control when the camera is on and they are able to ignore policy and protocol; however, the monopoly on truth that will shield them from the surveillant gaze is highly dependent on the existence of footage that can be used to support their claims. The incorporation of their agency and the strategic visibility that comes with it can only be achieved through the mastery of the cinematic logic discussed in the next section. The alternative is that the citizen footage they are working so hard to discredit will be left to tell the story. What we see are two modes of agency playing off one another. Therefore, while discussions of agency are critical to a real understanding of how BWV is being integrated into policing, they must be framed in terms of a tension between two competing agencies.

\subsection{Cinematic Logic}

Calgary kept its own pilot project experience mainly private, but based on the experience of 56 Edmonton cops who tested the cameras out between 2011 and 2014, officers forced to act as mobile movie makers aren't always impressed (Platt, June 24, 2015).

This statement published by The Calgary Sun raises one of the most important questions regarding the adoption of BWV video. Arguably the most significant consequence of using BWV as a policing tool is the emergence of what I call a cinematic logic.

Cinematic logic refers to the approach and mentality that officers are developing in order to ensure that they gather the desired footage with their BWV. This logic forces officers to think like their cameras and consider their environments in much the same way a videographer would. The components of this logic include a thorough understanding of the technology, a conscious attempt to leverage factors such as lighting, angles, 
background noise, field-of-view, etc., a recalibration of bodily movement, a commitment to producing footage that will meet the demands of the legal system, and in some cases taking steps to frame footage through practices like narration. Essentially, officers must fully embody the technology and approach their work using the same logic as their cameras, making them the directors of their own BWV films and changing the way officers look. The result is that for better or worse, officers are learning how to construct their footage, and more importantly to construct "better" footage.

The development of this logic is a clear departure from the ways that officers have traditionally approached their work. State surveillance such as CCTV and dashcams were minor considerations for officers responding to calls or out on patrol; however, by placing state cameras on their bodies a minor concern with surveillance has become a major consideration for the technologized officer. These devices are meant to document interactions between police and members of the public; they are meant to record data to be used as evidence. The need to gather visual evidence that might resolve disputes or lead to convictions down the road forces officers wearing BWV to consider their situation in the moment and identify what details will be of value later on, pushing them not only to adopt a cinematic logic but also to look at their surroundings through an evidentiary gaze. The result is that officers must approach their interactions with citizens with a very different mindset when using BWV devices. Here we see the emergence of an interactive panopticism that is disruptive and involves officers modifying their behaviour and submitting to a surveillant gaze in an attempt to control their long-term visibility. 
Although CCTV represents a more minor concern than BWV, traces of what I

refer to as cinematic logic started to emerge as a result of some officers being hyperaware of the presence CCTV surveillance. As stated by Goold (2003),

According to one shift sergeant at town A2, it was essential for officers to make use of the cameras and to incorporate them in their day-to-day thinking when working the town centre "for their own sake as well as for the sake of the community'. As a consequence, during shift briefings he made a point of reminding officers of the presence of CCTV and suggested ways in which they could turn CCTV to their advantage, such as making sure that the camera operators were actually watching and recording an incident before the police arrived so that if trouble developed the tape would help to put the actions of the police in their 'proper' context (p. 195).

The officers involved in Goold's piece exhibit modest signs of a cinematic logic in their acknowledgment that the CCTV camera's gaze needs to be considered in their everyday interactions. Given how removed CCTV cameras are from police bodies, it is not surprising that the need to consider their actions through the eye of the camera is exacerbated by the intimate gaze of BWV.

The shift toward a cinematic logic among officers can be observed in the way that BWV manufacturers discuss their products as well as the way that officer themselves describe their experiences. In addition, many of the features available on BWV devices suggest that officers are meant to review their footage and ensure that they are capturing what they need. The user manuals analysed for this project also make several references to ways that officers can ensure they are getting the "right" shot. The implication that these are considerations that officers should be making underscores the necessity of cinematic logic as second nature when using BWV. The need to mobilize this new logic when reviewing their recordings underscores my claim that officers are constructing evidence that must fit within the parameters of what is admissible in court. The problem 
is that they are constructing it, that the footage they make will hold the privileged position of evidence verité with the assumed truth status that accompanies that.

Much like the implicit suggestions that the injection of human agency into state surveillance will have substantial ramifications, nods to cinematic logic have also been unintentional, appearing subtly in the marketing of BWV and in the discussion of officers' experiences with the devices. The EPS report described the TASER AXON Flex as having, "A Bluetooth link with an MPS player or compatible cell phone provides real time viewing and instant playback" ("Body Worn Video: Considering the Evidence", 2015, p.15). Further, the report suggested that this was a feature that officers were particularly fond of, stating that, "The unit screen provides a real-time view of action being recorded and instant playback, operated by buttons located under the screen. Participants thought this feature potentially useful" ("Body Worn Video: Considering the Evidence", 2015, p. 16). Similarly, the screenshot below outlines Digital Ally's VuVaultGO app, which allows officers to use various functions directly from their smartphones, including a playback function.

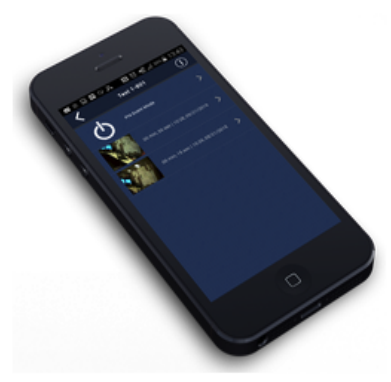

\title{
VUVAULT ${ }^{\mathrm{TM}}$
}

\author{
In the Palm of \\ Every Officer \\ The app allows for full system control \\ incuding the ability to view the video \\ feed, add notes and play back recorded \\ videos. You also have the ability to view \\ the remaining storage space and \\ battery life. VuVaultGOTM allows for \\ secure access to recordings and \\ camera controls, GPS \& event tagging. \\ VuVaultGO ${ }^{\text {TM }}$ is included with every \\ FirstVu HD purchase.
}

(“Digital Ally Inc.”, 2014). 
The officers that participated in the EPS pilot also made several references to the desire or need to review footage. In many cases, these officers found the review functions offered by their devices to be underwhelming, articulating a desire to be able to thoroughly review their footage. If this is the case, then perhaps law enforcement agencies have an expectation that officers gain and implement an understanding of how to gather the best footage. The EPS report stated that, "Sometimes members only reviewed the clips on the camera itself", however, the report also indicated that other officers were using computers to get a better look at their footage. ("Body Worn Video: Considering the Evidence", 2015, p. 29). The desire to review footage in more detail was articulated by one EPS officer who stated that the review process was, "Lot better now we have new computers with better speakers ... The cheap ear buds suck. They cause an echo. But now I make sure to get one of the new computers in the reporting room and the sound on those is much better" ("Body Worn Video: Considering the Evidence", 2015, p. 28). Another officer remarked that, “Regarding use of force: It hasn't changed my using it, but I do think about it afterwards and I would review the footage for those reports so as to increase the quality" ("Body Worn Video: Considering the Evidence", 2015, p. 65). Moreover, it appears that some agencies, including the EPS, specifically want officers to review their footage. The EPS report mentioned that, "We expected that the viewer screen on the front of the RS3 camera would help the participants with review and reporting. But they found the screen images too small to see the detail they needed when reviewing. Also, the playback sound quality on the camera was poor and there was no headphone jack to improve this" ("Body Worn Video: Considering the Evidence", 2015, p. 42). The desire to review footage recorded by BWV was underscored by Staff Sgt. 
Darren Laur of the Victoria Police. Laur coordinated the BWV pilot project in Victoria and stated that, "Eighty per cent of the officers interviewed stated that the video equipment provided them with a more accurate account of what happened, because they could rewind and review it" (Bell, March 25, 2010). The logic that officers should be reviewing their footage as they go positions them as videographers who should be studying their video footage in an effort to learn how to record superior footage in the future. However, this logic has the unintentional consequence of suggesting that officers should be editing their footage. By recommending that officers review their footage and correct any behaviours that might result in inferior recording, actors are prompting officers to practice a kind of soft editing that involves replacing natural actions with methodical and calculated ones.

The EPS post-pilot report outlines that officers who had an understanding of video capacities were kinder in their reviews of the project. This suggests that some knowledge of video technology and the various conditions that can affect footage makes necessary to properly use the devices.

Interview feedback showed that perceptions about BWV audio-visual quality were related to a general understanding of video capacities. Members with some understanding of how different lighting and sound conditions can affect video technology tended to be kinder in their opinions of the footage collected. Other participants had expected the footage to live up to promotional claims ("Body Worn Video: Considering the Evidence", 2015, p. 29).

The implication here is that officers with a pre-existing understanding of video technology had better experiences with the devices, as they were better equipped to exert their own agency within the framework of what the devices allow. Extending this, it is reasonable to infer that those with an understanding of the technology were able to identify environmental factors that would produce poor footage and were better equipped 
to compensate for lighting and sound conditions. These officers have, to some extent, already trained in the cinematic logic and are able apply it when using their BWV.

EPS officers also reported several conditions that impacted the footage that they were able to record, demonstrating that these officers were conscious of the ways that their footage is impacted by environmental factors. Again, officers would not have traditionally had to consider such factors; however, with the addition of BWV to their policing tools they must learn to find methods of counteracting conditions that might impede their ability to get quality footage. One officer reported that, "On the Avenue there is enough light at night and the BWV performs well. In darker street settings I sometimes have used the flashlight, which works well. In a dark night club there is not enough light, but that's just what it is" ("Body Worn Video: Considering the Evidence", 2015, p. 28). Another officer similarly stated that, "Orange street fluorescent is particularly bad for video clarity. Audio is terrible. I thought the audio was the worst feature. I heard myself perfectly but not anyone else. Very difficult when there was a background noise" ("Body Worn Video: Considering the Evidence”, 2015, p. 28). Further, the report includes one officer's statement that, "There is no light inside the wagon and the street light doesn't get in. Once the person is in the wagon they disappear from the video. But we do have the audio and short of a light on the camera, it's not going to be perfect" ("Body Worn Video: Considering the Evidence”, 2015, p. 28). A fourth officer reinforced these statements, "You can't hear with a lot of ambient noise, like at the Greyhound station, when a person is mumbling" ("Body Worn Video: Considering the Evidence", 2015, p. 28). 
These statements demonstrate the countless factors that can affect the officer's ability to produce quality footage; however, what is more is that the officers have had to consider these factors, something that would have previously been outside of the scope of police work. The redefinition of police work that accompanies the adoption of BWV has been almost entirely overlooked by every actor involved in the discussion of BWV. Limiting the scope of conversation to exclude considerations of the cinematic logic necessary to "properly" utilize BWV is impactful, as any suggestion that the footage can be manipulated would undermine all notions of objectivity and accountability. By framing BWV in such a way that closes down this line of critique, the actors involved in constructing the conversation are able to push the adoption of these devices with little opposition. Moreover, it has been suggested in the preceding chapters that part of the appeal of BWV is that it presents the officer's morally superior point-of-view meaning that any discussion of the agency or videography involved in using BWV would erode the attempts being made to ensure that the officer's footage is automatically privileged on the grounds that it is superior to the citizen's. Essentially, the war on visibility being waged by police officers is highly contingent on positioning BWV as non-threatening, making it crucial that the conversation avoids any explicit acknowledgement of the cinematic logic required for effective BWV use.

Going forward as BWV becomes increasingly popular in policing, the expectation that officers will provide footage of a certain standard will become important, forcing them to understand factors that contribute to poor recording conditions and devise strategies to compensate. Perhaps the most blatant display of cinematic logic, officers have acknowledged that they must make various modifications to their approach in order 
to gather quality footage. "No complaints about the quality of the video especially when I had time to aim the camera. It had the image I wanted and really good sound" ("Body Worn Video: Considering the Evidence", 2015, p. 28). It is interesting to consider the officers' references to getting the footage that they want rather than the footage that is necessary, accurate, or appropriate. Although a semantic detail, this might be suggestive of officers' desire to record the footage that they feel will vindicate them should they face scrutiny. The implication that officers seek to protect themselves with BWV footage reinforces my claim that these devices are being adopted as an attempt to secure a privileged position within the assemblage from which police organizations can maintain strategic visibility.

Adding to the cinematic logic being developed by officers using BWV, the EPS report also makes references to the potential that officers should be narrating their experience to some degree in order to ensure that the footage is clear to those who are watching it after-the-fact, almost as if they are producing a documentary. The following statements from the EPS demonstrate that these organizations have not only acknowledged the possibility that officers will narrate their experiences to some extent, in some instances they have included the need for some degree of narration in their BWV policies. The "Operational Procedures for BWV Employment" section of the EPS report outlines the following policy guidelines,

(1) Upon activating the recording, providing it is safe to do so, members shall verbally state the date, time, location, nature of the incident, and to those present that the incident is being recorded.

(2) While the recording is activated, members should, whenever possible, continue to state for the recording elements of the situation that may not be readily visible (such as activity on the peripheral of the incident; smells such as alcohol or drugs) ("Body Worn Video: Considering the Evidence", 2015, p. 222). 
Underscoring this desire for narration, in its discussion of the devices' ability to account for context, the report stated that, "A key factor was whether the EPS member making the recording voiced an explanation of what was happening during live action" ("Body Worn Video: Considering the Evidence", 2015, p.31). This suggests not only that officers were, in some cases, narrating their experience the EPS found this to be beneficial, pointing to an institutional push to adopt the role of videographer. Further, the Calgary Police have created a policy that outlines the expectation that, "If they want to turn off the camera, they will first have to speak into the camera and explain why" (Quan, January 9, 2015). The EPS policy stipulates a similar expectation and states, "The decision to deactivate ... can be done by stating the reason for deactivation prior to ending the recording ..." ("Body Worn Video: Considering the Evidence", 2015, p. 223).

Furthering the suggestion that officers should be narrating their footage in one capacity or another, the EPS report stated that, "The ability to determine date and time was another factor. As long as the date and time on the RS3 camera was correct, this was clear. But if the date and time were incorrect, the footage would be unusable for evidence unless the member had voiced the date and time during the recording" ("Body Worn Video: Considering the Evidence", 2015, p. 31). The suggestion that officers should be narrating their footage is an acknowledgement that these devices and the footage that they record do not necessarily speak for themselves, but are rather subjective and malleable accounts of an event. Narration underscores the perspective of the officer and considering that BWV footage already privileges the officer's point-of-view, narration could emphasize this bias while simultaneously rendering it invisible to the viewer. BWV footage tells a particular story, it provides a narrative like many other kinds of evidence; 
however, what is problematic is that it is not being recognized for the narrative that it is. We are pretending it is not a narrative and instead framing it as reality. This disregard for the narrative nature of BWV footage is visible as the biases outlined above are neglected in the dominant discourse. The reason for this neglect is that suggestions of bias undermine the truth-claims that are being attached to BWV. Despite arguments of technological neutrality, we are seeing a tension as these devices are both hailed as objective and marketed as providing point-of-view.

Adding to concerns that the officer's perspective will be overemphasized, some BWV devices offer additional features that allow the user to customize their recordings. The RS3-SX used by the EPS offers the user countless options for editing and customizing factors such as resolution and white balance that will affect the look of footage. Further, these terms are specific to photography and videography implying that officers using BWV not only need to learn to leverage the technology's capabilities but they must also learn the corresponding language. The table below outlines the customizable options offered by the RS3-SX. 


\section{Editable menu settings}

\begin{tabular}{|c|c|}
\hline \multirow[t]{5}{*}{ 1.RESOLUTION } & $1920 \times 1080$ 30FPS \\
\hline & $1440 \times 1080$ 30FPS \\
\hline & $1280 \times 72030$ FPS (Default) \\
\hline & $848 \times 48030 F P S$ \\
\hline & $640 \times 48030 F P S$ \\
\hline \multirow{2}{*}{$\begin{array}{l}\text { 2. PRE-RECORDING } \\
\text { Stores } 30 \text { seconds prior } \\
\text { to record activation. }\end{array}$} & ON \\
\hline & OFF (DEFAULT) \\
\hline \multirow[t]{2}{*}{ 3.AUDIO ALARMS } & ON (DEFAULT) \\
\hline & OFF \\
\hline \multirow[t]{2}{*}{ 4. WHITE BALANCE } & AUTO (DEFAULT) \\
\hline & $\begin{array}{l}\text { SUNNY / CLOUDY / } \\
\text { FLUORESCENT/INCANDESCENT }\end{array}$ \\
\hline 5. LANGUAGE & ENGLISH (DEFAULT) \\
\hline \multirow{2}{*}{$\begin{array}{l}\text { 6. TIME AND DATE } \\
\text { STAMP }\end{array}$} & ON (DEFAULT) \\
\hline & OFF \\
\hline $\begin{array}{l}\text { 7. TIME AND DATE } \\
\text { SETUP }\end{array}$ & $\underset{\mathrm{SET}}{\mathrm{HR} / \mathrm{MIN} / \mathrm{SEC}}$ \\
\hline \multirow{2}{*}{$\begin{array}{l}\text { 8.START IN } \\
\text { STEALTH MODE }\end{array}$} & ON \\
\hline & OFF (DEFAULT) \\
\hline
\end{tabular}

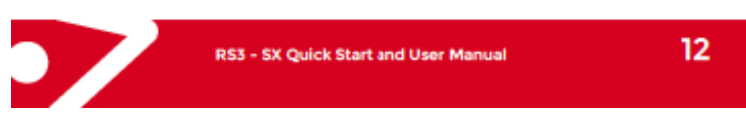

(“Quick Start User Manual”, n.d.).

The following chart details the EPS assessment of both the RS3-SX and the AXON Flex.

Note that many of the considerations reflect very cinematic considerations such as "focus on distant subject/object". This reinforces the claim that officers will not only have to learn to leverage the capacities of these devices, they will also be required to internalize the language of the camera. 
Table 3: Video Quality Mean Scores

\begin{tabular}{|c|c|c|}
\hline \multirow[t]{2}{*}{ VIDEO RATING CRITERIA } & \multicolumn{2}{|c|}{$\begin{array}{c}\text { MEAN RATING } \\
\text { (Total 5: 1. Unusable; 2. Poor; 3. Fair; 4. Good; } 5 . \\
\text { Excellent) }\end{array}$} \\
\hline & $\begin{array}{c}\text { RS3 SX } \\
N=107\end{array}$ & $\begin{array}{l}\text { FLEX }^{31} \\
N=39\end{array}$ \\
\hline Field of view - horizontal & 3.17 & 3.81 \\
\hline Field of view - vertical & 3.08 & 3.76 \\
\hline Clarity of image daylight good light & 4.25 & N/A \\
\hline Clarity of image daylight poor light & 3.45 & $\mathrm{~N} / \mathrm{A}$ \\
\hline Clarity of image night time good light & 3.71 & N/A \\
\hline Clarity of image night time poor light & 2.38 & N/A \\
\hline Clarity of image indoors good light & N/A & 3.62 \\
\hline Clarity of image indoors poor light & N/A & 2.75 \\
\hline Clarity of image outdoors good light & N/A & 3.58 \\
\hline Colour definition/accuracy & 3.26 & 3.48 \\
\hline Focus on distant subject/object & 3.22 & 3.62 \\
\hline Focus on close subject/object & 3.70 & 3.64 \\
\hline Stability during movement & 3.60 & 4.08 \\
\hline Clarity of sound quiet setting & 4.60 & 3.72 \\
\hline Clarity of sound noisy setting & 3.76 & 3.25 \\
\hline Clarity of sound close up & 4.65 & 3.96 \\
\hline Clarity of sound at a distance & 3.54 & 2.95 \\
\hline Ability to distinguish multiple speakers/other noises & 4.33 & 3.83 \\
\hline Ability to determine date and time & 3.86 & $\mathrm{~N} / \mathrm{A}$ \\
\hline Ability to determine overall context of incident & 3.85 & $\mathrm{~N} / \mathrm{A}$ \\
\hline Use of force incident & 3.20 & 3.40 \\
\hline Overall Score (mean of the means) & 3.64 & 3.56 \\
\hline
\end{tabular}

("Body Worn Video: Considering the Evidence", 2015, p. 30).

One of the main considerations that the EPS pilot took into account is the RS3-

SX's field-of-view. Field-of-view refers to the scope of what the camera can see in a given position - an incredibly important consideration for officers who are using BWV.

Understanding the field-of-view of their device means understanding what they are capturing and what they are not. As officers become increasingly responsible for ensuring that "useful" footage is recorded, their understanding of the scope of the device's fieldof-view becomes paramount. Officers must be aware of what their cameras are recording 
and what is falling outside of the BWV's field-of-view and be able to readjust themselves accordingly in order to ensure that nothing is left out: a false ideal. As the report states,

The field-of-view ratings considered how well the camera captured the horizontal and vertical space around the action. The focus ratings assessed how well the member using the camera captured the details relevant to the incident. We also rated stability as one of the five criteria for focus ("Body Worn Video:

Considering the Evidence", 2015, p. 31).

Further, the report's analysis specifies that the device's field-of-view is largely dependant on factors such as the height of the officer, the height of the subject, and their proximity to each other. Regarding issues with the RS3-SX's field-of-view capabilities the EPS stated that, "Limitations of the vertical field of view, which were affected by the height of the subject of focus, especially when in close proximity" ("Body Worn Video:

Considering the Evidence", 2015, p. 31). In addition, the field-of-view can be a hindrance when certain police tactics are taken into account. The result is that even if the BWV has a decent field-of-view from a technical perspective it may still fall short given the realities of police work. The report also claimed that, "The position of the member relative to the subject of focus. The tactic of 'blading' (standing side-on to a subject) meant the body-mounted camera was often pointing away from the subject" ("Body Worn Video: Considering the Evidence", 2015, p. 32).

The field-of-view issues experienced by the EPS are not specific to the particular device that it chose to use; they are issues that will persist regardless of the BWV product. It can certainly be generalized that all officers using BWV will encounter issues of camera placement, height differences, and difficulty capturing footage while engaging in tactics like blading. As a result, in order to properly use BWV technology technology officers must be aware of the ways that their camera's field-of-view can be compromised 
and be knowledgeable enough to compensate by changing their position relative to the scene. This becomes particularly problematic when their cinematic logic starts to trump preferred techniques of law enforcement, such as the practice of blading described above. Blading is a well-established tactic that becomes very difficult, if not impossible, when an officer is expected to gather visual evidence with their BWV.

Indications that officers will need to develop a cinematic logic in order to properly use their BWV devices are also prevalent in the AXON body ${ }^{\mathrm{TM}}$, Prima Facie, and RS3-SX user manuals. The following are functions and instructions offered by these manufacturers that underscore the need for officers to approach their work from the perspective of a videographer; taking into account all of the subtleties that can impact the footage that they record. As outlined in the AXON body ${ }^{\mathrm{TM}}$ User Manual (2013), "When you're wearing the camera, you can use the AXON Mobile application's live streaming feature to determine whether your camera is capturing the view you intended" (p. 7). This suggests that officers should be focusing their cameras on what they desire rather than documenting indiscriminately and with an attempt at inclusivity.

BWV manufacturers are also pointing to the logic that must be developed by officers in order to ensure that they are recording what they intend to. The need to adopt a cinematic logic is clear across manufacturers but has been emphasized by some more than others. For instance, the Prima Facie has several functions that allow officers to act as videographers - camera snapshot button, LCD/Stealth mode button, playback button, audio record button (Prima Facie User Guide, 2012, p. 6). The snapshot function is worth noting as it suggests that officers might want to isolate a specific detail to review later. This function has the potential to be a great asset for officers but it also gives the officer a 
level of control over what details are singled out for further inspection. This reinforces the need for officers to think about what details will need further review - allowing them to construct the event in a particular way by highlighting certain aspects while ignoring others. The result is that officers are able to construct how an event will be perceived by those who view their BWV footage after the fact. It is worth noting that the RS3-SX's manual also acknowledges the important role that camera angles play in collecting video footage. In its description of the camera's head mount option the RS3-SX manual states that, "for use when a higher view point is advantageous (optional extra)" ("Quick Start User Manual”, p.18). Not only does this particular manual touch on the need to change vantage points depending on various factors, the manufacturer also charges additional money for the option to do so - putting the option to change the position of the camera financially out of reach for many departments that are already struggling to roll out expensive BWV pilot programs. The opportunity to gain access to these additional vantage points at a cost is tied to futuristic claims that officers can always be better, more advanced, further extended.

Additionally, the Reveal Media website specifically highlights that their products provide the option of adjusting the camera in order to change the angle from which the officer is recording. The screenshot below explicitly markets the RS2-S2 as offering solutions to issues of height, uniform, etc. suggesting that this product will give the officer the best opportunity to "capture the right images". 


\section{Capture the right images}

The RS2-X2 body camera features a fully articulated camera head which allows accurate positioning of the lens regardless of height, shape, size or uniform. This flexibility goes beyond what simply a wide camera angle camera can offer, allowing for a range of additional uses including professional in-vehicle, table top and handheld recorders.

("Police Body Worn Cameras", n.d.).

Although there are countless new considerations of which officers must be conscious as they approach their work using BWV, the imprecise nature of video technology also offers the opportunity for them to manipulate their footage. As outlined in this section, there are many ways that subjectivity can be infused into BWV footage as a result of technical realities and imperfect conditions; however, there are also many ways in which these devices can be positioned and used to purposely highlight certain things and downplay - or exclude - others. These opportunities to infuse subjectivity into their footage further undermine claims of technological neutrality by suggesting that officers do some soft editing by learning from their footage and doing 'better' next time. The lack of attention paid to the cinematic logic being adopted by officers results from the need to preserve the superior claims to truth that have been attached to BWV. If the actors involved were to acknowledge that this logic is worth consideration, they would be undermining the supposed objectivity and neutrality of the devices eroding their monopoly on truth and undermining their attempts to remain invisible. 


\subsection{Collectors of Visual Evidence}

Whether the argument is that BWV will vindicate officers, provide oversight and accountability or facilitate the legal process, it is clear that BWV footage will be used as evidence to one degree or another. In some instances, the footage might serve as evidence to claim that the officer was justified in her or his use of force and in others it might serve as an evidentiary aid in a criminal case against an offender. Regardless of what BWV footage is being used to corroborate, it will be used to corroborate something or else the adoption of BWV would be a pointless endeavour. In order for BWV footage to be used in the various intended ways, the officer must record footage in the first place and it must be of good enough quality to withstand evidentiary standards and cross-examination. The footage must depict the details necessary to establish what occurred; making it essential that officers have a proper understanding of not only policy and procedure but also the technical aspects of their devices. In other words, officers using BWV are asked to internalize an evidentiary gaze; they must collect visual evidence as they go, keeping in mind all the details that might be of potential interest going forward. This is no small task. Officers often walk into unpredictable situations - domestic abuse, robberies, and drug busts to name a few. These situations are frequently fast-paced and can devolve quickly, making the addition of determining and documenting the appropriate visual information a large burden to place on officers.

The dominant public discourse has overwhelmingly positioned officers not as collectors of information, but as collectors of evidence. BWV is routinely discussed in terms of evidence rather than footage; despite the fact that footage must go through several steps before becoming evidence the implication is that there is a truth apparatus 
that has already vetted BWV footage. This implication works to support superior claims to truth and is directly in line with claims that evidence verité produced by state actors often becomes privileged (Silbey, 2010). Further, suggesting that officers are 'capturing' truth implies that a crime has been committed, reinforcing the fact that BWV is not there to document officers' work, it is there to document events: crimes. As stated in the EPS report, "The project findings on the use of BWV to inform reports shed light on this technology's potential as a tool for improving report content and evidentiary value. At a minimum, using BWV for this purpose will represent a shift in reporting expectations and adjustments to current processes. Members will also have to be re-trained to help them best understand how to use BWV in support of their notes" ("Body Worn Video: Considering the Evidence”, 2015, p.42). Echoing BWV's potential for evidence collection, Staff Sgt. Darren Laur of the Victoria Police stated that, "There was no doubt that this technology provided the best evidence possible" (Bell, March 25, 2010). Deputy Chief of the EPS, Danielle Campbell, has also stated that, "Those units are responding to calls where they're going to find people committing an offence. And so the value of collecting that evidence when they find people committing the offence will be hugely beneficial legally for the court system" (Ellwand, June 24, 2015). It is worth noting that the claims made by Laur and Campbell convey certainty and optimism with regard to BWV's ability to gather the 'best' possible evidence. In contrast, the EPS report, which documents officers' first-hand experience with the devices, is much more reserved in its claims.

The framing of BWV in this manner has been perpetuated by manufacturers who address officers as evidence collectors and are marketing the devices on the basis of their 
perceived ability to provide useful visual evidence. The screenshot below suggests that the rate of guilty pleas skyrockets when BWV is involved.

\section{Incorporate Video and Get to the Truth}

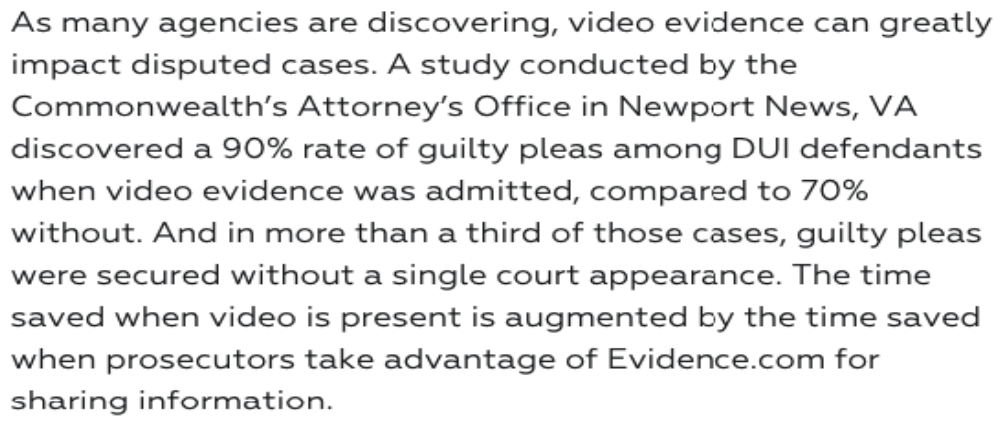

(“TASER”, n.d.).

When discussing the evidentiary potential of BWV footage, officers and other actors have been quick to praise the possibility that this footage will have a very positive impact on legal proceedings. The assumption is that the footage recorded by an officer's BWV will provide usable evidence that will help with convictions. However, as stated in the EPS report, the footage documented by these devices often undermines convictions as a result of the limitations of video and audio recording technologies,

In some instances, a possible detrimental effect on the prosecution's case. A member reported that a case didn't proceed because the prosecutor didn't think the subject looked very drunk in the video. The member stated, 'My notes recorded that the subject smelled of alcohol as well as the original driving reasons for the stop.' In another case, two members reported a charge dropped because of possible negative impact from the BWV evidence ("Body Worn Video: Considering the Evidence", 2015, p. 79).

What is particularly interesting here is that the officer's notes were superseded by the BWV footage that seemed to tell a different story. Traditionally, the officer's notes have served as a way of documenting their interactions with the public, making the prioritizing of BWV footage over the officer's testimony a catalyst for the desirability of the 
cinematic logic. Unlike the officer's notes, BWV will be considered actual evidence, not just the basis for the officer's testimony, forcing officers to infuse their interpretation into the footage they record in order to ensure that their experience is considered in the event that their notes are ignored. In the example described above, the officer might be motivated to find ways to document the subject's drunkenness in order to ensure that this fact is not undermined in court resulting in a dismissal. In order to make sure that their experience and subsequent interpretation of a situation is taken into account, officers might be forced to leverage BWV technology to produce their interpretation mechanically. The result would be officers that have to interpret the situation in the moment rather than upon reflection afterward; potentially having very serious impacts as their interpretation goes from one rooted in hindsight to one made hastily in the moment, trying to bring the future into the present.

\subsection{Officer Anxiety}

As demonstrated in the preceding sections, we can already see that the way officers need to approach their jobs using BWV is rather different from their traditional practices. As officers continue to adopt the cinematic logic necessary to properly utilize their devices, their work is changing, as the need to get the right shot becomes increasingly a concern. One of the by-products emerging as a result of this cinematic logic is an anxiety among officers who have become acutely aware that the footage they gather can have a profound impact on themselves, their colleagues, offenders, and the public.

One of the most frequent concerns raised by EPS officers that participated in the pilot program centred around an anxiety of having to justify what they chose to record or chose not to record. This anxiety was partially a result of difficulties determining when to 
turn the camera on; however, officers were also concerned that they would be forced to justify why they recorded what they chose to record. This suggests that officers are aware that it is not enough to just turn the device on and allow it to record, they must ensure that what they record is useful and complete. As one EPS officer stated,

I'd hate to have to try and explain why I recorded anything but what the focus should be. My notes are much better. Otherwise it just leads to questions. For example, the lack of audio on CCTV can/is used against us in court. Defence will point us talking and say that is where we said things we did not. The attitude of the courts to members is an issue. The thinking is that BWV is there because the member is not trusted, so if it is not perfect they will blame the member ("Body Worn Video: Considering the Evidence", 2015, p. 78).

The officer's claim that their analog notes are superior to the BWV's digital ones offers an interesting competition between old and new technologies; in turn, the officer's anxiety can in part be considered a typical reaction to the onset of new technology. Outlining the experience of EPS officers involved in the pilot, the report recounts that, "They faced the dilemma between having to explain why they didn't turn their camera on at all, or having to explain why they turned it on late and captured only part of the event" ("Body Worn Video: Considering the Evidence", 2015, p. 38). The potential of having to justify what they record and what they do not has been a recurring anxiety among officers and suggests that they are very aware that the absence of video footage could be a misstep worthy of reprimand.

In addition, officers are also reporting a level of anxiety that the footage their BWV documents will not accurately reflect their actions. Officers in the EPS pilot reported being concerned that they would act appropriately but that their actions would come across as wrong to someone watching the video after an event has taken place. As described by one EPS officer, "I don't think that I am doing anything wrong but what if 
someone watching the video thinks I am?” (“Body Worn Video: Considering the Evidence", 2015, p. 47). Going further, another officer suggested that, "Even if the cameras are on we hold back if someone else used force because of fear of it being used against us" ("Body Worn Video: Considering the Evidence”, 2015, p. 65). The report actually indicated that, “... 18\% expressed a lack of confidence in how their actions might be judged by others" ("Body Worn Video: Considering the Evidence”, 2015, p. 46). Almost a fifth of officers expressed anxiety at the thought of being judged based on their BWV footage.

Much like the fear of having to justify one's choice to record, the fear of misrepresentation in video also suggests that officers are hyperaware that they must get the right shot, not just any shot. Perhaps this anxiety also suggests a latent acknowledgement of the devices' subjectivity, further undermining truth-claims. In fact, the discourse produced by individual officers serves to reframe the devices as subjective and open to audience interpretation. Unsurprisingly, the officer's experience has been largely left out of the discussion, as it, too, would challenge BWV's status as a technology of truth.

Finally, officers have reported being concerned that the culturally appropriate ways that they interact with various groups will be misconstrued on camera. As these officers have pointed out, BWV does not necessarily account for ongoing context, as it can only document what happens once the officer hits record. As a result, much of the context that establishes the kind of social setting that the officer is engaging with will not be well represented in BWV footage. There is a potential that this lack of context will make officers look bad if the footage is presented without explanation. For example, as 
some of the officers below have expressed, it is sometimes culturally appropriate to use foul or aggressive language when dealing with certain groups of people. The use of such language allows the officer to establish a rapport with members of certain communities; however, taken out of context this type of language would suggest that an officer is being disrespectful, unprofessional or unnecessarily aggressive. As one EPS officer mentioned, "We have a beat member rapport with street involved people. So we may interact in a culturally appropriate way. Language is a big concern. An interaction viewed as an isolated event could be misinterpreted without the wider, ongoing context" ("Body Worn Video: Considering the Evidence", 2015, p.39). Mirroring this fear, another officer expressed that, "If I forget about the BWV and swear or am more aggressive in my attitude it concerns me afterwards" ("Body Worn Video: Considering the Evidence", 2015, p. 47).

It is interesting that the audio component seems to be a site for officer anxiety considering the devices' capacity to record conversation has been downplayed in the dominant discourse. It is worth noting that despite underrepresentation of the audio component in the discourse, BWV's ability to record audio is perhaps less problematic than visual considerations, as the audio is not as limited in scope as the camera. It is quite possible that conversation going on outside of the field-of-view will be picked up despite having no visual record due to camera limitations. As stated by another EPS officer, "But those around it more, it's not such a big deal now. There's video out there all the time, but the BWV has audio and that can be an issue" ("Body Worn Video: Considering the Evidence", 2015, p. 48). This suggests that in some cases officers are actually more concerned with BWV picking up their conversations than they are about how the footage 
will look. This neglect stems partially from our ocularcentrism but also speaks to the fact that these devices are being framed as a solution to problems of visibility - a problem of image in both senses - and as such, the visual capacities have overshadowed any consideration of how audio fits into the picture.

Some of the anxieties outlined by officers using BWV will have little impact on their effectiveness as police; however, officers have reported some startling new realities that result from the use of BWV and which demand attention. Specifically, some officers have found that the presence of BWV negatively impacts their ability to conduct some very important aspects of policing - namely the legitimate use of force. As discussed in the EPS report that, "members' experiences that BWV presence can cause them to hesitate to use force are worth noting" ("Body Worn Video: Considering the Evidence", 2015 , p. 66). There are situations in which officers must legitimately use force in order to protect themselves or others and the inability to do so could potential cause undue harm. Although BWV is being adopted in many cases as a means of oversight to ensure that officers do not use excessive force, it is important that they are not put in a position where they feel uncomfortable using legitimate force. Similarly, officers have reported that although, BWV in many cases increased professionalism, this was offset by, "hesitation and fear of judgment" ("Body Worn Video: Considering the Evidence”, 2015, p. 7). Therefore, it is not only that officers are anxious; they are hesitating to use the level force that might be necessary in a given situation because they are afraid that it will be seen as excessive when the BWV footage is reviewed.

In addition to reframing BWV as subjective, accounts of the officers' experiences have also undermined characterizations of BWV as nonintrusive and as a police aid. In 
fact, officer feedback suggests that these devices might actually hinder their ability to do their job. By avoiding discussions of how officers are experiencing the devices, actors involved in the discussion are maintaining the dominant discourse: protecting truthclaims. The lack of attention being paid to the development of anxiety among officers being fitted with BWV suggests that those involved in constructing the discussion, specifically the Canadian news media, police organizations, and BWV manufacturers, will protect the parameters of the dominant discourse even if that means officers are hesitating to use the force necessary to protect themselves and the public. As stated in the EPS report,

Pilot participants agreed that it was easy to start recording with the RS3 camera, but in volatile situations it was still one more action to consider during fastbreaking events. The project coordinator observed one such incident during a prepilot walk-along in the downtown area. A member was forced to quickly grab the arm of a man who was readying to throw a punch at another man. The member had restrained the subject by the time her partner took three strides to assist her. The subject did not resist and thanks to her quick reaction, the member prevented an assault. The coordinator noted that "had the member even though for a second about turning on a camera the punch would have been thrown" ("Body Worn Video: Considering the Evidence", 2015, p. 38).

This situation is not unusual in the context of police work and the acknowledgment that using BWV would have risked escalation in a precarious situation demonstrates exactly why it is necessary that those involved in the discussion of BWV consider the existence of anxiety induced hesitation among officers. While failing to stop a punch is significant, there are even more dangerous situations in which an officer's hesitation would be dire. However, if actors were to acknowledge these risks, they would be admitting that BWV is not self-evident. 


\subsection{Conclusion}

The privileging of the officer's point-of-view has contributed to a situation in which the officer's experience becomes official, giving them the opportunity to manage what is seen and what is not. However, this control is limited by the affordances of the device. The result is that officers must prioritize the device's agency over their own in order to produce the quality of footage necessary to maintain their monopoly on truth. In order to cope with this tension in agency, officers must develop a cinematic logic that involves approaching their work like videographers; they must learn to interpret situations in the moment, as opposed to after the fact. These considerations are exacerbated by the characterization of officers as evidence collectors, suggesting that their BWV footage is automatically vetted and ready to go to court. These factors fundamentally change the

nature of police work, by requiring that officers become the directors of their footage and that they are effective enough at leveraging the technology that they are able to construct the event using their BWV.

As BWV forces officers to become the camera, illusions of objectivity and moral superiority that underpin the dominant discourse surrounding the adoption of these devices as policing tools are eroded. This is reinforced by the emergence of officer anxiety that stems from the fear that footage will not accurately depict a situation. All of these considerations are being neglected by the dominant discourse, as they undermine the necessary conditions to maintain a monopoly on truth and, subsequently, managed visibility. By ignoring issues of subjectivity, bias, manipulation, affordances, and logics actors are able to roll out BWV as a solution to misconduct and excessive force despite realities of subjectivity. By becoming the camera individual officers develop a 
hyperawareness of their visibility; however, the emergence of a cinematic logic allows them to use the device's agency to their advantage. The result is a tension between police organizations and officers that are working to remain largely invisible and a surveillant apparatus that wishes to expose them. By fully embodying the camera, officers are able to re-exert their agency, subsequently giving police organizations back some of the control they have lost during their incorporation into the assemblage. However, this may come at the expense of the officers'.

As I have suggested throughout this project, the adoption of BWV by police organizations as an attempt to concentrate the surveillant gaze where they want it inspires us to reconsider our initial conceptions of the assemblage. Although it is clear that these devices and the environment they create are not entirely panoptic, the surveillant assemblage also falls short as an heuristic. These devices clearly inspire a level of panopticism; however, that panopticism is much more controlled and interactive than previously conceived, as officers modify their behaviour and submit to the gaze while managing what it sees. On the other hand, there is clearly an assemblage at work, as previously discrete surveillance systems become increasingly interwoven. However, unlike original conceptions of the surveillant assemblage, hierarchies of visibility are not really levelling - in this case they are reinforced by police organizations that are using the lack of centralized power within the assemblage to maintain opacity. The result is that BWV necessitates a new conception of the assemblage, one that folds in an active panopticism. 


\section{A Future with BWV: Conclusion}

In many ways, this project has been an attempt to establish how BWV is reshaping our understanding and expectations of what police are and what they do. The ubiquity of smartphones with recording capabilities means that each of us now plays a role in establishing the parameters of the surveillant assemblage, changing its boundaries and bringing previously exempt groups into the fold. As representatives of the state's authority, police have largely remained invisible, able to manage public perceptions and scrutiny. However, our smartphones coupled with platforms that facilitate viral circulation have meant that police organizations are experiencing heightened visibility with limited control over narratives that shape the public's perception of police. Despite attempts to force the removal of videos depicting their encounters, police organizations had been largely unsuccessful in the war on visibility. However, by embracing their own cameras, police are able establish a privileged position within the assemblage that allows them to manage their visibility strategically. That being said, the opportunity to manage their visibility is dependent on their ability to construct footage that passes as superior or 'official'. In order to do this, officers sporting BWV must master their devices, adopting the cinematic logic necessary to construct quality footage.

The dominant discourse in the Canadian press, police discussions, and marketing material alike, has tended to paint the adoption of BWV in terms of a seamless transition toward better policing and a more complete truth. However, the reality of BWV is much messier as officers struggle to learn their devices and internalize the logic of their cameras. A recent interactive article published by the New York Times attempts to demonstrate the complicated reality of these devices by having the reader interpret BWV 
footage and then contrasting it with external footage taken from a different perspective. The article, titled "Police Body Cameras: What do you see?" walks the reader through three scenarios providing them with BWV footage followed by footage taken by bystanders. The first scenario begins with footage recorded by a BWV device mounted to the "officer's" chest. ${ }^{7}$ The footage is shaky and the "citizen's" rapid movement toward the "officer" comes across as aggressive. The video clip is followed by two questions: How threatening was the situation the officer faced? And how confident are you in your answer? (Williams, Thomas, Jacoby \& Cave, 2016). As of April 3, 2016 a combined total of $73 \%$ of readers considered the situation at least somewhat threatening and $66 \%$ were somewhat to very confident in their answer (Williams et al., 2016). This clip is followed by one taken by a bystander - offering an entirely different perspective on the encounter. The external footage shows that the "officer" and the "citizen" were actually jumping and dancing playfully in proximity to one another - which explains the rapid, aggressive looking movement that suggested the "citizen" was coming at the "officer". The intent here was to highlight that when it comes to BWV, what often seems straightforward can easily be misinterpreted, in some cases quite drastically.

Although the point of these videos is to undermine the truth-claims attached to BWV and establish their technical limitations, it also works to illustrate how difficult it is to control the camera's gaze. The motion of the officer, the camera, and the subjects work against each other, constantly shifting the field-of-view and making it incredibly difficult to follow the footage - demonstrating one of many challenges facing officers: how do they ensure the production of useful footage? The producer of the videos featured in the

\footnotetext{
${ }^{7}$ The videos for this piece were staged using actors and do not involve actual police officers or policecitizen encounters.
} 
New York Times piece is Seth W. Stoughton, a law professor at the University of South Carolina. Stoughton argues that the first clip (from the "officer's" BWV device) reflects what he calls "deceptive intensity" (Williams et al., 2016). We often associate intense movement with aggression and threat which can lead us to assume that the officer in the first clip is being threatened when it reality he was simply jumping about jovially. The article goes on to demonstrate many of the shortcomings of BWV that I have addressed throughout this project including the fact that these cameras prioritize the officer's pointof-view. As Stoughton articulates, “when video allows us to look through someone's eyes, we tend to adopt an interpretation that favors that person" (Williams et al., 2016). In other words, by privileging the officer's point-of-view, BWV compels us to identify with the officer's experience, further accentuating their privilege.

The challenges outlined above are just a few of the limitations that police must overcome if they want to maintain a level of control over their visibility. Although officers must account for the many factors that can influence the visual quality of their footage, they must also recognize that there is an audio component that presents an additional hurdle. The availability or lack of audio plays a significant part in whether the viewer is able to decipher BWV footage and what conclusions they draw as a result. As I have argued throughout, there are significant gaps in the research surrounding the adoption of BWV by police organizations. I have attempted to fill one of those gaps with this project; however, there remains significant room for additional investigation. One of the remaining gaps results from the lack of attention being paid to that very important audio component. Although the EPS officers that participated in the pilot project conveyed concern over the potential that the audio traces of their encounters could be 
misjudged given the limited context provided in the footage, few others have paid significant attention to the subjectivity of audio recordings and how that subjectivity can impact not only our interpretation of the audio but of the visual as well.

The fact is that the audio component of these devices has different affordances and limitations than the visual. It is even possible that in some cases the available auditory documentation of an event might be superior or more complete than the visual recording. As the audio capabilities of BWV have been largely overlooked by various actors, it would be interesting to see if going forward the audio plays an important role in evidentiary proceedings. For the reasons outlined above, it would be prudent for future research to address questions regarding the audio aspect of BWV.

Although the adoption of BWV as a policing tool has been tumultuous, the dominant discourse is working to position the resulting police footage in such a way that police re-establish a level of advantage within the surveillant assemblage. The decentralized, all-encompassing nature of the assemblage is meant to level hierarchies of visibility; however, despite a momentary recalibration of the hierarchy, we are now seeing a re-emergence of power within the system as police learn to manage the assemblage. I argued in the preceding chapters that it was this very decentralization that offered those within the assemblage an opportunity to resist as long as they did so within the parameters of the system. This is precisely what the BWV example is demonstrating. The system demands visibility and by adopting technologies of visibility, police are able to exercise a level of control over the gaze. By using the system's lack of centralized power to their advantage, police organizations are challenging our conceptions of the assemblage by demonstrating that pockets of control can exist. It is interesting that the 
devices that are allowing police to manage their visibility are actually leaving the citizens that incorporated officers into the assemblage increasingly exposed as BWV simultaneous records from the officer's perspective and faces away from the officer, watching the citizen.

The result of technologically extending officers with BWV is that despite claims that these devices will provide much needed transparency and accountability, they are actually poised to undermine the level of visibility that citizens with smartphones had established. In order to use BWV to manage how exposed their organizations are, individual officers must learn to control these unruly devices, accounting for their technical limitations. The shift in logic necessary to do so challenges notions of policing as officers struggle to develop the skills required to ensure they are getting the right shot. Failure to do so would leave interpretation to viral videos recorded by bystanders - the very thing police organizations are trying to avoid. As officers become increasingly aware that they are now responsible for constructing visual evidence, we are seeing not only the development of a cinematic logic but also an anxiety among those officers that are aware of how exposed these devices make them, reinforcing the pressure to adopt the role of videographer. The result is that officers are forced to become their cameras to manage both their personal visibility and to shield their organizations from a pervasive surveillant gaze. If successful, these politically motivated RoboCops will be positioned to control the visual and audio traces of their encounters and, subsequently, the narratives that emerge when they are accused of misconduct. 


\section{$\underline{\text { References }}$}

A Whole New Meaning to Criminal 'Record'. (2012, October 10). The London Free Press.

Apuzzo, M. (2014, June 8). War Gear Flows to Police Departments. New York Times. Retrieved from: http://www.nytimes.com/2014/06/09/us/war-gear-flows-topolice-departments.html

Ariel, B., Farrar, W.A., \& Sutherland, A. (2015). The Effect of Police Body-Worn Cameras on the Use of Force and Citizens' Complaints Against the Police: A randomized controlled trial. Journal of Quantitative Criminology, 31(3), 509-535.

Arresting Disputes. (2015, January 19). Calgary Herald. Retrieved from: http:/calgaryherald.com/opinion/editorials/editorial-body-cameras-for-policewill-arrest-false-claims

Baker, A., Goodman, J.D., \& Mueller, B. (2015, June 13). Beyond the Chokehold: The path to Eric Garner's Death. New York Times. Retrieved from:

http://www.nytimes.com/2015/06/14/nyregion/eric-garner-police-chokeholdstaten-island.html

Balko, R. (2013). Rise of the Warrior Cop: The militarization of America's police forces. New York: Public Affairs.

Balsamo, A.M. (1996). Technologies of the gendered body: reading cyborg women. Durham: Duke University Press.

Balsamo, A. (1995). Forms of Technological Embodiment: Reading the body in contemporary culture. In M. Featherstone and R. burrows (Eds.), Cyberspace, Cyberbodies, Cyberpunk: Cultures of technological embodiment (215-238). London: SAGE.

Bell, J. (2010, March 25). Body-worn Cameras May Show Future of Crime-Fighting. Victoria Times Colonist.

Body Cameras for Police. (2015, March 1). CTV National News.

Body Cameras Pose Challenges. (2014, December 20). The StarPheonix. Retrieved from: http://www.pressreader.com/canada/thestarphoenix/20141220/281663958359111/TextView

Bogard, B. (2003). Hyperfacticity and Fatal Strategies. Science Fiction Studies, 30(2), 178-179.

Bogard, W. (1996). The Simulation of Surveillance: Hypercontrol in telematics societies. Cambridge: Cambridge University Press.

Brennan, T. \& Jay, M. (1996). Vision in Context: Historical and contemporary perspectives on sight. New York: Routledge.

Brown, M.K. (1981). Working the Street: Police discretion and the dilemmas of reform. New York: Sage.

Burgmann, T. (2015, February 24).Body Cameras for Police gets Thumbs up in B.C. Global News. Retrieved from: http:/globalnews.ca/news/1846744/body-camerasfor-police-gets-thumbs-up-in-b-c/

Carlson, K.B. (2013, August 19). Toronto Police Officer Charged in Sammy Yatim Shooting to Turn Himself in Tuesday. The Globe and Mail. Retrieved from: http://www.theglobeandmail.com/news/toronto/ontario-police-watchdog-layssecond-degree-murder-charge-in-sammy-yatim-shooting/article13837354/ 
Carrabine, E. (2012). Just Images: Aesthetics, ethics and visual criminology. British Journal of Criminology, 52, 463-489.

Chan, J. (1997). Changing Police Culture: Policing in a multicultural society. Cambridge: Cambridge University Press.

Chan, J. (1996). Changing Police Culture. British Journal of Criminology, 36(1), 109134.

Davis, B. (2015, May 21). No Timeline to Introduce Police Body Cameras in Waterloo Region. Waterloo Region Record. Retrieved from: http://www.therecord.com/news-story/5638929-no-timeline-to-introduce-policebody-cameras-in-waterloo-region/

Deleuze, G. (1992). Postcript on the Societies of Control. The MIT Press, 59, 3-7.

Deleuze, G. \& Guattari, F. (1987). A Thousand Plateaus: Capitalism and schizophrenia. Minneapolis: University of Minnesota Press.

The Department of Homeland Security. (2015). Body-Worn Video Cameras for Law Enforcement: Assessment report.

Digital Ally, Inc. (2014). Law Enforcement. Retrieved from: http://www.digitalallyinc.com/law.cfm

Digital Ally, Inc. (2015). Law Enforcement Catalogue. Retrieved from: http://www.digitalallyinc.com/documents/LawCatalog_Ver1-1.pdf

Drover, P. \& Ariel, B. (2015). Leading and Experiment in Police Body-Worn Video Cameras. International Criminal Justice Review, 25(1), 80-97.

Dvorak, J.L. (2008). Moving Wearables into the Mainstream: Taming the Borg. New York: Springer.

The Edmonton Police Service. (2015). Body Worn Video: Considering the Evidence. Final Report. Retrieved from: http://www.edmontonpolice.ca /News/BWV.aspx

Edwards, J. (2015, May 1). Obama Administration says to Provide \$20 Million for Police Body Cameras. Reuters. Retrieved from: http://www.reuters.com/article/us-usapolice-cameras-idUSKBN0NM3PL20150501

Ellwand, O. (2015, June 24). 'Video is the way of the future'; Edmonton Police Department to Add Body Cameras to Some Officers' Uniforms. Edmonton Journal. Retrieved from: http://edmontonjournal.com/news/local-news/video-isthe-way-of-the-future-for-edmonton-police

Eric Garner Protests Continue in Cities Across America Through Second Night. (2014, December 4). The Guardian. Retrieved from: http://www.theguardian.com/usnews/2014/dec/05/eric-garner-case-new-york-protests-continue-through-secondnight

Ericson, R. \& Haggerty K. (1997). Policing the Risk Society. Oxford: Clarendon Press. Estabrooks, T. (2015, June 23). Edmonton Police Not Ready to Equip All Officers with Cameras. CBC News. Retrieved from: http://www.cbc.ca/news/canada/edmonton/ edmonton-police-not-ready-to-equip-all-officers-with-cameras-1.3124503

Feenberg, A. (2010). Between Reason and Experience: Essays in technology and modernity. Cambridge: The MIT Press.

Feigenson, N. (forthcoming). What It's Like: Demonstrative evidence of subjective experience. In S. Hamilton, D. Majury, D. Moore, N. Sargent \& C. Wilke (Eds.), Sensing Law. Uk: Routledge. 
Feigenson, N. (2014). The Visual in Law: Some problems for legal theory. Law, Culture, and the Humanities, 10(1), 13-23.

Ferguson Protests: What we need to know about Michael Brown's last minutes. (2014, November 25). BBC World News. Retrieved from: http://www.bbc.com/news/world-us-canada-28841715

Feuille, P. \& Juris, H.A. (1976). Police Professionalization and Police Unions. Sociology of Work and Occupations, 3(1), 88-113.

Finn, J. (2009). Capturing the Criminal Image: From mug shot to surveillance society. Minneapolis: University of Minnesota Press.

Foucault, M. (1977). Discipline and Punish. New York: Vintage Books.

Gandy, O. (1993). The Panoptic Sort: A political economy of personal information. Colorado: Westview.

Gillis, W. (2016, January 19). Toronto police purchase 51 military style rifles. Toronto Star. Retrieved from: http://www.thestar.com/news/crime/2016/01/19/torontopolice-purchase-51-military-style-rifles.html

Gillis, W. (2015, September 12). Body Cams Shouldn't Capture 'Informal' Interactions, Police Chief Says. Toronto Star.

http://www.thestar.com/news/crime/2015/09/11/body-cams-shouldnt-captureinformal-interactions-police-chief-says.html

Gladwell, M. (2005). Blink. New York: Little, Brown and Company.

González, J.A. (2000). Envisioning Cyborg Bodies: Notes from current research. In G. Kirkup, L. Janes, K. Woodward, and F. Hovenden (Eds.), The Gendered Cyborg: $A$ reader (58-73). London: Routledge.

Goodwin, C. (1994). Professional Vision. American Anthropologist, 96(3), 606-633.

Goold, B.J. (2003). Public Area Surveillance and Police Work: the impact of CCTV on police behaviour and autonomy. Surveillance \& Society, 1(2), 191-203.

Green, T. \& Gates, A. (2014). Understanding the Process of Professionalisation in the Police Organisation. Police Journal: Theory, Practice and Principles, 87, 75-91.

Haggarty, K.D. (2006). Tear Down the Walls: On demolishing the panopticon. In D. Lyon (Ed.), Theorizing Surveillance (23-45). London: Routledge.

Haggerty, K.D. \& Ericson. R.V. (2000). The Surveillant Assemblage. British Journal of Sociology, 51(4), 605-622.

Haraway, D.J. (2000). A Manifesto for Cyborgs: Science, technology, and socialist feminism in the 1980's. In G. Kirkup, L. Janes, K. Woodward, and F. Hovenden (Eds.), The Gendered Cyborg: A reader (50-57). London: Routledge.

Haraway, D.J. (1991). Simians, Cyborgs and Women. London: Free Association Books. Holdaway, S. (1996). The Racialisation of British Policing. London: Macmillan.

How Body Cameras are a Path to Rebuilding Trust in the Police. (2015, May 21). The Globe and Mail. Retrieved from:

http://www.theglobeandmail.com/opinion/editorials/how-body-cameras-are-apath-to-rebuilding-trust-in-the-police/article24526543/

Intille, A. (1999). Video Surveillance and Privacy: Implications for wearable computing. Suffolk University Law Review, 32(4), 729-765.

Jay, M. (1993). Downcast Eyes: The denigration of vision in twentieth-century French thought. Berkeley: University of California Press. 
Jay, M. (1991). The Disenchantment of the Eye: Surrealism and the crisis of ocularcentrism. Visual Anthropology Review, 7(1), 15-38.

Jennings, W.G., Fridell, L.A., \& Lynch, M.D. (2014). Cops and Cameras: Officer perceptions of the use of body-worn cameras in law enforcement. Journal of Criminal Justice, 42, 549-566.

Jones, J.M. (2015, June 19). In U.S., Confidence in Police Lowest in 22 Years. Gallup. Retrieved from: http://www.gallup.com/poll/183704/confidence-police-lowestyears.aspx

Kahan, D.M., Hoffman, D.A. \& Braman, D. (2009). Whose Eyes Are You Going to Believe? Scott V. Harris and the perils of cognitive illiberalism. Harvard Law Review, 122(3), 837-903.

Keller, J. (2014, October 14). Vancouver police to wear body cameras for disbanding of homeless camp. The Canadian Press.

Knight, L. (2013, November 13). Police body cams will offer full picture. 24 hours Vancouver. Retrieved from: http://vancouver.24hrs.ca/2013/11/12/police-bodycams-will-offer-full-picture

Kotsis, J. (2014, December 24). Police urged to use body-worn video cameras; A'burg part of pilot project. The Windsor Star. Retrieved from: http://windsorstar.com/news/local-news/amherstburg-police-continue-to-testbody-worn-video-cameras

Lichfield, G. (2015). The Minutes of Marshall Jones. Data \& Society.

Loftus, B. (2009). Police Culture in a Changing World. Oxford: Oxford University Press.

Logan, S. (2014, October 1). Smile! Candid Cop Cameras are Coming. The Calgary Sun. Retrieved from: http://www.calgarysun.com/2014/09/30/smile-candid-copcameras-are-coming

Lyon, D. (2007). Everyday Surveillance: Personal data and social classifications. In S.P. Hier and J. Greenberg (Eds.), The Surveillance Studies Reader. New York: McGraw-Hill.

Lyon, D. (2006). Theorizing Surveillance: the panopticon and beyond. London: Routledge.

Lyon, D. (2002). Surveillance as Social Sorting: Privacy, risk and automated discrimination. London: Routledge.

Mann, S., Nolan, J. \& Wellman, B. (2003). Sousveillance: Inventing and Using Wearable Computing Devices for Data Collection in Surveillance Environments.

Surveillance \& Society, 1(3), 331-355.

Mann, S. (2001). Wearable Computing: Toward humanistic intelligence. IEEE Intelligent Systems, 16(3), 10-15.

Manning, P. (1977). Police Work. Cambridge Massachusetts: MIT Press.

Marx, L. (2010). Technology: The Emergence of a Hazardous Concept. Technology and Culture, 52(3), 561-577.

Mateescu, A., Rosenblat, A., \& boyd, d. (2015). Police Body-Worn Cameras. Data \& Society.

Mathiesen, T. (1997). The Viewer Society: Michel Foucault's 'panopticon' revisited. Theoretical Criminology, 1(2), 215-234.

McConville, M., \& Shepherd, D. (1992). Watching the Police, Watching Communities. London: Routledge. 
McConville, M., Sander, A., \& Leng, R. (1991). The Case for the Prosecution: Police suspects and the construction of criminality. London: Routledge.

McDiarmid, J. (2014, February 18) Toronto Police to Test out Lapel Cameras. Toronto Star. Retrieved from:

http://www.thestar.com/news/crime/2014/02/18/toronto_police_to_test_out_lapel cameras.html

Meeks, D. (2006). Police Militarization in Urban Areas: The obscure war against the underclass. The Black Scholar, 35(4), 33-41.

Mehta, D. (2015, May 16). Toronto Police Start Year-Long Pilot Project to Test Body Cameras for Officers. The Globe and Mail. Retrieved from:

http://www.theglobeandmail.com/news/toronto/toronto-police-start-year-longpilot-project-to-test-body-cameras-for-officers/article24452340/

'Militarizing Police': Winnipeg buys \$343K armoured vehicle for officers. (2015, December 9). CBC News. Retrieved from:

http://www.cbc.ca/news/canada/manitoba/

militarizing-police-winnipeg-buys-343k-armoured-vehicle-for-officers1.3357289

Miller, C. (2009, January 24). Do police have the right to confiscate your camera?

InfoWars. Retrieved from: http://www.infowars.com/do-police-have-the-right-toconfiscate-your-camera/

Miller, M.E. (2015, October 9). A Body Cam Caught an Officer Being a Hero. So Why are Cops Afraid of Them? The Hamilton Spectator. Retrieved from: http://www.thespec.com/news-story/5952981-a-body-cam-caught-an-officerbeing-a-hero-so-why-are-cops-afraid-of-them-/

Mills, M. (2011). Hearing Aids and the History of Electronics Miniaturization. IEEE Annals of the History of Computing, 33(2), 24-44.

Mnookin, J.L. (2014). Semi-Legibility and Visual Evidence: An Initial Exploration. Law, Culture and the Humanities, 10(1), 43-65.

Mobile Phone Footage Shows Freddie Gray in Agony During Arrest. (2015, April 28).

The Telegraph. Retrieved from:

http://www.telegraph.co.uk/news/worldnews/northamerica/usa/11567318/Mobilephon

e-footage-shows-Freddie-Gray-in-agony-during-arrest.html

Monahan, T. (2006). Counter-Surveillance as Political Intervention. Social Semiotics, 16(4), 515-534.

Nasiopoulos, E., Risko, E.F., Foulsham, T., \& Kingstone. A. (2015). Wearable Computing: Will it make people prosocial. Journal of Psychology, 106(2), 209216.

Palamarchuk, A. (2015, May 28). Ontario Human Rights Commission says it did not 'partner' with Toronto police on body-worn camera project. City Centre Mirror. Retrieved from: http://www.insidetoronto.com/news-story/5649527-ontariohuman-rights-commission-says-it-did-not-partner-with-toronto-police-on-bodyworn-cameras-p/

Pentland, A. (2000). Looking at People: Sensing for ubiquitous and wearable computing. IEEE Transactions on Pattern Analysis and Machine Intelligence, 22(1), 107-119. 
Platt, M. (2015, June 24). Edmonton Police Service Report Reveals Reservations Over Body-Mounted Cameras for Officers. The Calgary Sun. Retrieved from: http://www.calgarysun.com/2015/06/23/edmonton-police-service-report-revealsreservations-over-body-mounted-cameras-for-officers

The Police and Video Cameras. (2010, March 25). Victoria Times Colonist.

Poster, M. (1984). Foucault, Marxism \& History. Cambridge: Polity Press.

Potts, L.W. (1982). Police Professionalization: Elusive or Illusory. Criminal Justice Review, 7(2), 51-57.

Price, B.R. (1977). Police Professionalism: Rhetoric and Action. Lexington: Lexington Books.

The pros and cons of police body cameras. (2015, April 10). CTV Canada AM.

Quan, D. (2015, January 9). Calgary police officers to don body cameras. Calgary Herald.

Reiner, R. (2000). The Politics of the Police. Oxford: Oxford University Press.

Reiner, R. (1992). The Politics of the Police. Toronto: University of Toronto Press.

Reiner, R. (1985). The Politics of the Police. Brighton: Wheatsheaf Books.

Reiner, R. (1978). The Blue-Coated Worker: A sociological study of police unionism. Cambridge: Cambridge University Press.

Reveal Media. (n.d.). About Body Worn Video. Retrieved from: http:/www.revealmedia.com/can/about-body-worn-video

Reveal Media. (n.d.). Police Worn Body Cameras. Retrieved from: http://www.revealmedia.com/can/police-body-worn-cameras

Reveal Media. (n.d.). Quick Start User Manual.

Safety Vision. (2012). Prima Facie User ${ }^{\circledR}:$ User Guide.

Sanburn, J. (2014, November 25). The One Battle Michael Brown's Family Will Win. Time. Retrieved from: http://time.com/3606376/police-cameras-fergusonevidence/

Schaefer, B.P. \& Steinmetz, K.F. (2014). Watching the Watchers and McLuhan's Tetrad: The limits of cop-watching in the internet age. Surveillance \& Society, 12(4), 502511.

Schmidt, M.S. (2015, April 7). South Carolina Officer is Charged with Murder of Walter Scott. New York Times. Retrieved from: http://www.nytimes.com/2015/04/08/us/south-carolina-officer-is-charged-withmurder-in-black-mans-death.html

Scowen, P. (2013, October 26). Lights! Camera! Busted? The Globe and Mail. Retrieved from: http://www.theglobeandmail.com/news/national/lights-camera-busted-areon-body-cameras-for-police-officers-a-good-idea/article15086139/

Shilling, C. (2005). The Body in Culture, Technology and Society. London: SAGE.

Shingler, B. (2014, January 21). Cops with Cameras: Growing number of police armed with recording devices. Macleans. Retrieved from:

http://www.macleans.ca/general/cops-with-cameras-growing-number-of-policearmed-with-recording-devices/

Silbey, J. (2010) Evidence Verité and the Law of Film. Cardozo Law Review, 31(4), $1257-1277$.

Silbey, J. (2008). Cross-Examining Film. Suffolk University Legal Studies Research Paper Series. 
Simon, B. (2005). The Return of Panopticism: Supervision, subjection and the new surveillance. Surveillance \& Society, 3(1), 1-20.

Sloane, C.F. (1954). Police Professionalization. The Journal of Criminal Law, Criminology, and Police Science, 45(1), 77-79.

Skogan, W.G. (2008). Why Reforms Fail. Policing and Society: An International Journal of Research and Policy, 18, 23-34.

Skolnick, J.H. (1966). Justice Without Trial: Law enforcement in democratic society. New York: Macmillan.

Smith, G.J.D. (2007). Exploring Relations between Watchers and Watched in Control(ed) Systems: Strategies and tactics. Surveillance \& Society, 4(4), 280-313.

Smyth, M. (2015, March 1). Body-worn cameras for cops inevitable, says police chief; Reporting urges B.C. government to take the lead in implementing policy. The Province. Retrieved from:

http://www.theprovince.com/news/Smyth+Body+worn+cameras+coming+cops + whether+they+like+government+urged+take+lead/10848811/story.html

Stancu, H. (2010, August 3). No mini-cameras sighted on Toronto police - yet. Toronto Star. Retrieved from: http://www.thestar.com/news/crime /2010/08/02/toronto_police_wont_use_body_cams_yet.html

Staples, M. (2014, March 5). RCMP tests wearable video cameras in N.B. The Victoria Star.

Stark, E. (2015, November 27). Smile, you're on the police body camera; Public's interactions with officers will be recorded for use as evidence. Calgary Herald. Retrieved from: http://calgaryherald.com/news/local-news/calgary-police-toexpand-body-worn-cameras-for-frontline-officers

Stark, E. (2014, October 2). Civil Liberties Group Urges Caution Over Police BodyWorn Cameras. Calgary Herald. Retrieved from: http://calgaryherald.com/news/local-news/civil-liberties-group-urges-cautionover-police-body-worn-cameras

Staufenberger, R.A. (1977). The Professionalization of Police: Efforts and obstacles. Public Administration Review, 37(6), 678-685.

TASER. Axon Body 2: Unlimited HD. No Distractions. Retrieved from: http://www.axon.io/products/body2

TASER. (2013). TASER AXON® body ${ }^{\mathrm{TM}}$ Camera: User Manual.

The Timeline of Freddie Gray's Arrest and the Charges Filed. (2016, May 21). New York Times. Retrieved from: http://www.nytimes.com/interactive/2015/04/30/us/whathappened-freddie-gray-arrested-by-baltimore-police-department-maptimeline.html? $\mathrm{r}=0$

Tomas, D. (1995). Feedback and Cybernetics: Reimagining the body in the age of cybernetics. In M. Featherstone and R. burrows (Eds.), Cyberspace, Cyberbodies, Cyberpunk: Cultures of technological embodiment (20-43). London: SAGE.

Verhoeven, P. (Director). (1987). RoboCop [Motion Picture]. United States: Orion Pictures.

Wall, T. \& Linnemann, T. (2014). Staring Down the State: Police power, visual economies, and the "War on Cameras". Crime, Media, Culture, 10(2), 133-149.

Westley, W. (1970). Violence and the police: A sociological study of law, custom and morality. Massachusetts: MIT. 
What is a Good Photograph, and How do I Take it? (2012, May 19). North Thompson Journal. Retrieved from:http://proxy.library.carleton.ca/login?url $=\mathrm{http}: / /$ search.proquest.com.proxy.library.carleton.ca/docview/1014341154?accou ntid $=9894$

White, M.D. (2014). Police Officer Body-Worn Cameras: Assessing the evidence. Washington, DC: Office of Community Oriented Policing Services.

Wilkinson, B. \& Lippert, R. (2012). Moving Images Through an Assemblage: Police, visual information, and resistance. Critical Criminology, 20(3), 311-325.

Williams, T., Thomas, J., Jacoby, S., \& Cave, D. (2016, April 1). Police Body Cameras: What do you see? New York Times. Retrieved from: http://www.nytimes.com/interactive/ 2016/04/01/us/police-bodycam-video.html?hp\&action=click\&pgtype= Homepage \&clickSource=story-heading\&module=photo-spot-region\&region=topnews\&WT.nav=top-news\&_r $=1$

Wilson, R.R. (1995). Cyber(body)parts: Prosthetic consciousness. In M. Featherstone and R. burrows (Eds.), Cyberspace, Cyberbodies, Cyberpunk: Cultures of technological embodiment (239-260). London: SAGE.

Winner, L. (1986). The Whale and the Reactor. Chicago: The University of Chicago Press.

Wittmeier, B. (2010, July 24). Smile - soon you could be on Cop Cam; City police seek test of body-worn cameras as 'way of the future'. Edmonton Journal. Retrieved from: http://www.pressreader.com/canada/edmontonjournal/20100724/287582421224080/TextView

Young, A. (2014). From Object to Encounter: Aesthetic politics and visual criminology. Theoretical Criminology, 18(2), 159-175. 